\title{
Retrofitting Forced Air Combi Systems: A Cold Climate Field Assessment
}

B. Schoenbauer, D. Bohac, J. McAlpine, and M. Hewett

NorthernSTAR

June 2017 


\section{NOTICE}

This report was prepared as an account of work sponsored by an agency of the United States government. Neither the United States government nor any agency thereof, nor any of their employees, subcontractors, or affiliated partners makes any warranty, express or implied, or assumes any legal liability or responsibility for the accuracy, completeness, or usefulness of any information, apparatus, product, or process disclosed, or represents that its use would not infringe privately owned rights. Reference herein to any specific commercial product, process, or service by trade name, trademark, manufacturer, or otherwise does not necessarily constitute or imply its endorsement, recommendation, or favoring by the United States government or any agency thereof. The views and opinions of authors expressed herein do not necessarily state or reflect those of the United States government or any agency thereof.

This report is available at no cost from the National Renewable Energy Laboratory (NREL) at www.nrel.gov/publications.

Available electronically at SciTech Connect http:/www.osti.gov/scitech

Available for a processing fee to U.S. Department of Energy and its contractors, in paper, from:

U.S. Department of Energy

Office of Scientific and Technical Information

P.O. Box 62

Oak Ridge, TN 37831-0062

OSTI http://www.osti.gov

Phone: 865.576.8401

Fax: 865.576.5728

Email: reports@osti.gov

Available for sale to the public, in paper, from:

U.S. Department of Commerce

National Technical Information Service

5301 Shawnee Road

Alexandria, VA 22312

NTIS http://www.ntis.gov

Phone: 800.553 .6847 or 703.605 .6000

Fax: 703.605.6900

Email: orders@ntis.gov 


\title{
Retrofitting Forced Air Combi Systems: A Cold Climate Field Assessment
}

\author{
Prepared for: \\ The National Renewable Energy Laboratory \\ On behalf of the U.S. Department of Energy's Building America Program \\ Office of Energy Efficiency and Renewable Energy \\ 15013 Denver West Parkway \\ Golden, CO 80401 \\ NREL Contract No. DE-AC36-08GO28308 \\ Prepared by: \\ Ben Schoenbauer, Dave Bohac, Jake McAlpine, Martha Hewett \\ NorthernSTAR Building America Partnership \\ University of Minnesota \\ 2004 Folwell Avenue \\ St. Paul, MN 55108 \\ NREL Technical Monitor: Stacey Rothgeb \\ Prepared under Subcontract No. KNDJ-0-40338-00
}

June 2017 
The work presented in this report does not represent performance of any product relative to regulated minimum efficiency requirements.

The laboratory and/or field sites used for this work are not certified rating test facilities. The conditions and methods under which products were characterized for this work differ from standard rating conditions, as described.

Because the methods and conditions differ, the reported results are not comparable to rated product performance and should only be used to estimate performance under the measured conditions. 


\section{Acknowledgments}

This report was prepared for the U.S. Department of Energy Building America Program. Funding for this work was provided by the National Renewable Energy Laboratory under contract KNDJ-0-40338-02. Additional funds to support this work were provided by the Weatherization Assistance Program through a Sustainable Energy Resources for Consumers grant, the Center for Energy and Environment, and the Energy Conservatory. Additional support through loaned or donated equipment was provided from Rinnai, AO Smith, American Water Heaters, Eternal, Heat Transfer Products, Navien American, Ennerzone, Life Breath, Nuaire, and Advanced Distributor Products.

The primary authors were Ben Schoenbauer, Dave Bohac, and Martha Hewett, Center for Energy and Environment, and Jake McAlpine, Sustainable Resource Center.

These authors would like to acknowledge the contributions and support of Becky Olson, Sustainable Resource Center, for project management and cost analysis; Pat Huelman, University of Minnesota, for expertise and role as an advisor to the project; Alex Haynor, Corinne Wichser, Andrew Lutz, and Josh Novacheck, Center for Energy and Environment, for work on field installations and data analysis; Anna Jursik, Center for Energy and Environment, for report editing; Gary Nelson, The Energy Conservatory, for donating space for the laboratory and his time as an advisor; Gary Klein, Affiliated International Management, for his time and expertise; Louise Goldberg, University of Minnesota - BBE, for the BEopt modeling and analysis; and Tom Schirber, University of Minnesota, for coordinating and editing reports. 


\section{Contents}

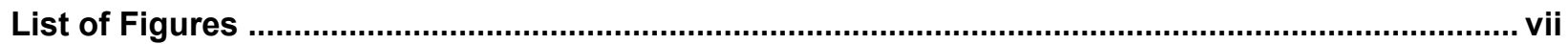

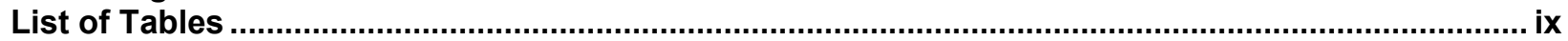

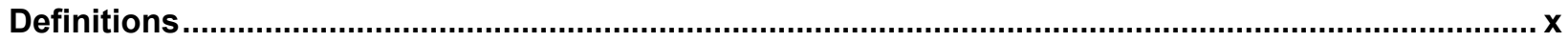

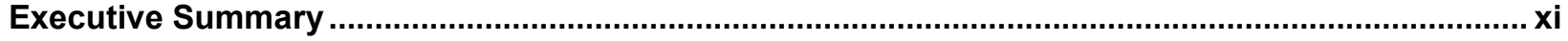

1 Problem Statement

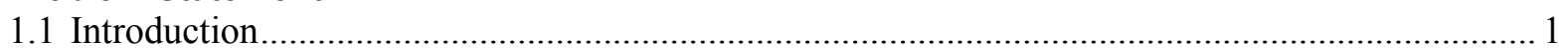

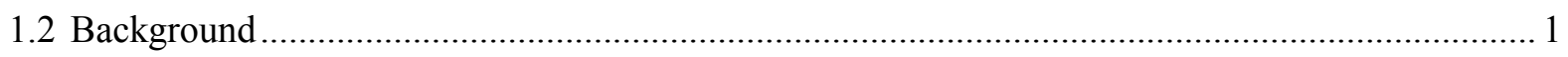

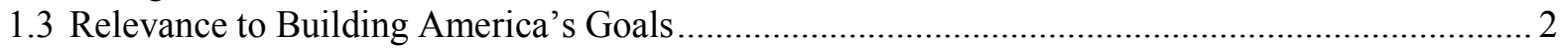

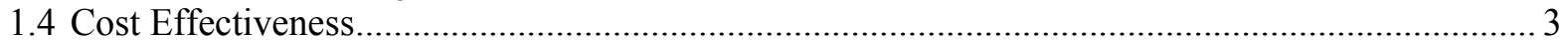

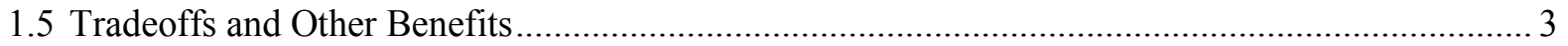

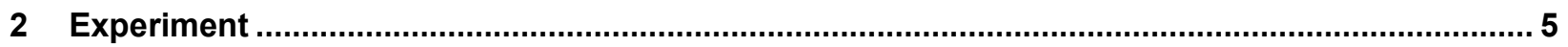

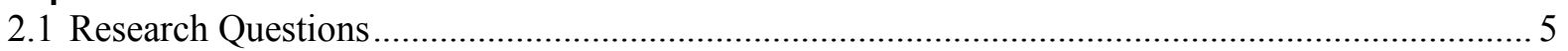

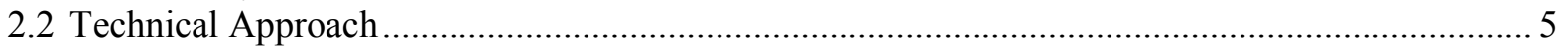

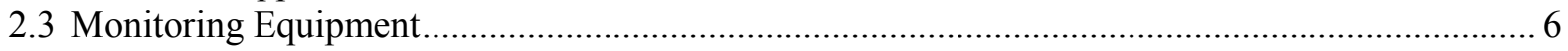

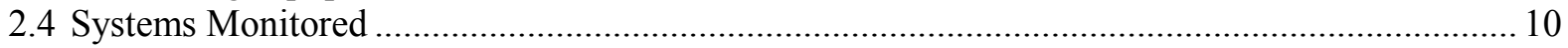

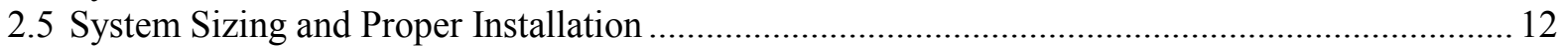

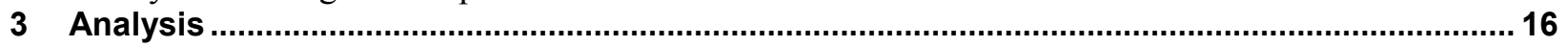

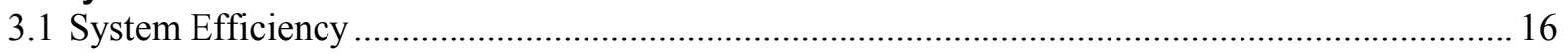

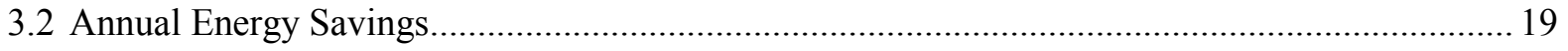

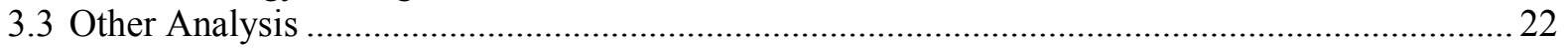

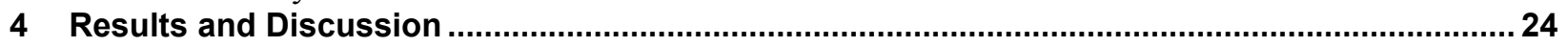

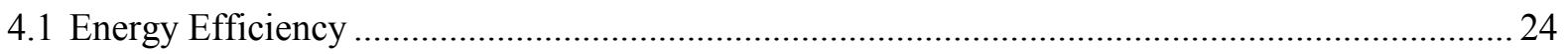

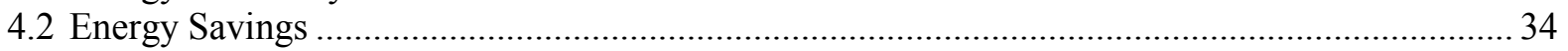



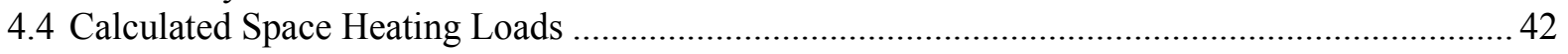

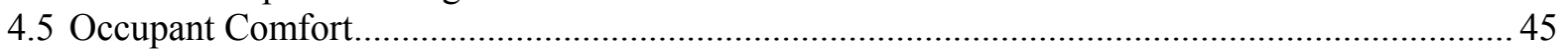

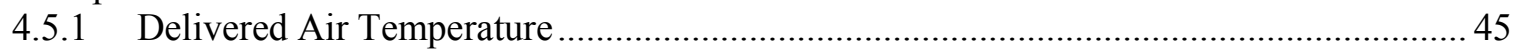

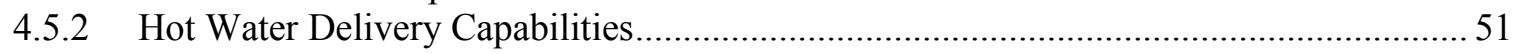

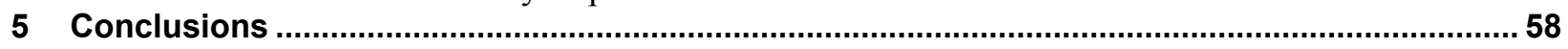

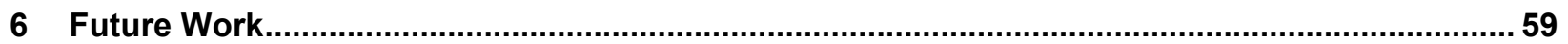

Appendix A

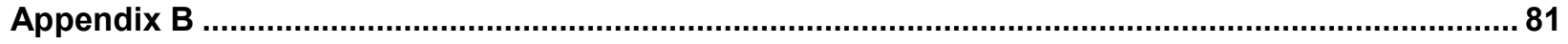




\section{List of Figures}

Figure 1. Monitoring instrumentation for existing space and DHW systems ................................. 7

Figure 2. Field monitoring instrumentation for an SWH system................................................... 8

Figure 3. Field instrumentation for a TWH combi system ….......................................................... 9

Figure 4. Field instrumentation for boiler-based combi systems ...................................................... 10

Figure 5. Laboratory testing of heating plant efficiency over a range of return water temperatures 15

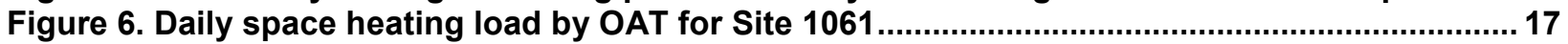

Figure 7. Input versus output relationship for the combi system on days with space and water

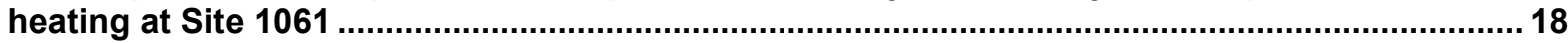

Figure 8. Input versus output relationship for the combi system on days with DHW only at Site

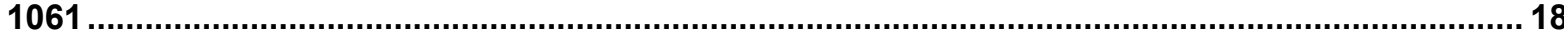

Figure 9. Existing furnace energy consumption versus OAT for Site 1061 ..................................... 19

Figure 10. Inlet water temperature measured and modeled data at Site 1052 ............................... 21

Figure 11. Average domestic water heating load for Site 1061 ..................................................... 21

Figure 12. Comparing existing WH energy use model to measured data........................................ 22

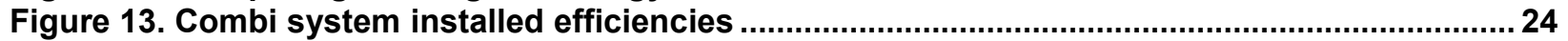

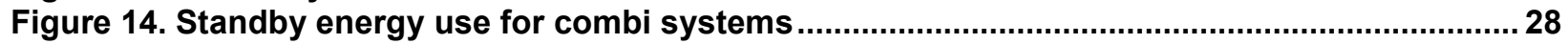

Figure 15. Combi system summer efficiency versus DHW load ....................................................... 30

Figure 16. Impact of daily average event length on DHW efficiency ............................................ 30

Figure 17. Comparison of field and laboratory efficiencies for storage-based combi systems........ 32

Figure 18. Comparison of field and laboratory efficiencies for TWH and hybrid-based combi

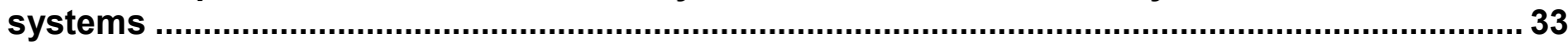

Figure 19. Comparison of field and laboratory efficiencies for boiler-based combi systems.......... 34

Figure 20. Annual natural gas consumption for space and water heating pre- and post-

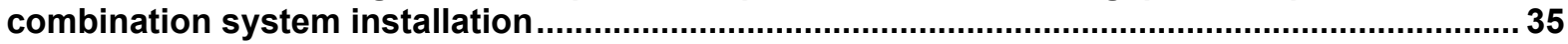

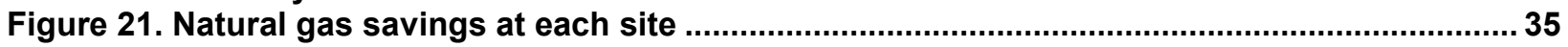

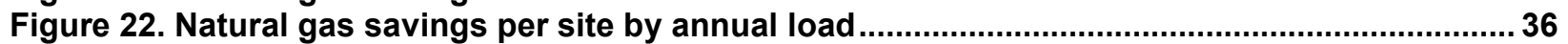

Figure 23. Cost changes over time for the most installed systems (Phoenix, Polaris, and Eternal)38

Figure 24. Installation costs for residential HVAC systems ............................................................. 40

Figure 25. Comparison of the measured space heating load and the contractors estimates .......... 43

Figure 26. Comparison of the measured space-heating load and the NEAT software...................... 44

Figure 27. Supply air temperature distributions for SWH-based combi systems...........................45

Figure 28. Delivered air temperature of each space-heating event at Site 1061 with a SWH-based combi system.

Figure 29. Supply air temperature distributions for TWH-based combi systems ............................ 46

Figure 30. Delivered air temperature of each space-heating event at Site 1045 with a TWH-based

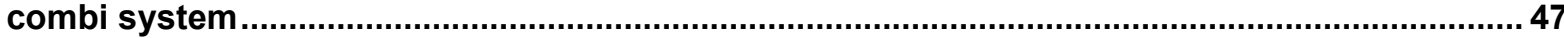

Figure 31. Supply air temperature distributions for hybrid WH-based combi systems ..................47

Figure 32. Delivered air temperature of each space-heating event at Site 1049 with a hybrid WHbased combi system

Figure 33.Supply air temperature distributions for boiler-based combi systems ........................... 49

Figure 34. Delivered air temperature of each space-heating event at Site 1037 with a low-mass boiler-based combi system ................................................................................................... 49

Figure 35. Delivered air temperature of each space-heating event at Site 1063 with a boiler-based

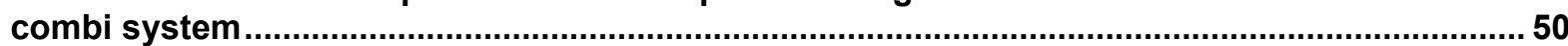

Figure 36.Time series discharge air temperatures for combi systems........................................ 51

Figure 37. Time series plots of DHW temperatures after mixing valve of the SWH at Site $1078 \ldots . . .52$

Figure 38. Delivered water temperatures for the storage-based combi systems ...........................5 53

Figure 39. Time series plots of DHW temperatures after mixing valve of the TWH at Site $1030 \ldots . .54$

Figure 40. Delivered water temperatures for the TWH-based combi systems ................................5 54

Figure 41.Time series plots of DHW temperatures after mixing valve of the hybrid WH at Site 107055

Figure 42. Delivered water temperatures for the hybrid WH-based combi systems ......................55

Figure 43.Time series plots of DHW temperatures after mixing valve of the low-mass boiler at Site 1055 
Figure 44. Time series plots of DHW temperatures after mixing valve of the boiler at Site 1063 .... 56 Figure 45. Delivered water temperatures for the boiler-based combi systems measured 6 inches

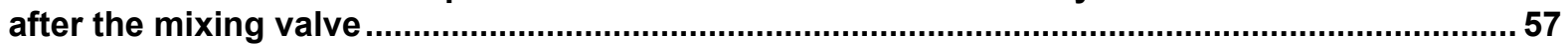

Figure 46. Time series plots for DHW temperatures at outlet of WH for an ND storage tank WH....57

Unless otherwise noted, all figures were created by NorthernSTAR. 


\section{List of Tables}

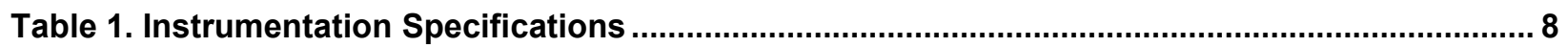

Table 2. Characteristics of the Existing WH and Furnace at Each Site ............................................11

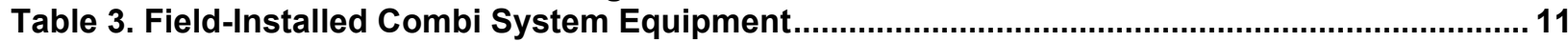

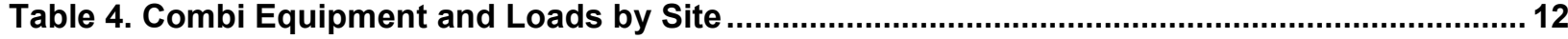

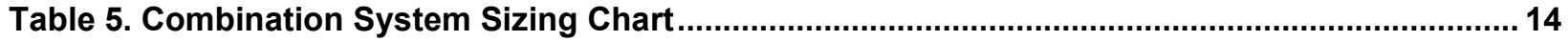

Table 6. Comparison of the Space Heating Output Models.............................................................. 20

Table 7. Installed Efficiency of the Combi Systems at Each Site..................................................... 25

Table 8. Input Versus Output Models for the Combi Space Heating Systems .................................. 26

Table 9. Load Curves for Space and Water Heating ........................................................................ 27

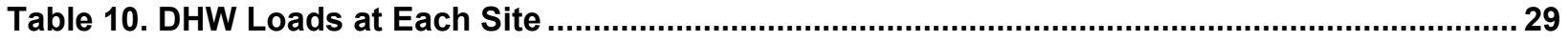

Table 11. Average Installation Costs From Implementation Project ................................................... 39

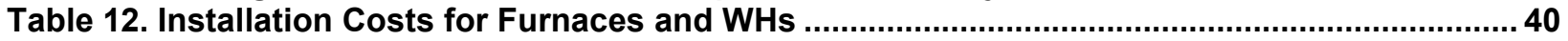

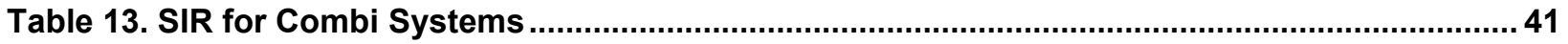

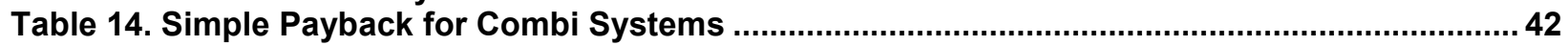

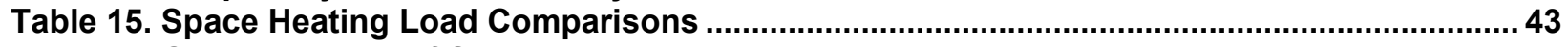

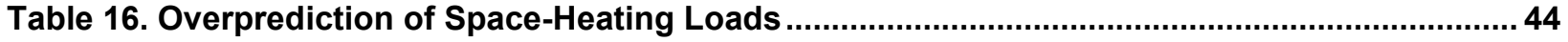

Table 17. Supply Air Temperature Distribution Characteristics ................................................. 50

Unless otherwise noted, all tables were created by NorthernSTAR. 


\section{Definitions}

$\begin{array}{ll}\text { AFUE } & \text { Annual fuel utilization efficiency } \\ \text { AHU } & \text { Air handling unit } \\ \text { BC } & \text { Best case (installation) } \\ \text { BEoptrm } & \text { Building Energy Optimization software } \\ \text { DHW } & \text { Domestic hot water } \\ \text { EF } & \text { Energy factor } \\ \text { ND } & \text { Natural draft } \\ \text { NEAT } & \text { National Energy Audit Tool } \\ \text { NOAA } & \text { National Oceanic Atmospheric Administration } \\ \text { NQBC } & \text { Not quite best case (installation) } \\ \text { OAT } & \text { Outdoor air temperature } \\ \text { RTD } & \text { Resistance temperature detector } \\ \text { SIR } & \text { Savings-to-investment ratio } \\ \text { SWH } & \text { Storage water heater } \\ \text { TWH } & \text { Tankless water heater } \\ \text { WH } & \text { Water heater }\end{array}$




\section{Executive Summary}

This project analyzed combined condensing water heaters or boilers and hydronic air coils to provide high efficiency domestic hot water (DHW) and forced air space heating. Called "combi" systems, they provided similar space and water heating performance less expensively than installing two condensing appliances. The system's installed costs were cheaper than installing a condensing furnace and either a condensing tankless or condensing storage water heater. However, combi costs must mature and be reduced before they are competitive with a condensing furnace and power vented water heater (energy factor of 0.60 ).

Better insulation and tighter envelopes are reducing space heating loads for new and existing homes. For many homes, decreased space heating loads make it possible for both space and domestic water heating loads to be provided with a single heating plant. These systems can also eliminate safety issues associated with natural draft appliances through the use of one common sealed combustion vent.

The combined space and water heating approach was not a new idea. Past systems have used non-condensing heating plants, which limited their usefulness in climates with high heating loads. Previous laboratory work (Schoenbauer et al. 2012a) showed that proper installation was necessary to achieve condensing with high efficiency appliances. Careful consideration was paid to proper system sizing and minimizing the water temperature returning from the air handling unit to facilitate condensing operation.

Experiment. Twenty sites were selected for a detailed monitoring project to characterize how combi systems perform when installed in real homes. The homes were monitored for 1-2 months to evaluate the performance of the existing systems. A combi system was installed in each home after the completion of the existing system monitoring. At each of the 20 sites a detailed monitoring system was installed, collecting data on energy usage, household load, and system efficiency. This report describes the monitoring protocol, installed combi systems, energy savings, and installed performance of the combi systems. Combi system monitoring was conducted for a full year in order to obtain information on both combined space/DHW operation and DHW-only operation.

Analysis. Monitored field data were used to characterize combination systems. Collected data were analyzed to determine:

- The annual energy consumption of both the existing furnace and water heater and the combi system

- The installed efficiency of the combi systems

- The delivery capabilities for space heating and DHW.

The output measurement data were also analyzed to access the delivery capabilities of these systems. Capabilities were assessed both in terms of occupant comfort and sizing capacity. Both delivered air and water temperatures were analyzed to access occupant comfort. 
Results/Conclusions. Fifteen sites have been monitored and analyzed for both the existing and combi systems (instrumentation and occupancy issues prevented complete analysis at five sites). Combi systems, on average, saved $19 \%$ of natural gas usage for space and water heating. The measured annual combined efficiency was $81 \%-92 \%$ with an average of $87 \%$.

System installation was very important to achieve these savings. Careful equipment pairing and operation parameter selection guidelines were required to achieve high efficiencies and good savings. Deviation from these installation parameters would have reduced performance considerably. 


\section{Problem Statement}

\subsection{Introduction}

Better insulation and tighter envelopes are reducing space heating loads for new and existing homes. For many homes, decreased space heating loads make it possible for both space and domestic water heating loads to be provided with a single heating plant. For these systems, called dual integrated appliances or combination (combi) systems, the use of a direct-vent burner can also eliminate safety issues associated with natural draft (ND) appliances, especially in tighter homes (Bohac and Cheple 2002; Bohac 2002).

The project used combi systems consisting of water heater $(\mathrm{WH})$ or boiler heating plants teamed with forced air distribution space heating systems. In each house, a hydronic air handling unit (AHU) that included an AHU, water coil, and water pump to circulate water between the heating plant and coil replaced the existing forced air furnace. Either a WH or a boiler with a separate circuit for domestic hot water (DHW) replaced the existing ND storage water heater (SWH). Various options for DHW priority, DHW tempering, and heating plant temperature set point control were considered.

This project characterized the installed performance of combi systems that used several types of condensing heating plants. Measurement of installed performance of combi systems was the primary objective of this project; a pre/post analysis was also used to estimate energy savings. The monitoring included key system parameters such as water return temperature in order to better understand variations from expected performance and identify improved system designs. The project also tracked the installation costs and evaluated potential cost reductions with improved contractor familiarity with the systems.

\subsection{Background}

Historically, mechanical contractors have most often custom engineered and pieced together combi systems in the field. They focused on assembling functional systems and often paid little attention to efficiency and optimization. As high efficiency condensing WHs and boilers gain a larger share of the residential market, there is greater potential to use these systems to improve the efficiency of providing both space heating and DHW loads.

Field research and demonstration projects are needed to address several outstanding questions about combi systems. For example, what is the actual installed energy savings of properly configured combi system with a condensing heating plant? What are the installation costs and paybacks of these systems? Can contractor familiarity and experience with combi systems reduce installation prices?

The concept of a single heating plant to supply both space and water heating has been in use for many years. Bohac et al. (1995) installed and monitored combis in small commercial and multifamily buildings in 1989. These systems used an ND SWH as the heating plant. The 1.5 years of monitored operation demonstrated that these systems could be reliably installed and perform without failure while saving energy. The combi systems in this project had annual efficiency ratings of at least $78 \%$ and replaced ND WHs with an energy factor (EF) rating of about $50 \%$ and furnaces with annual fuel utilization efficiencies (AFUEs) around $60 \%$. The study found an average energy savings of $24 \%$. 
Twenty years ago, combi systems using non-condensing WHs could provide energy savings when they were used to replace older furnaces and WHs. Space heating equipment with $90 \%+$ furnaces have become more common in the past 20 years (Comstock 2013). Laboratory testing (Thomas et al. 2011) demonstrated that when used to replace mechanical equipment in modern homes, combi systems must utilize condensing heating plants to achieve similar or improved energy performance.

Combi systems using high efficiency heating plants are relatively new on the market. Several laboratory test and field installations identified potential problems. Laboratory tests by Brookhaven National Laboratory (Butcher and Arena 2011) showed that the manufacturerspecified plumbing configuration with a primary and secondary loop made it difficult to achieve the high efficiency potential of condensing combi boilers. A field installation by the New York State Energy Research and Development Authority (Rudd 2012) examined durability issues for systems using tankless water heaters (TWHs). The study assessed problems with hard water, scaling, and short cycling. The combi system installed in that project had buildup on the inlet water filter on a TWH. This buildup eventually prevented the TWH from activating. The study installed an industrial strainer on the inlet water line, which prevented WH failure and reduced the maintenance interval to an annual filtering.

In 2009, the Consortium for Advanced Residential Buildings, analyzed the performance of six condensing boilers in existing homes (Steven Winter Associates 2011). In space heating mode the frequency of condensing (as a fraction of total runtime) for the boilers was $14 \%-69 \%$. In domestic water heating mode the frequency of condensing operation was $18 \%-65 \%$. Measuring return water temperatures in the system and relating them to a criterion for condensing determined in the laboratory allowed for analysis of the condensing of each system. Three major factors contributed to the lack of condensing at these six sites: set point temperature higher than $180^{\circ} \mathrm{F}$ for all sites, high secondary or distribution system flow rates produced low temperature drop across the radiation system, and primary/secondary plumbing loop configuration increased return water temperatures.

This large sample field study was designed to help determine how these systems work in the real world, as well as assess the actual installed efficiency and performance of combi systems. These field tests used commercially available, high efficiency products laboratory tested and configured to achieve condensing operation (Schoenbauer et al. 2012a) to determine the actual energy savings of well-designed combi systems.

\subsection{Relevance to Building America's Goals}

Combi systems have the potential to significantly reduce home energy use. A properly installed combi system can provide both space and water heating with $90+\%$ efficiency compared to a minimum efficiency $78 \%$ AFUE furnace and a $0.59^{1}$ EF WH. Additionally, replacing an ND SWH with a direct-vent heating plant allows the home to be more airtight without causing combustion safety issues and eliminates combustion makeup air. These two measures can further improve the energy performance of a home.

\footnotetext{
${ }^{1}$ For a gas-fired water heater with a rated storage volume of 40 gal.
} 
Combi systems are feasible for typical houses in most climate regions. In colder climates the application may not be possible in larger homes with poorly insulated and leaky envelopes. Some currently available equipment can meet space heating design loads up to $60,000 \mathrm{Btu} / \mathrm{h}$ while still operating in the condensing mode. Higher capacity hydronic coils would allow current heating plans to meet even higher space heating loads.

The implementation portion of this project installed more than 200 combi systems in Minnesota homes. It was expected that by the completion of this project, contractors would be ready to install the systems across the state. In addition, this project is developing installation guidelines and specifications to increase the success of installations in all climates.

\subsection{Cost Effectiveness}

The installation cost of a high efficiency combi system may be lower than the cost of a similar efficiency separate furnace and WH. In a retrofit application, a homeowner can expect to pay approximately $\$ 4,250$ for a high efficiency (90\%-98\% AFUE) furnace and $\$ 5,300$ for a high efficiency (0.80-0.95 EF) storage water heater (SWH). ${ }^{2}$ As the number of high efficiency WH installations increased over the past few years, the installed cost dropped dramatically. In the Minneapolis area, contractors with limited experience with combi systems currently bid a high efficiency system for $\$ 8,200$, on average, with a typical range from $\$ 6,500$ to $\$ 10,000$.

A preliminary EnergyPlus analysis of a high efficiency boiler used for space and domestic water heating estimated $12 \%$ natural gas and $7 \%$ source energy savings compared to an $80 \%$ AFUE furnace and 0.55 EF WH. However, EnergyPlus is not easily adapted and may not properly model high efficiency combi system performance. For example, the heating plant steady-state efficiency varies with return water or inlet water temperature and the form of that relationship varies for different plants. In addition, the boiler used for the EnergyPlus model was found to have high off-cycle losses and was not included in the field installations. It is expected that the recently available test laboratory measurements for individual combi components will provide performance data necessary for improved EnergyPlus models. The laboratory results should also help verify the accuracy of the predicted EnergyPlus combined space and domestic water heating efficiency. Project results will be processed to generate data that National Renewable Energy Laboratory staff can use in the development of accurate EnergyPlus combi system models, with the ultimate goal of incorporating combi system models into Building Energy Optimization $\left(\right.$ BEopt $\left.^{\mathrm{TM}}\right)$ software.

\subsection{Tradeoffs and Other Benefits}

There are several secondary benefits to the combi system. The system replaces a separate furnace and WH with a single boiler or WH. This reduces the number of gas lines and exhaust vents and can reduce the equipment footprint. A combi system using an SWH will be the same size as a forced air furnace and traditional WH. A system using a TWH or hybrid WH can be wall mounted and reduce the footprint. These small types of WHs can allow for a more versatile mechanical room. In new construction, this may allow the mechanical equipment to be placed closer to the end uses, reducing delivery losses and hot water wait times.

\footnotetext{
${ }^{2}$ Cost estimates come from the standard bid amounts from the project contractors.
} 
A single high efficiency burner also has combustion safety and venting benefits. The high efficiency combi heating plants have forced mechanical draft venting systems. These eliminate combustion safety depressurization issues that pose a significant problem as homes become tighter. Direct vent burners may provide an additional energy benefit by eliminating combustion makeup air openings and may allow an existing chimney common vent to be sealed.

For the implementation portion of this project the selected combi system components include a warranty, and their durability is expected to equal or exceed that of the alternatives. In addition, the single heating plant for combi systems is expected to require less annual maintenance than a separate furnace and $\mathrm{WH}$.

As part of the laboratory portion of the project, properly installed combi systems were demonstrated to code officials and contractors who were expected to bid on the installations. The demonstrations allowed code officials to identify potential code concerns, such as water stagnation in potable rated AHUs, and recommend acceptable solutions. The improved codeofficial acceptance of this newer technology reduced issues requiring attention during the installation process. 


\section{Experiment}

\subsection{Research Questions}

The field research was designed to address the following research questions:

- What are the minimum performance criteria, installation specifications, and quality control methods that must be included in the install to ensure proper performance and expected efficiency? What trouble areas of the installation can be addressed through these criteria and quality control methods?

- What is the installed performance of combi systems and what is the savings potential of this technology in real homes? How do monitored performance and savings results compare to modeled results?

- Are there heat delivery advantages and/or disadvantages of different combi systems? What are system response times? How consistent are delivered temperatures?

- What were the initial installed costs for combi systems and does increased contractor training and installation experience reduce these costs?

- How can these systems benefit from improved combi products (boilers, WHs, hydronic AHUs, controls, etc.)?

\subsection{Technical Approach}

This project examined energy savings achieved by using a single high efficiency appliance to provide both space and water heating. The Sustainable Resource Center in Minneapolis, Minnesota, received a Sustainable Energy Resources for Consumers grant to install approximately 400 combined space and water heating systems in homes participating in the State of Minnesota Low-Income Weatherization Assistance Program. The limited contractor awareness and agency experience with the systems led to extensive laboratory tests to generate detailed design and installation specifications. The grant required that each home participated in the low income weatherization program. Older mechanical systems are frequently replaced in the weatherization process, and this project did not want to remove a new condensing furnace. That meant that only homes that had gone through weatherization and did not have the furnace replaced could qualify for this installation. The added time required for system design and the increased difficulty of finding appropriate homes reduced the total number of installations to just over 200. Building America funds were used to install more extensive field monitoring to measure and analyze the system's performance for a subset of the homes. The original goal was to monitor 20 of the installations, but one site dropped from the study after the pre-monitoring when the owner did not proceed with the combi installation. In addition, a pre/post analysis of daily average space and domestic water heating energy use was included for 18 homes. Premonitoring was not performed at the final site because there was not enough heating season remaining to accurately characterize the existing system.

Laboratory tests were conducted on a variety of complete systems and individual components before combi systems were installed in the field. The results from the laboratory work were reported in the Building America report titled Retrofitting Integrated Space and Water Heating Systems: Laboratory Tests (Schoenbauer et al. 2012b). The laboratory analysis was used to develop a set of specific parameters for several categories of home space and DHW design loads 
so that each system would achieve condensing operation during the space heating mode, provide acceptable supply air temperatures, and produce space heat sufficient to meet or exceed design conditions.

At 19 of the 200 sites, data on the natural gas and electricity use of the existing furnace and WH were collected for at least 1 month prior to the installation of the combi system. Combi installations were conducted between January and March 2012, allowing 2011/2012 heating season data to be collected on both systems. Models of daily average energy use with local National Oceanic Atmospheric Administration (NOAA) weather stations' outside temperature and seasonal variations in inlet water temperature were used to characterize the daily energy use of the existing systems. These models were used to compute the annual gas use of the existing systems. A similar analysis was conducted for the installed combi systems to estimate the combi system energy savings.

Instruments were added to each combi system to measure the space and DHW energy output at 1 -second intervals. The energy output and input data were used to compute short- and long-term system efficiencies and disaggregate the space and water heating loads. The field data collected will be made available to National Renewable Energy Laboratory staff to assist them in developing more representative EnergyPlus models, with the ultimate goal of including a high efficiency combi system option in BEopt.

Water flow rates and water supply and return temperatures were recorded for both the space and DHW loads along with AHU return/supply air temperature and air temperature at the thermostat. The measurements were made at 1-second intervals. Portions of the short interval data were used to help identify system installation issues, quality control measures, and design changes to improve the performance of installed systems.

Quality control procedures established for previous projects were used to calibrate instruments before field deployment, verify operation at the time of installation, and confirm operation on an ongoing basis after installation. Site data were collected and reviewed 1 week after the initial installation, and the collection process continued at 2- to 4-week intervals through the end of the monitoring period.

\subsection{Monitoring Equipment}

The energy performance and operating characteristics of the existing and combi systems at the 19 test sites were monitored using a Campbell Scientific model CR-3000 data logger. The natural gas and electricity use of the existing furnace and WH were computed from burner runtime measurements. WH burner runtimes were monitored using either gas valve pressure switches or thermocouple sensors near the burner; both strategies were tested and verified under simultaneous operation at multiple sites. Furnace burner-on times were monitored using current switches on the burner signal. Air temperature data near the thermostat, furnace return air temperature, and supply air temperature were also monitored. The outdoor air temperature (OAT) data were obtained from a local NOAA weather station. Figure 1 shows the instrumentation configuration for monitoring the existing equipment. All existing SWHs and air furnaces had single-stage, constant input burners. This type of equipment enabled the use of natural gas valve runtime monitoring and measured gas input rate to determine the appliance gas use. Electricity use was computed from runtime monitoring and one-time measurements of 
circulation fan and off-cycle power. Surface mount thermocouples were used to track WH inlet and outlet temperatures, but were not used for the energy analysis.
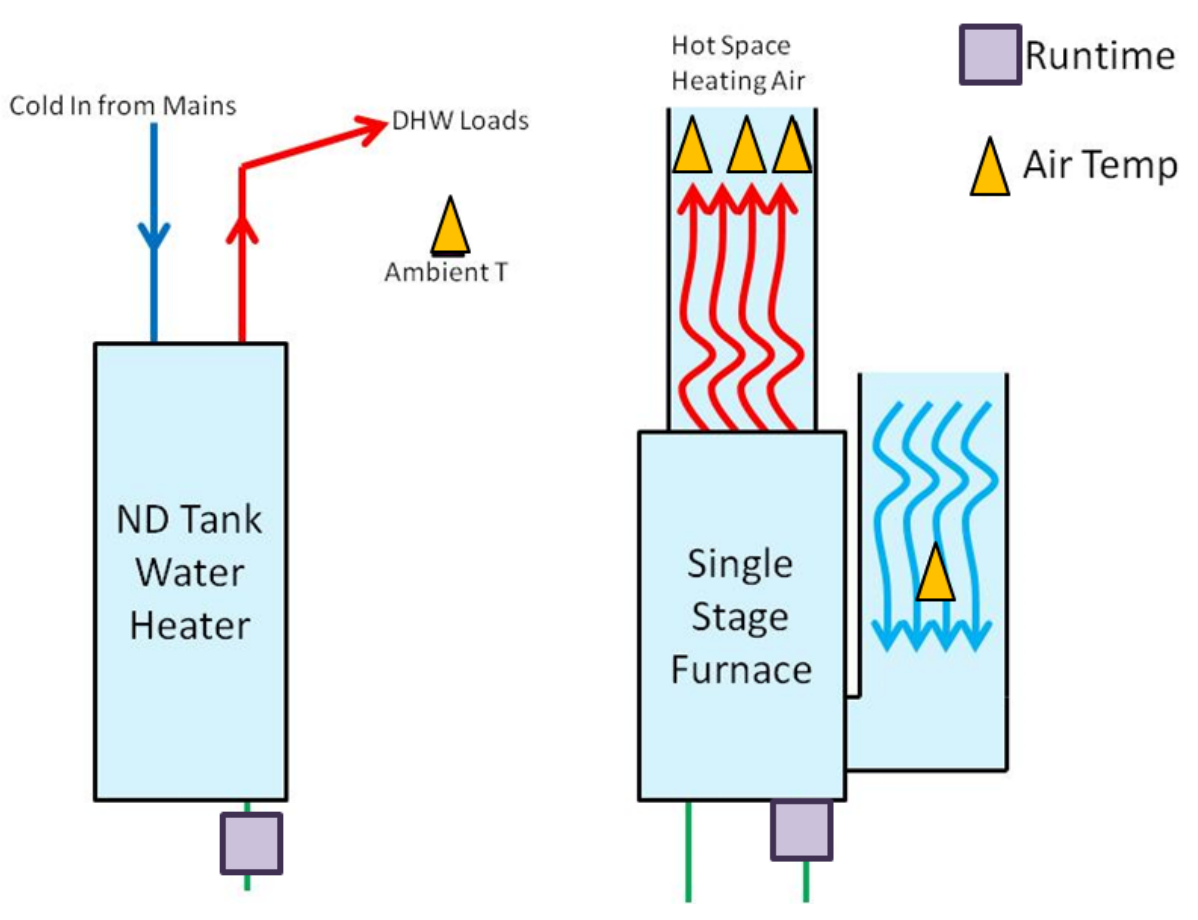

Figure 1. Monitoring instrumentation for existing space and DHW systems

At the time of the combi system installation, a comprehensive and accurate monitoring system utilizing high precision instruments (see Table 1) was installed to monitor space and DHW heating energy input and output along with several key operating characteristics of the systems. Water temperature and flow rate measurements were used to calculate the hot water energy output by the heating plant for the DHW and space heating loads. The two energy outputs were summed to obtain the total output. The gas use was measured with a diaphragm meter and the electricity use by a watt transducer. The instrument configurations for storage tank WHs, TWHs, and boilers are shown in Figure 2, Figure 3, and Figure 4, respectively. The purple triangles indicate the location of the immersion resistance temperature detectors (RTDs) used for energy output calculations. In addition, AHU supply air temperatures and conditioned space temperatures were used to help identify customer comfort issues and diagnose complaints. 
Table 1. Instrumentation Specifications

\begin{tabular}{|c|c|c|c|c|}
\hline Measurement & Sensor Type & Resolution $^{\mathrm{a}}$ & Precision $^{\mathrm{a}}$ & Range \\
\hline $\begin{array}{l}\text { Water Volume } \\
\text { Flow Rate }\end{array}$ & $\begin{array}{l}\text { Nutating disk flow } \\
\text { meter }\end{array}$ & 198.4 pulses/gal & $2 \%$ of reading & $0.5-25 \mathrm{gpm}^{\mathrm{b}}$ \\
\hline $\begin{array}{l}\text { Natural Gas } \\
\text { Volume }\end{array}$ & $\begin{array}{l}\text { Diaphragm meter } \\
\text { with pulse output }\end{array}$ & 40 pulses $/ \mathrm{ft}^{3}$ & $0.3 \%$ of reading & $0-250 \mathrm{cfm}$ \\
\hline $\begin{array}{c}\text { Water } \\
\text { Temperatures }\end{array}$ & $\begin{array}{l}\text { Matched pair of } \\
\text { immersion RTDs }\end{array}$ & $0.002^{\circ} \mathrm{F} @ 140^{\circ} \mathrm{F}$ & $\begin{array}{l}\text { 1/10 DIN: } 0.03^{\circ} \mathrm{F} \\
\text { @ } 32^{\circ} \mathrm{F}\end{array}$ & $-148^{\circ}$ to $752^{\circ} \mathrm{F}$ \\
\hline $\begin{array}{l}\text { Electric } \\
\text { Energy }\end{array}$ & Watt transducer & 0.02 Watts & $0.2 \%$ of reading & $0-1000$ Watts \\
\hline $\begin{array}{c}\text { Air } \\
\text { Temperature }\end{array}$ & $\begin{array}{l}\text { Thermocouple } \\
\text { array }\end{array}$ & $0.003^{\circ} \mathrm{F} @ 140^{\circ} \mathrm{F}$ & $\begin{array}{c}\text { Greater of } 1.8^{\circ} \mathrm{F} \text { or } \\
0.75 \% \text { of reading }\end{array}$ & $-454^{\circ}$ to $725^{\circ} \mathrm{F}$ \\
\hline
\end{tabular}

${ }^{\text {a }}$ Resolution is used to measure the granulation of instrument measurement and precision is used to indicate the ability of the instrument to measure the actual value.

${ }^{\mathrm{b}}$ The meter measures flow rates $<0.5 \mathrm{gpm}$, but the precision decreases for flow rates outside the specified range.

For the DHW load calculation the water flow meter and inlet temperature immersion RTD were placed before the tee to the mixing valve, and the RTD for the supply temperature was placed at the mixing valve outlet. This provided an accurate measurement of the energy output, as well as the volume and temperature of hot water provided to the house. An immersion thermocouple was placed near the heating plant DHW outlet (before the mixing valve) to measure the transient performance of the heating plant (see yellow triangles in Figure 2 through Figure 4).

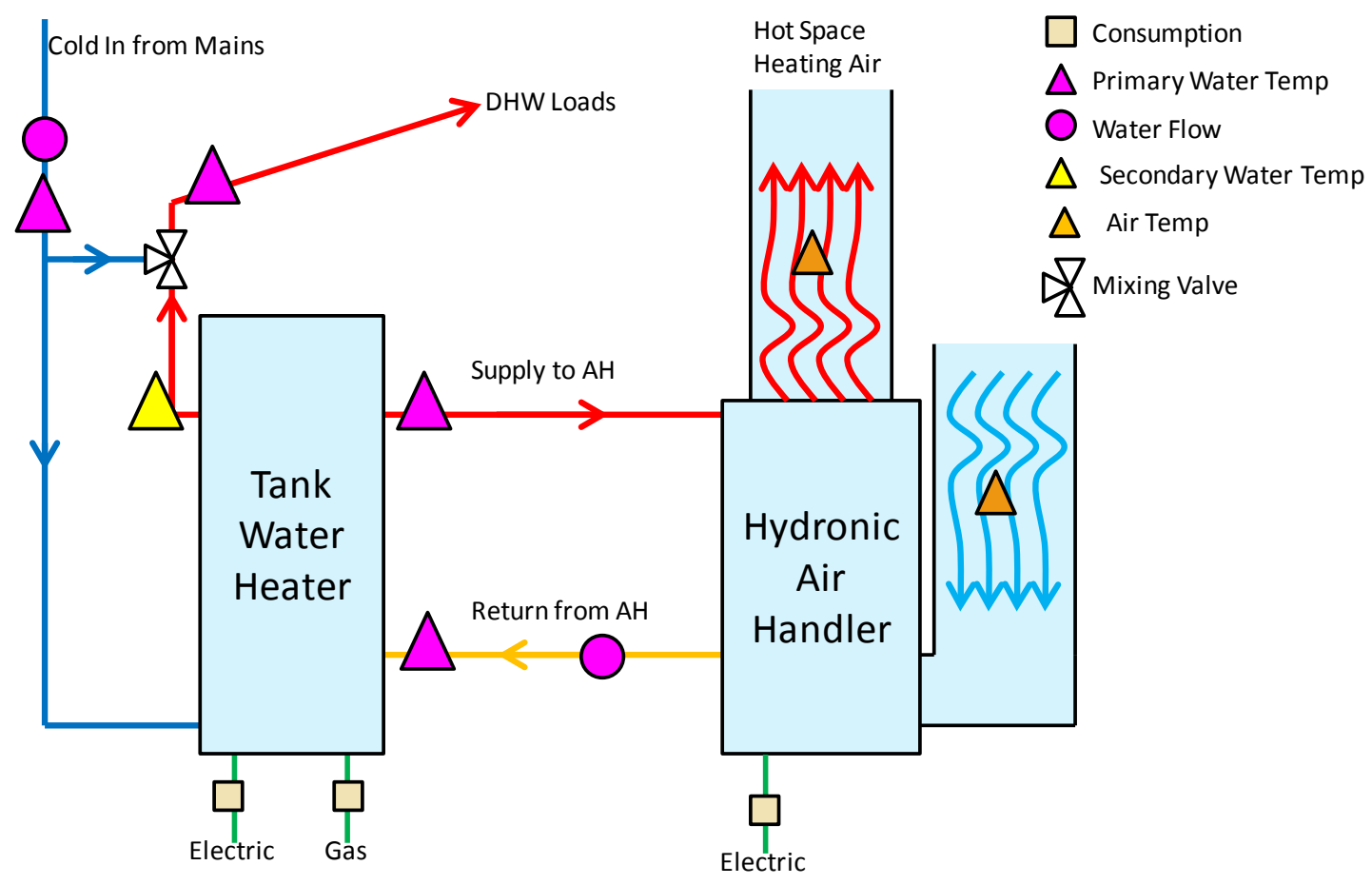

Figure 2. Field monitoring instrumentation for an SWH system 


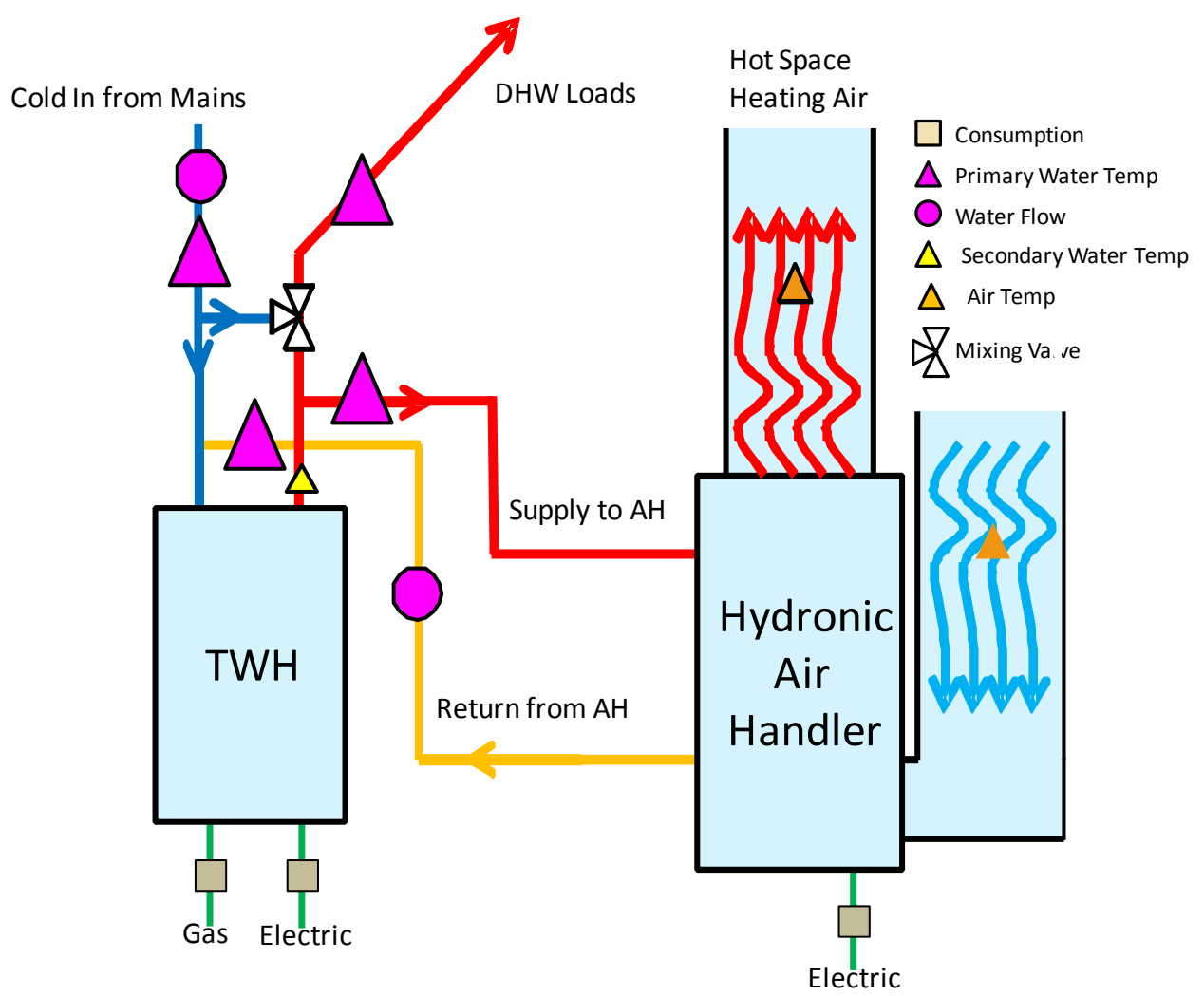

Figure 3. Field instrumentation for a TWH combi system 


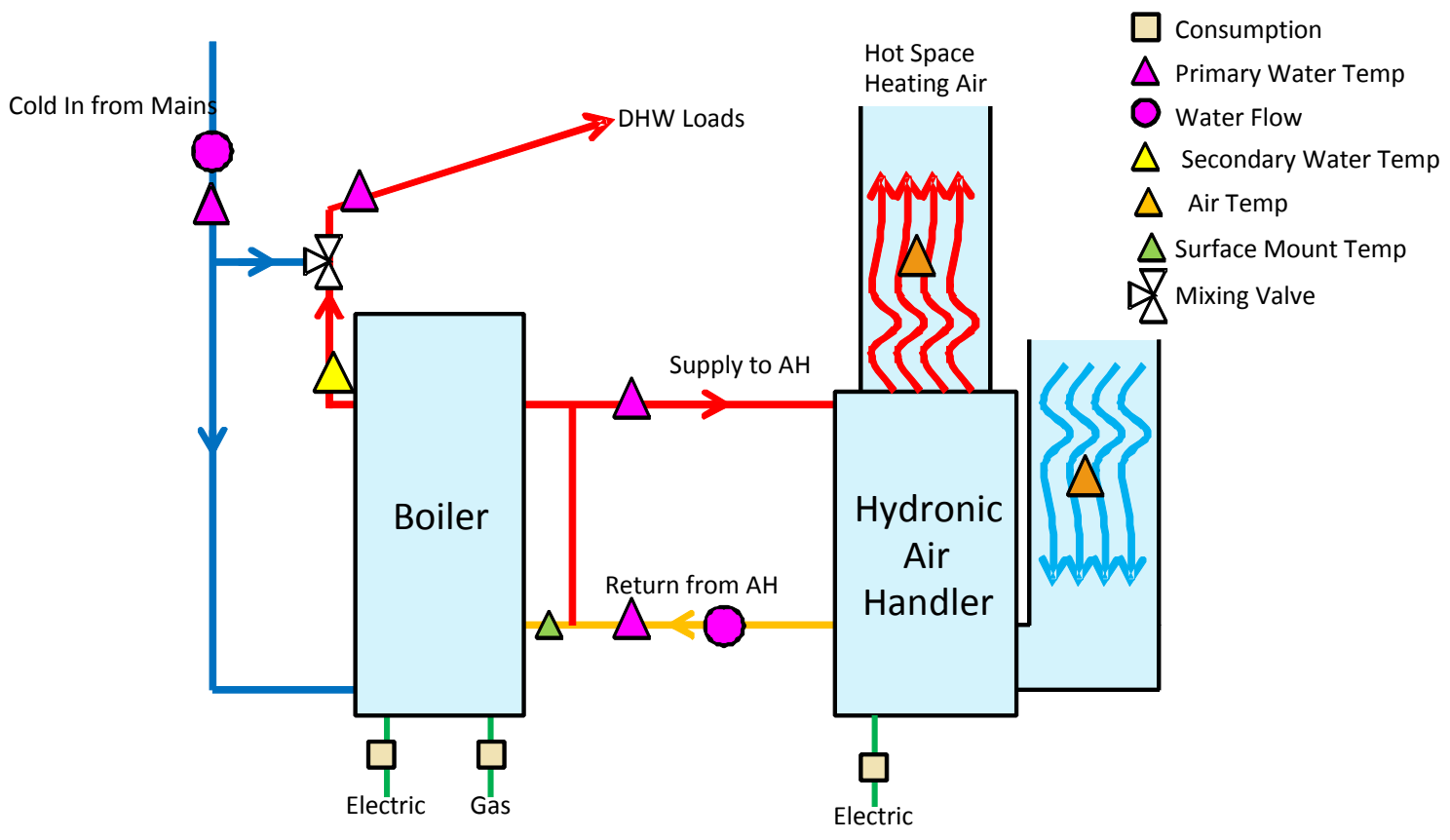

Figure 4. Field instrumentation for boiler-based combi systems

\subsection{Systems Monitored}

The existing space and water heating equipment was measured in 18 homes. Each home had an ND SWH and a forced air furnace. Sixteen of the sites had ND furnaces with AFUE ratings around $80 \%$ and the other two sites had condensing furnaces with efficiencies listed around $90 \%$. Table 2 lists the characteristics of the existing equipment at each site.

Table 3 shows the manufacturer and model information for the combi system heating plants and hydronic AHUs used for the field installations. The project tested a standard model of both the American Polaris (PG10 34-130) and HTP Phoenix (ph100-55) in two homes, with higher capacity models (PG10 50-150 and ph160-50) for homes with larger loads. The third storage model, the AO Smith Vertex, was installed in only two homes. This WH does not have a larger model suitable for higher load homes. Two combination boilers (Navien Combi Boiler and Rinnai 37AHB075) and two TWHs (Rinnai 98Lsi and Grand Hall Eternal) were installed in three homes. 
Table 2. Characteristics of the Existing WH and Furnace at Each Site

\begin{tabular}{c|c|c|c|c|c|c|c|c|c}
\hline \multirow{2}{*}{$\begin{array}{c}\text { Site } \\
\text { Number }\end{array}$} & \multicolumn{7}{|c|}{ Existing WH } & \multicolumn{4}{c}{ Existing Furnace } \\
\cline { 2 - 9 } & $\begin{array}{c}\text { Install } \\
\text { Year }\end{array}$ & $\begin{array}{c}\text { Input } \\
(\mathbf{B t u} / \mathbf{h})\end{array}$ & $\begin{array}{c}\text { Storage } \\
\text { (gal) }\end{array}$ & $\mathbf{E F}$ & $\begin{array}{c}\text { Vent } \\
\text { Type }\end{array}$ & $\begin{array}{c}\text { Install } \\
\text { Year }\end{array}$ & $\begin{array}{c}\text { Input } \\
\text { (Btu/h) }\end{array}$ & AFUE & $\begin{array}{c}\text { Vent } \\
\text { Type }\end{array}$ \\
\hline $\mathbf{1 0 2 6}$ & 2009 & 40,000 & 40 & 0.59 & ND & 2001 & 88,000 & $80 \%$ & ND \\
$\mathbf{1 0 2 7}$ & 2006 & 38,000 & 40 & $0.59 *$ & ND & 1999 & 90,000 & $80 \%$ & ND \\
$\mathbf{1 0 2 8}$ & 1999 & 40,000 & 40 & 0.56 & ND & 1979 & - & $80 \%$ & ND \\
$\mathbf{1 0 3 0}$ & 2004 & 36,000 & 40 & 0.59 & ND & 2004 & 66,000 & $80 \%$ & ND \\
$\mathbf{1 0 3 1}$ & 2001 & 40,000 & 40 & 0.56 & ND & 2007 & 60,000 & $93 \%$ & Direct \\
$\mathbf{1 0 3 7}$ & 2009 & 38,000 & 50 & 0.58 & ND & - & 75,000 & $80 \%$ & ND \\
$\mathbf{1 0 4 5}$ & - & 40,000 & 40 & 0.59 & ND & 1999 & 80,000 & $80 \%$ & ND \\
$\mathbf{1 0 4 7}$ & 1982 & 32,000 & 40 & $0.56 *$ & ND & 2003 & 75,000 & $80 \%$ & ND \\
$\mathbf{1 0 4 9}$ & 2004 & 40,000 & 40 & 0.59 & ND & 2004 & 88,000 & $80 \%$ & ND \\
$\mathbf{1 0 5 2}$ & 2008 & 38,000 & 50 & 0.58 & ND & - & 80,000 & $90 \%$ & Direct \\
$\mathbf{1 0 5 4}$ & 2006 & 34,000 & 40 & 0.59 & ND & 2003 & 88,000 & $80 \%$ & ND \\
$\mathbf{1 0 5 5}$ & 1991 & 32,000 & 40 & 0.56 & ND & 1991 & 75,000 & $78 \%$ & ND \\
\hline $\mathbf{1 0 5 6}$ & 2006 & 40,000 & 40 & 0.59 & ND & 1997 & 75,000 & $80 \% *$ & ND \\
$\mathbf{1 0 6 1}$ & 2004 & 40,000 & 40 & 0.59 & ND & 2004 & 88,000 & $80 \%$ & ND \\
$\mathbf{1 0 6 2}$ & 2005 & 40,000 & 40 & 0.59 & ND & 1998 & 60,000 & $80 \% *$ & ND \\
$\mathbf{1 0 6 3}$ & 2001 & 40,000 & 40 & 0.59 & ND & 1989 & 95,000 & $80 \% *$ & ND \\
$\mathbf{1 0 6 5}$ & 2002 & 40,000 & 40 & $0.59 *$ & ND & 1989 & 71,000 & $80 \%$ & ND \\
$\mathbf{1 0 7 0}$ & 2003 & 40,000 & 40 & $0.59 *$ & ND & 2007 & 75,000 & $80 \%$ & ND \\
$\mathbf{1 0 7 8}$ & & & N/A & & & & N/A & \\
\hline
\end{tabular}

* Efficiency ratings could not be determined and were estimated based on vintage and other model characteristics

Table 3. Field-Installed Combi System Equipment

\begin{tabular}{c|c|c|c|c|c}
\hline \multirow{2}{*}{ Equipment Type } & \multirow{2}{*}{ Manufacturer } & \multirow{2}{*}{ Model } & \multicolumn{3}{|c}{ Rating } \\
\cline { 4 - 6 } & & AFUE & $\begin{array}{c}\text { Thermal } \\
\text { Efficiency }\end{array}$ & EF \\
\hline SWH & AO Smith & Vertex & - & 0.96 & - \\
SWH & American & Polaris & - & 0.95 & - \\
SWH & HTP & Phoenix & - & 0.95 & - \\
\hline TWH & Rinnai & 98LSI & - & - & 0.95 \\
Hybrid WH & Grand Hall & Eternal & - & - & - \\
Boiler & Navien & Combi Boiler & $91 \%$ & - & - \\
Boiler & Rinnai & Q175C & $96 \%$ & - & - \\
\hline Hydronic AHU & Rinnai & 37 AHB75 & - & - & - \\
\hline Hydronic AHU & Ennerzone & $7500 \%$ & - & - & - \\
\hline
\end{tabular}

Sites were selected from homes participating in the State of Minnesota Low Income Weatherization Program. These sites had received building envelope air sealing and insulation upgrades, but no mechanical system updates. Homes with an estimated design space heating load less than $50,000 \mathrm{Btu} / \mathrm{h}$ and one or two showers were chosen for the study. The design space heating loads were determined from National Energy Audit Tool (NEAT) modeling used to 
select cost-effective energy improvements. Table 4 shows the combi heating plant and hydronic AHU specified for each site along with the site load information. Homes with lower heating loads (20,000 to $37,000 \mathrm{Btu} / \mathrm{h})$ and a single shower were considered to be a "best case" (BC) installation. Homes with a larger heating load (37,000 to 50,000 Btu/h) and a single shower were considered to be "not quite best case" (NQBC) installations. Homes with two showers were considered "stress case" (STRESS) installations. The load category specification indicates the expected level of difficulty for the heating plant to satisfy the home's combined space heating and DHW loads.

Table 4. Combi Equipment and Loads by Site

\begin{tabular}{|c|c|c|c|c|c|c|}
\hline \multirow{2}{*}{$\begin{array}{c}\text { Site } \\
\text { Number }\end{array}$} & \multicolumn{2}{|c|}{ Combi Appliance } & \multirow{2}{*}{$\begin{array}{l}\text { Calc Load } \\
(\text { Btu/h) }\end{array}$} & \multirow{2}{*}{$\begin{array}{l}\text { Number of } \\
\text { Showers }\end{array}$} & \multirow{2}{*}{$\begin{array}{l}\text { Number } \\
\text { of People }\end{array}$} & \multirow{2}{*}{$\begin{array}{c}\text { Load } \\
\text { Category }\end{array}$} \\
\hline & Heating Plant & AHU & & & & \\
\hline 1026 & Vertex & Ennerzone & 46,248 & 1 & 3 & NQBC \\
\hline 1027 & Polaris & Ennerzone & 38,774 & 2 & 4 & STRESS \\
\hline 1028 & Polaris & Rinnai & 35,716 & 2 & 1 & $\mathrm{BC}$ \\
\hline 1030 & Rinnai TWH & Ennerzone & 32,064 & 2 & 5 & STRESS \\
\hline 1031 & Polaris & Ennerzone & 38,260 & 2 & 1 & NQBC \\
\hline 1037 & Navien & Ennerzone & 28,534 & 2 & 3 & STRESS \\
\hline 1045 & Rinnai TWH & Ennerzone & 31,461 & 1 & 3 & $\mathrm{BC}$ \\
\hline 1047 & Navien & Ennerzone & 42,636 & 1 & 2 & NQBC \\
\hline 1049 & Eternal & Ennerzone & 36,277 & 2 & 5 & STRESS \\
\hline 1052 & Rinnai Boiler & Ennerzone & 33,474 & 2 & 1 & BC \\
\hline 1054 & Eternal & Ennerzone & 40,101 & 2 & 1 & NQBC \\
\hline 1055 & Navien & Rinnai & 30,729 & 1 & 2 & BC \\
\hline 1056 & Phoenix & Ennerzone & 26,112 & 1 & 1 & $\mathrm{BC}$ \\
\hline 1061 & Phoenix & Ennerzone & 37,368 & 1 & 2 & NQBC \\
\hline 1062 & Rinnai TWH & Ennerzone & 41,966 & 2 & 1 & NQBC \\
\hline 1063 & Rinnai Boiler & Ennerzone & 32,640 & 2 & 2 & STRESS \\
\hline 1065 & Vertex & Ennerzone & 35,136 & 1 & 1 & BC \\
\hline 1070 & Eternal & Ennerzone & 29,111 & 1 & 1 & BC \\
\hline 1078 & Phoenix & Ennerzone & 40,320 & 2 & 5 & STRESS \\
\hline
\end{tabular}

Large load installations required some larger model heating plants

These cases are noted as stress models

\subsection{System Sizing and Proper Installation}

Previous laboratory test results were used to develop guidelines for component selection, sizing requirements, and system installation. These results were presented in the 2012 Building America report titled Retrofitting Combined Space and Water Heating Systems: Laboratory Tests (Schoenbauer et al. 2012b). The first step in the combi design process is to measure or determine the key household characteristics: space and water heating loads, occupancy, distribution systems, and hot water end use.

The space heating loads are estimated from the building envelope characteristics and used to calculate the space heating design load. The home's gas utility billing history and corresponding outdoor temperatures can help verify the space heating load estimates. The water heating load can be estimated with a survey of end uses and number of residents. For sizing purposes, the large hot water draws are more important than the total DHW load. The shower events are 
typically the largest loads and have the greatest impact on occupant satisfaction with DHW delivery (Schoenbauer et al. 2012a). The actual shower hot-water flow rates provide more reliable sizing estimates, but person-to-person variances of flow, cold water temperature into the home, and shower temperature selection necessitate the use of typical values. Low flow shower heads were recommended to replace shower heads with flow rates greater than 2.0 gpm for the field portion of this project to avoid excessive shower flow rates that could cause occupant dissatisfaction.

Codes handle sizing for WHs and space heating systems differently and manufacturers often use their own proprietary software. Neither codes nor manufacturers adequately address combined appliance sizing. Contractors have traditionally sized systems using their own rules of thumb or guidance from local manufacturer representatives. For this project the heating plants were sized for each home using the expected shower load and estimated space heating load. The natural gas burner input rate, storage capacity, and heating plant controls (DHW priority) were considered when sizing the system. Table 5 lists sizing guidelines for the three types of combi systems studied in this project. The sizing guidelines were developed by assuming an output capacity for each system based on the unit specifications. A conservative thermal efficiency of $85 \%$ was used to determine the energy output capacity for the burner size. The output capacity of the hot water storage volume was considered to be the energy available from a $30^{\circ} \mathrm{F}$ temperature drop in the storage volume over 20 minutes. These assumptions were similar to residential usage, around 2 gpm, and the 20-minute time interval was similar to shower lengths. Inlet water temperatures were assumed to be $60^{\circ} \mathrm{F}$ and the mixed shower temperature was assumed to be $105^{\circ} \mathrm{F}$.

Additionally, the energy rates that resulted from these calculations were compared to rates measured in the laboratory during hot water events prior to the burner firing. The total output capacity of the unit was the combined output from storage and the burner. This output was compared to the combined DHW and space heating load, unless the heating plant used DHW priority. In that case the output capacity was compared to each load independently. Each row corresponds to a heating plant that was considered for use in the field monitoring portion of the project. The first four columns of the table (type of heating plant, burner maximum input, water storage capacity, and DHW priority) characterized the combi system. The next six columns display the system output capacity as a percentage of load for the six load profiles. These columns indicate whether the system would be properly sized for the specified loads. For example, a boiler with $199 \mathrm{kBtu} / \mathrm{h}$ input, zero storage, and DHW priority would have more than 2 times the capacity needed in a $40 \mathrm{kBtu} / \mathrm{h}$, one-shower home. A heating plant would be undersized if the number listed was less than $100 \%$, meaning the required output was greater than the available capacity. The loads in Table 5 were selected to represent the range of the housing stock considered. When sizing was done for a specific home, the estimated loads of that home were used. 
Table 5. Combination System Sizing Chart

\begin{tabular}{|c|c|c|c|c|c|c|c|c|c|}
\hline & \multirow[b]{2}{*}{$\begin{array}{c}\text { Max Input } \\
(\mathbf{k B t u} / \mathbf{h})\end{array}$} & \multirow[b]{2}{*}{$\begin{array}{l}\text { Storage } \\
\text { (gal) }\end{array}$} & \multirow[b]{2}{*}{$\begin{array}{c}\text { DHW } \\
\text { Priority? }\end{array}$} & \multirow{2}{*}{\multicolumn{2}{|c|}{\begin{tabular}{c|c} 
1 Shw & 2 Shw \\
SP: 40,000 Btu/h \\
$(\%)$
\end{tabular}}} & $1 \mathrm{Shw}$ & 2Shw & $1 \mathrm{Shw}$ & 2 Shw \\
\hline & & & & & & \multicolumn{2}{|c|}{$\begin{array}{c}\text { SP: } 50,000 \text { Btu/h } \\
(\%)\end{array}$} & \multicolumn{2}{|c|}{$\begin{array}{c}\text { SP: } 60,000 \text { Btu/h } \\
(\%)\end{array}$} \\
\hline \multirow{12}{*}{ 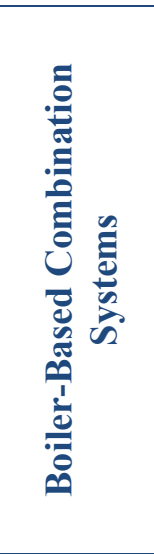 } & 75 & 0 & Yes & 92 & 53 & 92 & 53 & 92 & 53 \\
\hline & 100 & 0 & Yes & 122 & 71 & 122 & 71 & 122 & 71 \\
\hline & 150 & 0 & Yes & 183 & 107 & 183 & 107 & 183 & 107 \\
\hline & 199 & 0 & Yes & 243 & 142 & 243 & 142 & 243 & 142 \\
\hline & 75 & 6 & Yes & 97 & 57 & 97 & 57 & 97 & 57 \\
\hline & 100 & 6 & Yes & 128 & 74 & 128 & 74 & 128 & 74 \\
\hline & 150 & 6 & Yes & 189 & 110 & 189 & 110 & 189 & 110 \\
\hline & 199 & 6 & Yes & 248 & 145 & 248 & 145 & 248 & 145 \\
\hline & 75 & 12 & Yes & 102 & 60 & 102 & 60 & 102 & 60 \\
\hline & 100 & 12 & Yes & 133 & 78 & 133 & 78 & 133 & 78 \\
\hline & 150 & 12 & Yes & 194 & 113 & 194 & 113 & 194 & 113 \\
\hline & 199 & 12 & Yes & 254 & 148 & 254 & 148 & 254 & 148 \\
\hline \multirow{8}{*}{ 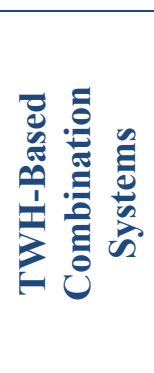 } & 150 & 2 & No & 117 & 85 & 108 & 76 & 99 & 72 \\
\hline & 199 & 2 & No & 155 & 113 & 142 & 101 & 131 & 95 \\
\hline & 150 & 0 & No & 116 & 84 & 107 & 75 & 98 & 71 \\
\hline & 199 & 0 & No & 154 & 112 & 141 & 100 & 130 & 94 \\
\hline & 150 & 2 & Yes & 185 & 108 & 185 & 108 & 185 & 108 \\
\hline & 199 & 2 & Yes & 245 & 143 & 245 & 143 & 245 & 143 \\
\hline & 150 & 0 & Yes & 183 & 107 & 183 & 107 & 183 & 107 \\
\hline & 199 & 0 & Yes & 243 & 142 & 243 & 142 & 243 & 142 \\
\hline \multirow{12}{*}{ 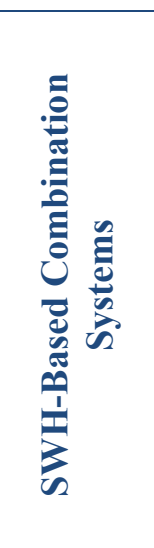 } & 100 & 50 & No & 106 & 77 & 98 & 69 & 90 & 65 \\
\hline & 150 & 50 & No & 145 & 105 & 133 & 94 & 123 & 89 \\
\hline & 199 & 50 & No & 183 & 133 & 168 & 119 & 155 & 112 \\
\hline & 100 & 80 & No & 124 & 90 & 113 & 80 & 105 & 76 \\
\hline & 150 & 80 & No & 163 & 118 & 149 & 105 & 137 & 99 \\
\hline & 199 & 80 & No & 201 & 145 & 184 & 130 & 170 & 123 \\
\hline & 100 & 50 & Yes & 106 & 77 & 98 & 69 & 90 & 65 \\
\hline & 150 & 50 & Yes & 145 & 105 & 133 & 94 & 123 & 89 \\
\hline & 199 & 50 & Yes & 183 & 133 & 168 & 119 & 155 & 112 \\
\hline & 100 & 80 & Yes & 124 & 90 & 113 & 80 & 105 & 76 \\
\hline & 150 & 80 & Yes & 163 & 118 & 149 & 105 & 137 & 99 \\
\hline & 199 & 80 & Yes & 201 & 145 & 184 & 130 & 170 & 123 \\
\hline
\end{tabular}

Note: The SP value refers to the space heating load and 2 Shw refers to 2 simultaneous showers. The percentage in each column specifies the ratio of system capacity to household load. Values less than $100 \%$ indicate the system would be undersized and greater than $100 \%$ means the system would be oversized.

An appropriate AHU can be selected based on the required space heating output. The detailed selection process was described in Section 2.3 of the laboratory test report (Schoenbauer et al. 2012a). The capacity range of the properly installed AHU must be greater than the home space heating demand plus a safety factor. In order to achieve condensing heating plant operation, the AHU coil must be large enough to transfer the required heat output at an acceptable air temperature $\left(115^{\circ} \mathrm{F}\right.$ was selected for this study) and a low return water temperature. In order to meet acceptable operating parameters (especially $115^{\circ} \mathrm{F}$ air temperature) combi system heating capacities often exceeded the required capacity to meet the home load. Figure 5 shows the 
relationship between return water temperature and system efficiency as determined by laboratory testing. There was a $2 \%$ reduction in efficiency of the Polaris system from reducing return water temperature from $100^{\circ} \mathrm{F}$ to $90^{\circ} \mathrm{F}$. Return water temperatures below $100^{\circ} \mathrm{F}$ resulted in loads on the system near the maximum input rating of the WHs. These conditions resulted in small reductions in output, reducing the overall efficiency. A maximum return water temperature of $105^{\circ} \mathrm{F}$ was selected to provide a good tradeoff between higher efficiency and reasonable coil size and cost. These conditions will help maximize the combi system energy efficiency. Larger capacity hydronic coils were not available at the time of this study that would meet the installation criteria for high load homes.

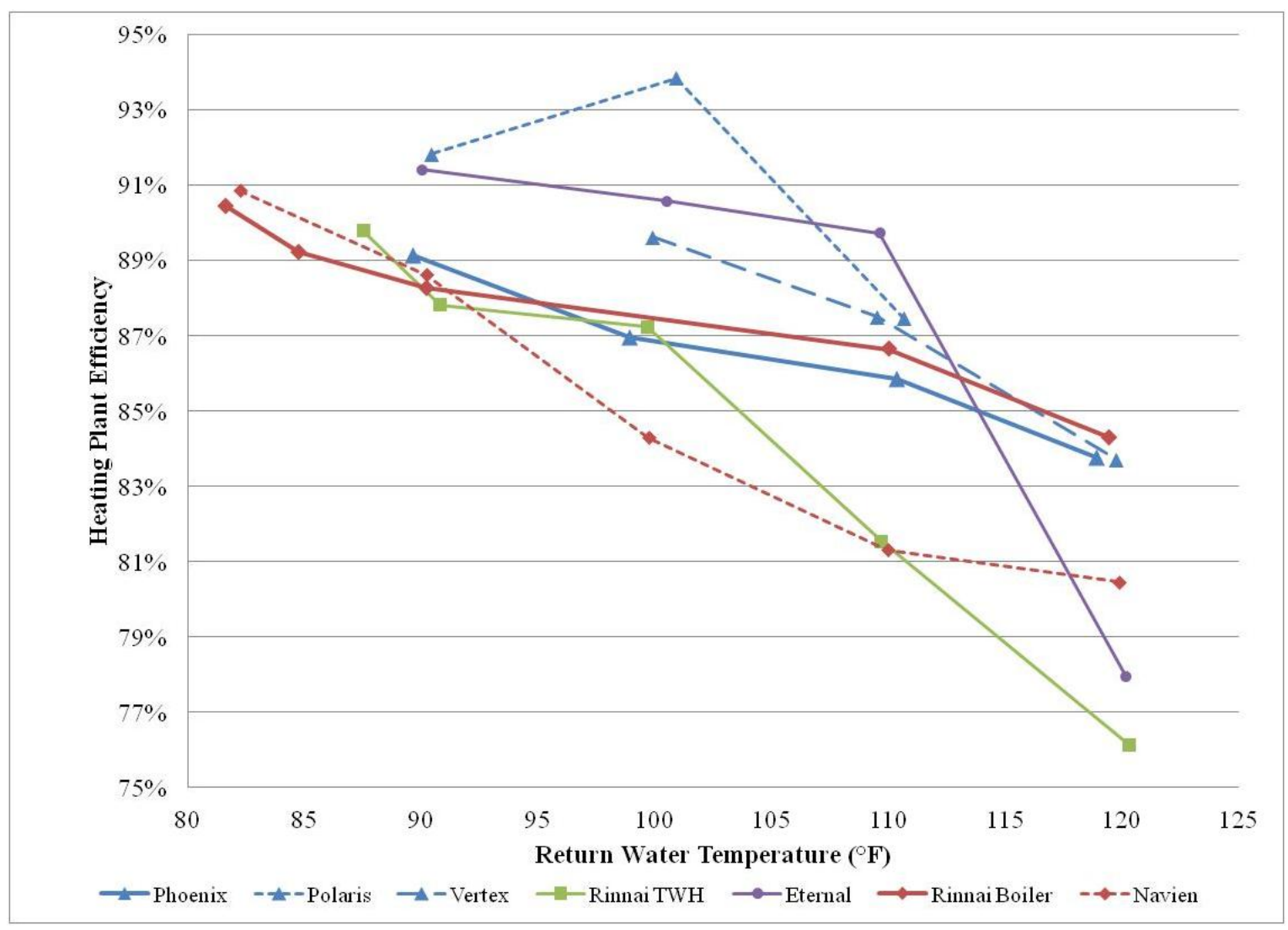

Figure 5. Laboratory testing of heating plant efficiency over a range of return water temperatures

A DHW mixing or tempering valve was included on every combi system to provide acceptable hot water temperatures at the fixtures. A mixing valve blends the heating plant DHW supply water with cold inlet water to produce the hot water supplied to the fixtures. Space heating supply water temperatures are often required to be higher than $120^{\circ} \mathrm{F}$ in order to meet the demand at an acceptable supply air temperature. For this study the systems used a set point or operating temperature of $140^{\circ} \mathrm{F}$. The mixing valve set point was initially set to $120^{\circ} \mathrm{F}$ at each site to decrease the risk of scalding. The mixing valve temperature control capabilities also helped to reduce some of the transient changes in the temperature of the hot water delivered to the fixtures. 


\section{Analysis}

Two types of analysis were performed. The first was an energy savings calculation computed from the difference between the annual energy use of the existing furnaces and WHs and that of the combi systems. The second computed the combi system water heating, space heating, and combined annual efficiency.

\subsection{System Efficiency}

When the combi systems were installed, additional instruments were added to calculate the space and DHW heating energy outputs and document system operating characteristics. The space heating energy output rate was computed from the hydronic coil's water flow rate and temperature difference across the coil (see equation 2). The DHW energy output was calculated from the DHW flow rate and temperature difference between the water entering the tee to the mixing valve and leaving the mixing valve. The relationship between the system energy input and output was used to determine the system efficiency over a wide range of loads.

$q_{\text {in }}=Q_{g} \cdot \mathrm{HF}$

$q_{\text {out }}=C_{p} \cdot \rho \cdot Q_{w} \cdot 60 \cdot \Delta T$

$\eta=q_{\text {out }} / q_{\text {in }}$

where:

$$
\begin{aligned}
& q_{i n}=\text { natural gas energy input, } \mathrm{Btu} / \mathrm{h} \\
& q_{\text {out }}=\text { energy output, } \mathrm{Btu} / \mathrm{h} \\
& \left.C_{p}=\text { specific heat of water (varies by temperature), Btu/(lb*o } \mathrm{F}\right) \\
& \rho=\text { water density at the flow meter (varies by temperature), lb/gal } \\
& Q_{w}=\text { water flow rate, gal } / \text { min } \\
& \Delta T=\text { water outlet }- \text { inlet temperature difference, }{ }^{\circ} \mathrm{F} \\
& Q_{g}=\text { burner natural gas flow rate, } \mathrm{ft}^{3} / \mathrm{h} \\
& \mathrm{HF}=\text { natural gas heat factor, } \mathrm{Btu} / \mathrm{ft}^{3} \\
& \eta=\text { thermal efficiency }
\end{aligned}
$$

The approach described above generated a linear relationship between daily average energy input and output of the combi system. This approach has been used previously for WHs (Schoenbauer et al. 2011) and commercial boilers (Butcher 2011). Because the combi system efficiency changed with the space/DHW load ratio and there was not a simple linear relationship between the two loads, the combi system energy use analysis required a more complicated modeling scheme than that for the existing systems. Energy use and system efficiencies could not be estimated by year or season; they were determined for each day and then summed to get annual results. A Minneapolis/St. Paul Typical Meteorological Year 3 dataset was used to generate the daily average outdoor temperatures and the site specific inlet water temperature models were used to determine the daily inlet water temperature. The same set of site specific linear relationships between the DHW inlet water temperature and load used for the existing systems (see Figure 11) were used to compute the combi system daily average DHW load. A linear regression of the combi system daily average space heating output and outside temperature (see 
Figure 6) was used to determine the daily space heating loads. The daily total load was simply the sum of the DHW and space heating loads.

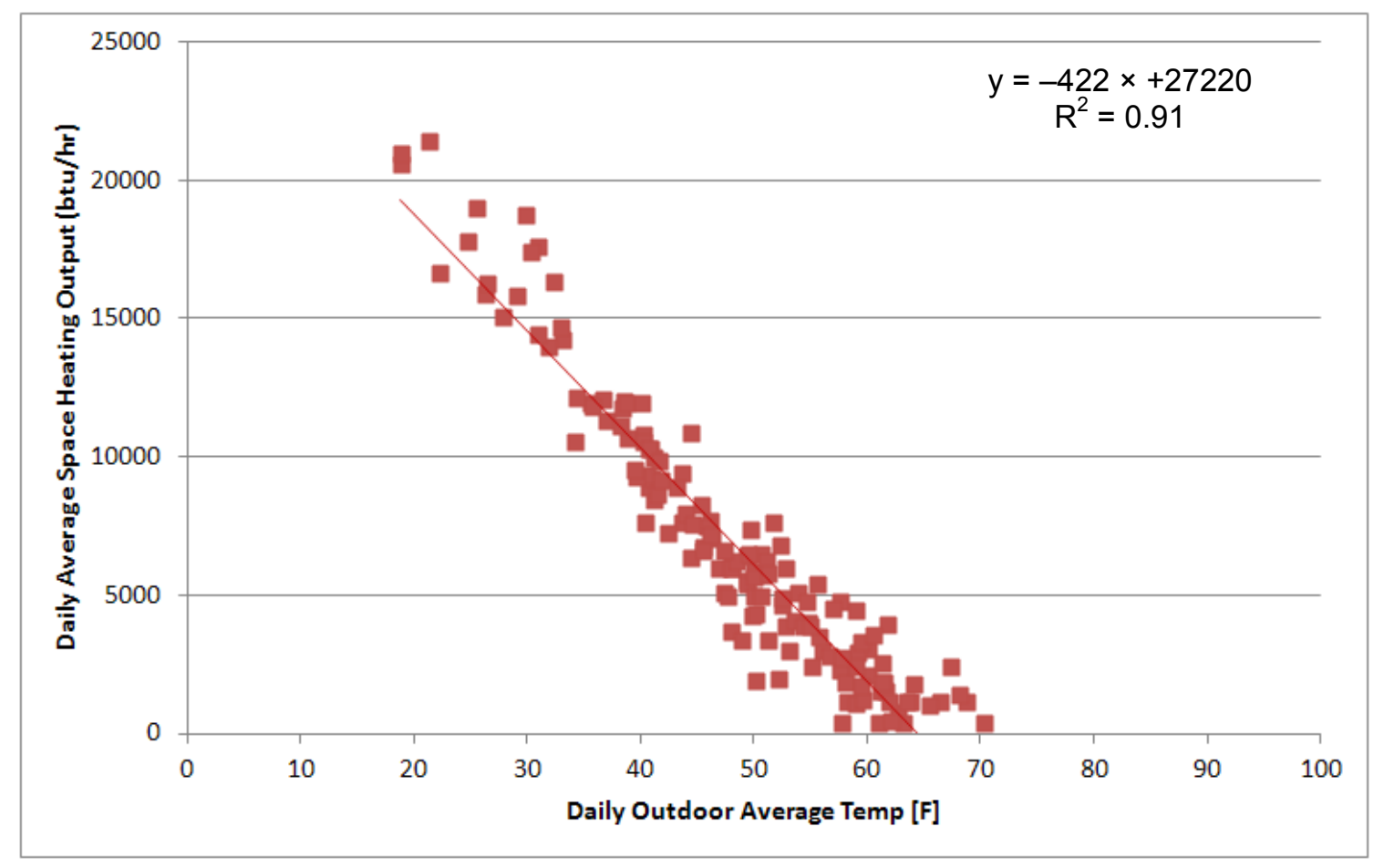

Figure 6. Daily space heating load by OAT for Site 1061

A model of space heating output versus the temperature difference of the conditioned space and the outside air was also considered. This model was less reliable than the output versus outdoor air model described above.

Monitoring days were split into two categories: those with space and water heating and those with DHW only. The data from each category were used to develop two separate linear energy input/output relationships. Figure 7 shows the natural gas input versus the combined space and water heating energy output (or load) for days when there was space heating. Figure 8 shows the same relationship for days with water heating only. Figures for these relationships for all sites are available in Appendix A and Appendix B. 


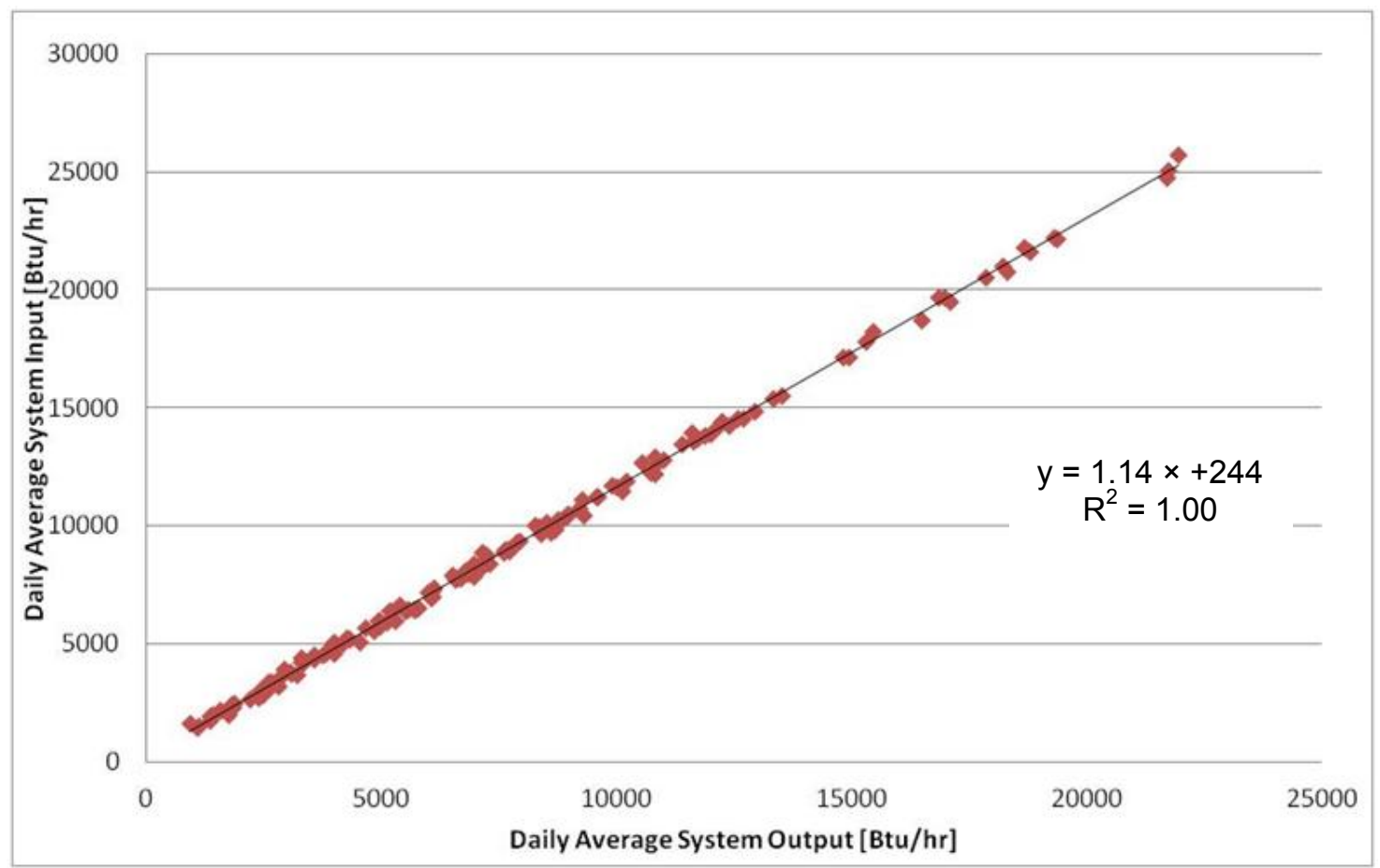

Figure 7. Input versus output relationship for the combi system on days with space and water heating at Site 1061

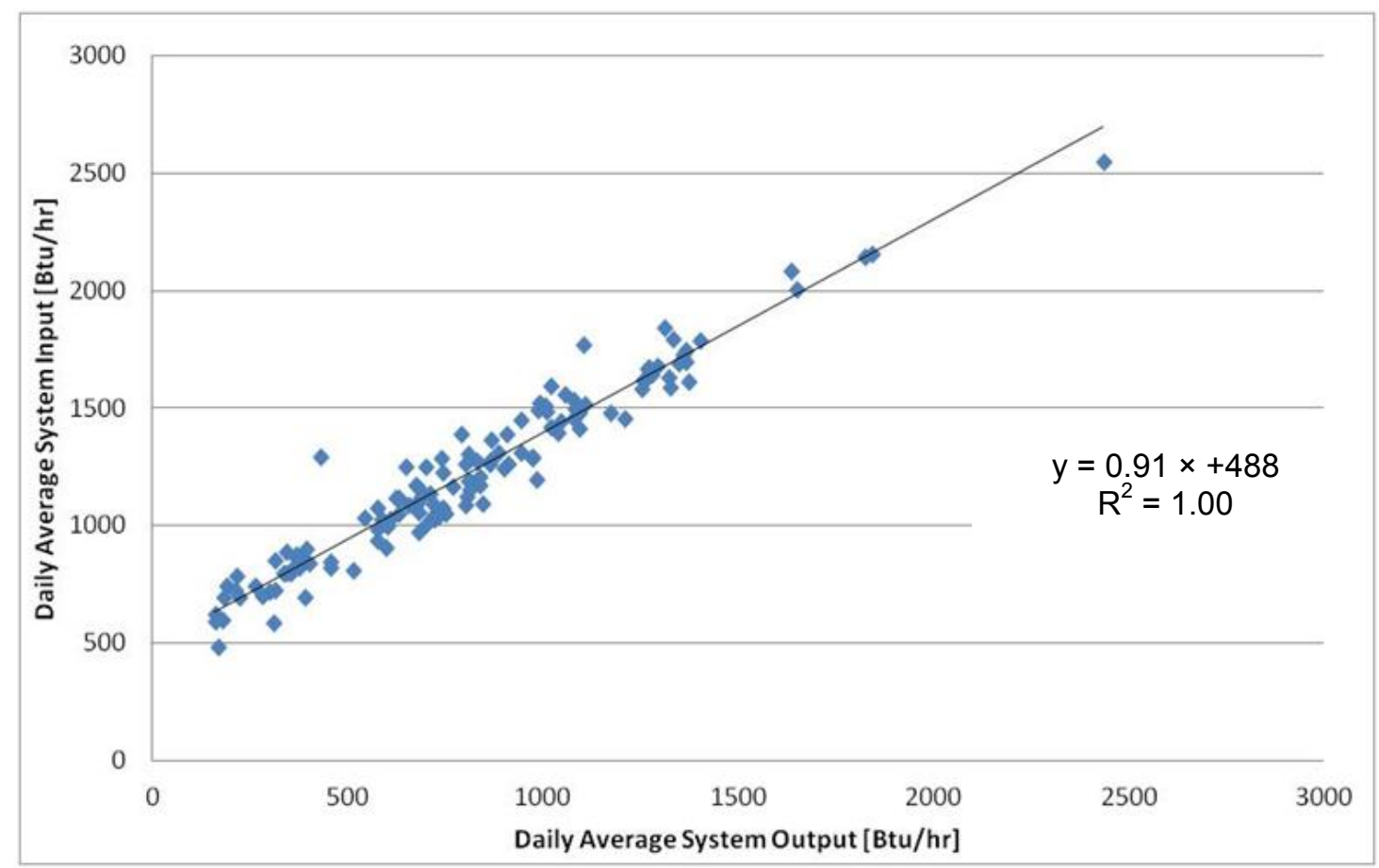

Figure 8. Input versus output relationship for the combi system on days with DHW only at Site 1061 


\subsection{Annual Energy Savings}

The estimated annual energy uses of the existing systems were computed from models of daily use with outside temperature applied to historical outside temperature data. The existing system energy use was computed using furnace and WH burner runtimes with measured burner gas flow rates and furnace electricity use. A linear model of space heating gas use with outside temperature was generated from a linear regression of the furnace daily average gas use and outside temperature (see Figure 9). This was used to determine the house balance point temperature or outside temperature above which no space heating is required. The balance point temperature was applied to a Typical Meteorological Year dataset for the local NOAA station (Minneapolis-St. Paul International Airport) to determine the heating season average outside temperature and duration. The average outside temperature was used with the regression model to compute the average energy use, and that was multiplied by the heating season duration to determine the annual energy use. A linear model of the energy use with the difference between inside and outside temperature was also generated. The heating season average inside temperature was applied to that model to determine the balance point temperature, and then the method described above was used to determine the annual space heating energy use. The model using OAT alone proved to be more reliable and was used at all sites. Figure 9 shows the comparison of the R-squared values for both models. Most sites showed a very small difference in the models, likely due to very little day-to-day change in the indoor air temperature. Two sites had significantly worse models using the temperature difference; therefore the OAT model was selected for the analysis.

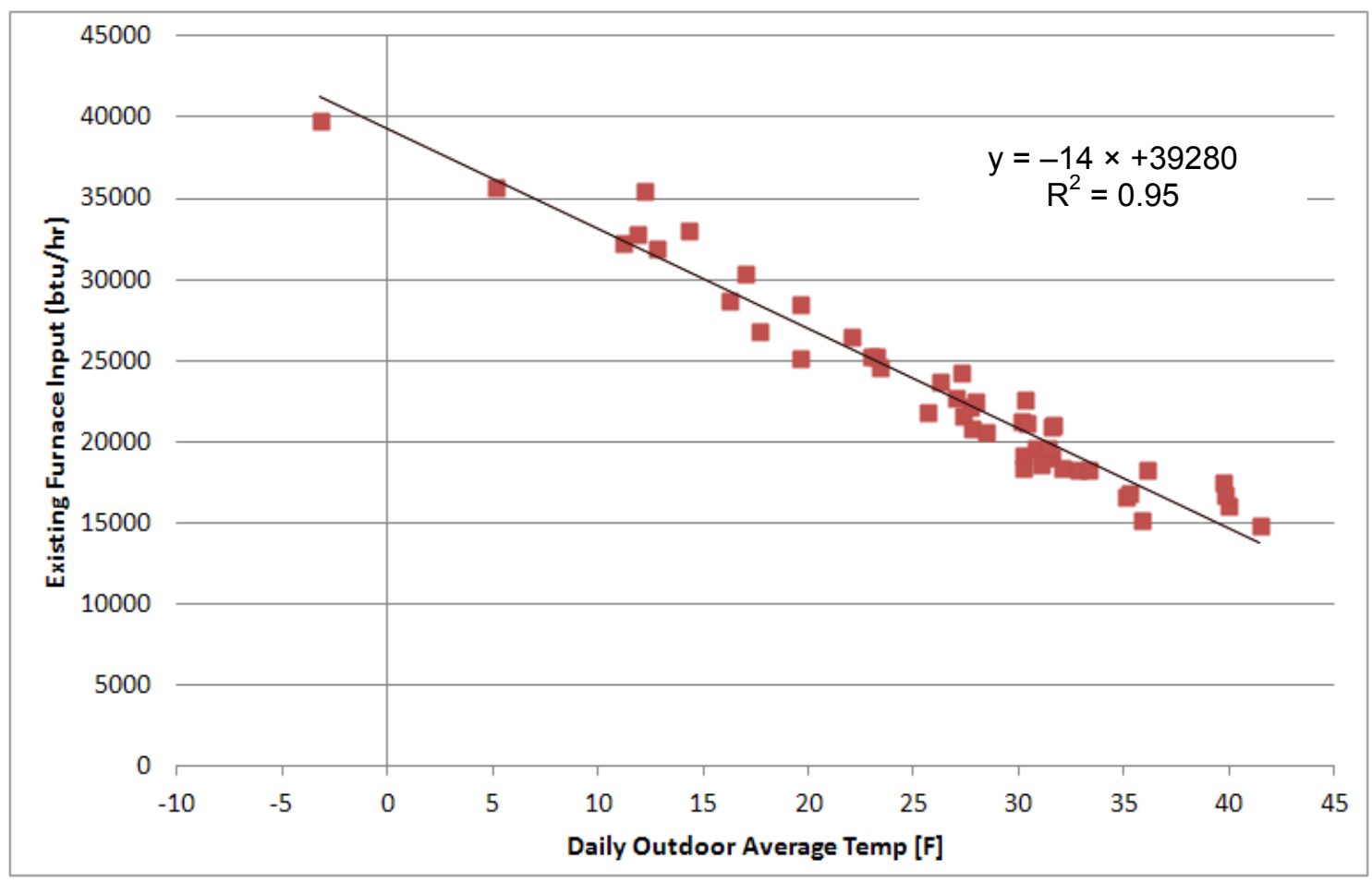

Figure 9. Existing furnace energy consumption versus OAT for Site 1061 
Table 6. Comparison of the Space Heating Output Models

\begin{tabular}{c|c|c|c}
\hline Site \# & $\begin{array}{c}\text { OAT Model } \\
\text { (R-Squared) }\end{array}$ & $\begin{array}{c}\text { Indoor-OAT Model } \\
\text { (R-Squared) }\end{array}$ & \% Difference \\
\hline $\mathbf{1 0 2 6}$ & 0.85 & 0.87 & 1 \\
$\mathbf{1 0 2 7}$ & 0.83 & 0.84 & 2 \\
$\mathbf{1 0 2 8}$ & 0.95 & 0.95 & 1 \\
$\mathbf{1 0 3 0}$ & 0.42 & 0.31 & -35 \\
$\mathbf{1 0 3 1}$ & 0.87 & 0.91 & 5 \\
$\mathbf{1 0 3 7}$ & 0.66 & 0.68 & 3 \\
$\mathbf{1 0 4 5}$ & 0.88 & 0.88 & 1 \\
$\mathbf{1 0 4 7}$ & 0.85 & 0.90 & 6 \\
$\mathbf{1 0 4 9}$ & 0.84 & 0.84 & 0 \\
$\mathbf{1 0 5 2}$ & 0.84 & 0.84 & 0 \\
$\mathbf{1 0 5 4}$ & 0.64 & 0.68 & 7 \\
$\mathbf{1 0 5 5}$ & 0.80 & 0.86 & -2 \\
$\mathbf{1 0 5 6}$ & 0.87 & 0.86 & -2 \\
$\mathbf{1 0 6 1}$ & 0.91 & 0.90 & 0 \\
$\mathbf{1 0 6 2}$ & 0.86 & 0.86 & 3 \\
\hline $\mathbf{1 0 6 3}$ & 0.70 & 0.72 & 0 \\
$\mathbf{1 0 6 5}$ & 0.98 & 0.97 & -24 \\
$\mathbf{1 0 7 0}$ & 0.72 & 0.58 & -3 \\
\hline $\mathbf{1 0 7 8}$ & 0.65 & 0.63 & \\
\hline
\end{tabular}

A three-step process was used to compute the annual DHW daily or annual energy use based on inlet water temperatures, DHW demand models, and appliance efficiency models. First, a model was developed for inlet water and OAT by day of the year to establish the seasonal variation and annual average inlet water temperature. The inlet temperature has been found to have a sinusoidal relationship with day of the year (Burch and Christensen 2007). The inlet temperature model parameters are functions of the average OAT, time lag from the OAT, and difference in the maximum and minimum average monthly temperatures. Figure 10 shows the measured and modeled weekly inlet water temperatures at Site 1052. For each site the existing and combi system inlet water temperature measurements were used to develop the model for daily average inlet water temperature.

The second step was to develop a linear relationship between the inlet water temperature and DHW demand or load. Due to the high variance in the daily water usage and the limited change of the inlet water temperature over the monitoring period for the existing systems, it was not possible to generate separate models for the existing and combi systems. However, Schoenbauer et al. (2011) demonstrated that hot water energy demand does not differ significantly for a TWH and tank type WH in the same house. The data from both the existing and the combi system was combined to establish a single inlet water temperature to DHW load linear relationship for each site. Figure 11 shows the inlet water temperature and hot water energy output relationship for Site 1062. 


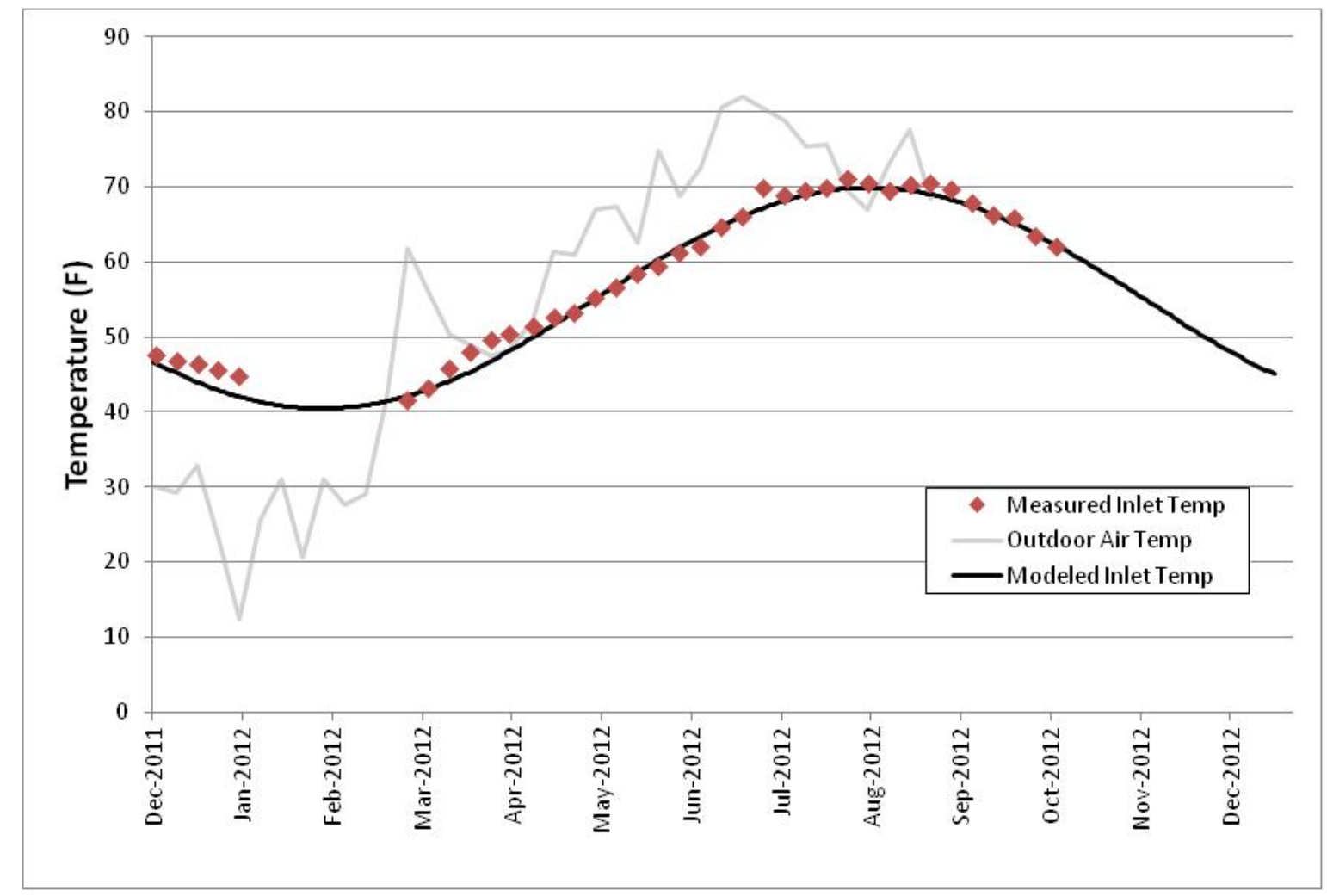

Figure 10. Inlet water temperature measured and modeled data at Site 1052

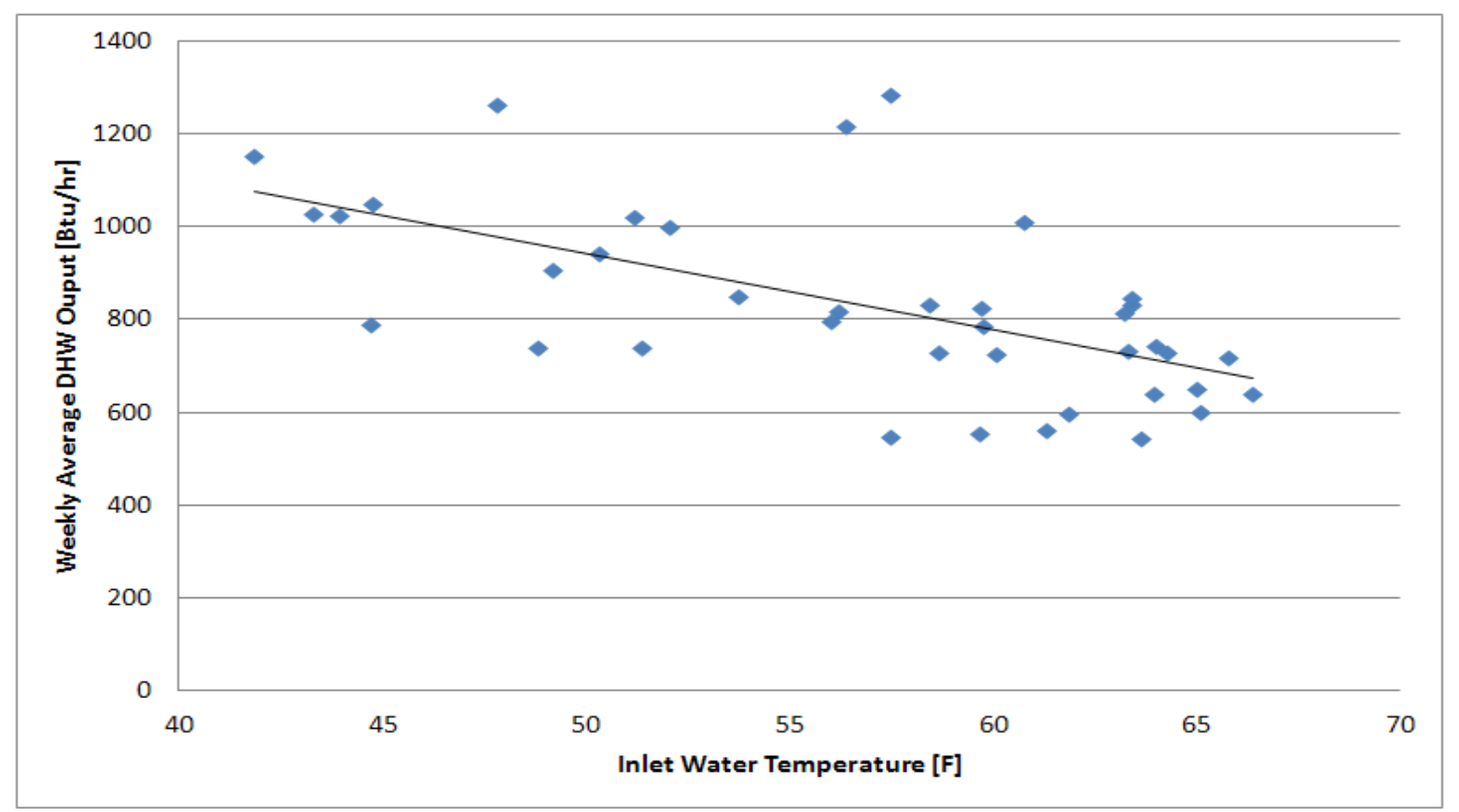

Figure 11. Average domestic water heating load for Site 1061

The third and final step was to use a linear model of appliance energy use with DHW load to compute daily or annual energy use. The energy load or output of the existing WHs was not monitored. The input versus output relationship was based on results for eight identical 0.60 EF, 
40-gal, ND SWHs from a previous study (Schoenbauer et al. 2011). The SWH models were very well defined, each model had R-squared values higher than 0.94 . The eight models were also consistent; at a daily load of $30,000 \mathrm{Btu} / \mathrm{h}$ (about 50 gallons at a $70^{\circ} \mathrm{F}$ temperature rise) the models varied by only $8 \%$. This approach was expected to slightly underestimate the actual energy use of the existing WHs that had confirmed or estimated EFs from 0.56 to 0.59 . The energy input versus output relationship for the combi system DHW operation was based on linear regressions of measured data from days when the systems were not used for space heating.

The measured natural gas use of the existing WH during the pre-period was compared to the modeled value over the same time period to evaluate the accuracy and bias of the modeling method. The three-step process described previously was performed using the OATs for the monitoring period, inlet water temperature and DHW load models for each site, and the energy input versus output model for the $0.60 \mathrm{EF}$ WH. Figure 12 shows a comparison of the measured and modeled gas use. The average difference between the measured and modeled use was $0.6 \%$. The median percent difference was $0 \%$ with an interquartile range of $-0.04 \%$ to $0.1 \%$.

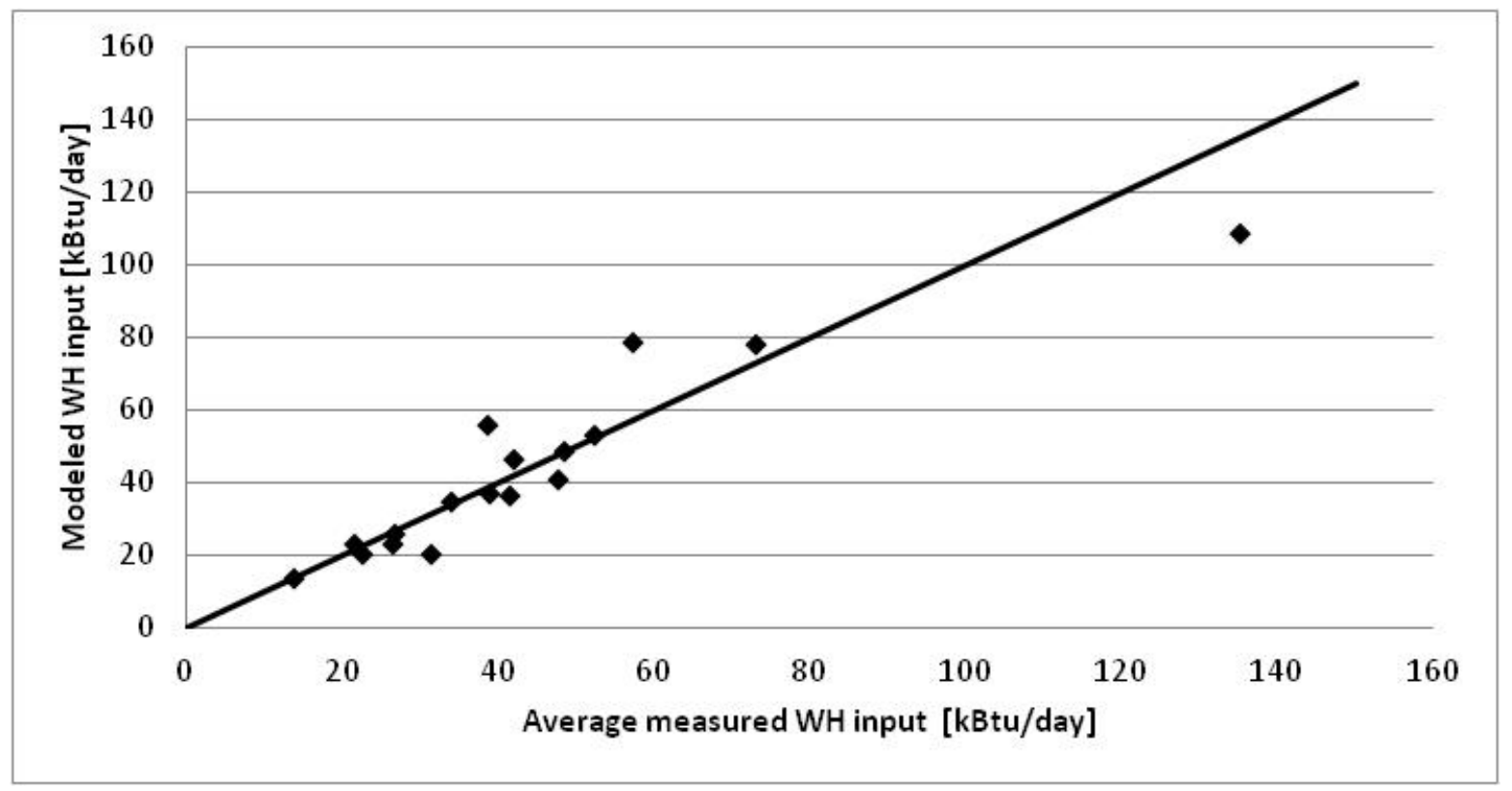

Figure 12. Comparing existing WH energy use model to measured data

The combi system gas consumption was computed from the measured gas flow rate and heating value (see equation 1), and a watt transducer measured electricity use. The combi system annual energy use was computed using a similar analysis approach as that used for the existing systems. However, since the heating plant input versus output relationship was different for the DHW only and combined DHW/space heating operation, it was necessary to use a daily calculation of energy use. The details of the calculation procedure are described in the following section. The uncertainties of the existing and combi system annual energy uses were determined using a standard procedure for propagating the instrumentation and regression uncertainties.

\subsection{Other Analysis}

The AHU supply air and conditioned space temperatures helped identify occupant comfort issues and complaints. An analysis of the frequency distribution of water temperature returning from 
the AHU and the supply air temperature and transient temperatures when the AHU was first turned on helped determine whether the systems were properly sized and correctly installed with an acceptable control strategy.

Detailed cost data were collected from each installation in the implementation project of 200+ systems. These data were used for a cost benefit analysis, a simple payback calculation, and evaluation of the change in cost as contractors became more familiar with the installations.

The space heating design load for each house was estimated from the linear models of space heating output with outside temperature. Those values were compared to the hydronic AHU steady-state output to determine the degree of coil under or over sizing. In addition, the analysis compared the computed design loads to values from the NEAT software and contractor calculations to assess the reliability and bias of the NEAT and contractor estimates. The space heating models included linear regressions of existing furnace gas use with outside temperature and inside/outside temperature difference. The computed use for the outdoor design temperature was multiplied by the furnace AFUE to estimate the space heating design load. Linear regressions of the hydronic AHU energy use with outside temperature provided two separate calculations of the space heating design load. 


\section{Results and Discussion}

Combi systems were characterized using detailed field monitoring data. The energy efficiency, savings potential, installed cost, delivered load, and occupant comfort were all assessed under typical installed conditions with real occupants. Each category was analyzed to determine the potential of combi systems to provide improved efficiency, lower energy cost, and improved combustion safety.

\subsection{Energy Efficiency}

The primary goal of this project was to assess whether it was possible to provide high installed efficiency with a single heating plant. The summer efficiency was used to characterize the combi system DHW-only performance and the winter efficiency used to characterize performance when space heat is the dominant load. The annual efficiency showed the combined efficiency of all space and water heating in a year.

Efficiency was calculated by summing the daily output energy for space and water heating over an entire year and dividing by the year's input energy. Figure 13 and Table 7 show the calculated efficiencies at each site.

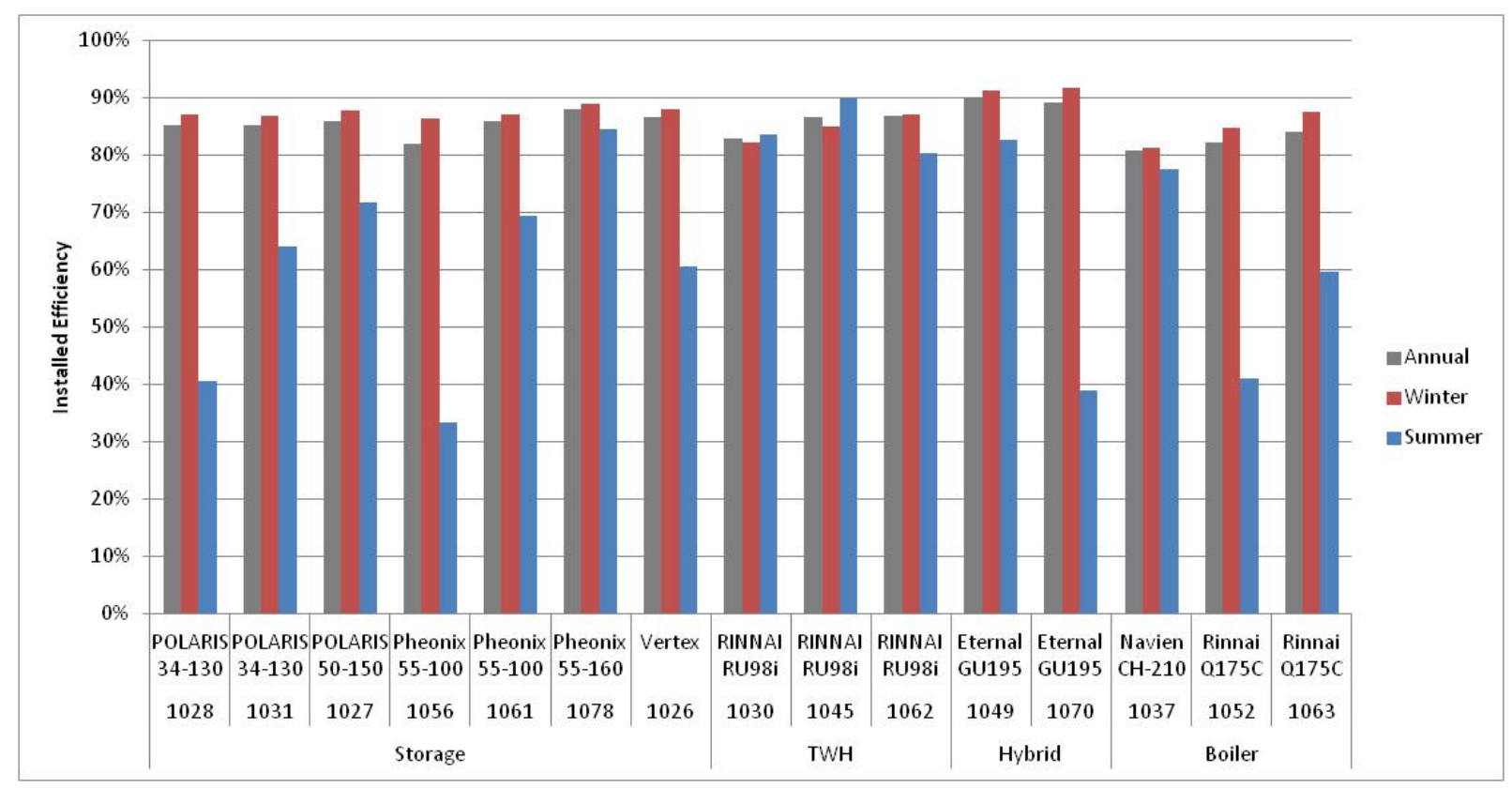

Figure 13. Combi system installed efficiencies

Note: Analysis of this figure continues throughout Section 4. 
Table 7. Installed Efficiency of the Combi Systems at Each Site

\begin{tabular}{|c|c|c|c|c|}
\hline \multirow[b]{2}{*}{$\begin{array}{c}\text { Site } \\
\text { Number }\end{array}$} & \multirow[b]{2}{*}{ Heating Plant } & \multicolumn{3}{|c|}{ Combination Installed Efficiency } \\
\hline & & $\begin{array}{c}\text { Annual } \\
(\%)\end{array}$ & $\begin{array}{c}\text { Winter } \\
\text { (Space Heat) } \\
(\%)\end{array}$ & $\begin{array}{c}\text { Summer } \\
\text { (DHW) } \\
(\%)\end{array}$ \\
\hline 1028 & Polaris & 85 & 87 & 41 \\
\hline 1031 & Polaris & 85 & 87 & 64 \\
\hline 1027 & Polaris & 86 & 88 & 72 \\
\hline 1056 & Phoenix & 82 & 86 & 33 \\
\hline 1061 & Phoenix & 86 & 87 & 69 \\
\hline 1078 & Phoenix & 88 & 89 & 84 \\
\hline 1026 & Vertex & 87 & 88 & 60 \\
\hline 1030 & Rinnai TWH & 83 & 82 & 84 \\
\hline 1045 & Rinnai TWH & 87 & 85 & 90 \\
\hline 1062 & Rinnai TWH & 87 & 87 & 80 \\
\hline 1049 & Eternal & 90 & 91 & 83 \\
\hline 1070 & Eternal & 89 & 92 & 39 \\
\hline 1037 & Navien & 81 & 81 & 77 \\
\hline 1052 & Rinnai Boiler & 82 & 85 & 41 \\
\hline 1063 & Rinnai Boiler & 84 & 87 & 60 \\
\hline
\end{tabular}

The combination system energy load, use, and efficiency were calculated for each day in a typical year as described in Section 3. Field data were used to define the relationships between environmental conditions, the household loads and the energy consumption of each system. These relationships characterized the household and the occupants as well as system performance.

Regressions of the system inputs versus output showed the natural gas consumption necessary to produce a given amount of DHW and space heat (Table 8). Days with both space heat and DHW loads (winter) were analyzed separately from days with only DHW (summer). Water use at one site (1056) was low on most days, and the low usage prevented the system from being fully characterized, resulting in a low R-squared value. However, the remaining system performance regressions had very strong fits (R-squared values from 0.89 to 1.00 ). 
Table 8. Input Versus Output Models for the Combi Space Heating Systems

\begin{tabular}{|c|c|c|c|c|c|c|c|}
\hline \multirow{2}{*}{$\begin{array}{c}\text { Site } \\
\text { Number }\end{array}$} & \multirow{2}{*}{$\begin{array}{c}\text { Heating } \\
\text { Plant } \\
\text { Type }\end{array}$} & \multicolumn{3}{|c|}{ DWH Only Days } & \multicolumn{3}{|c|}{ Space Heating and DHW Days } \\
\hline & & Slope & $\begin{array}{c}\text { Intercept } \\
\text { (Btu/h) }\end{array}$ & $\begin{array}{c}\text { R- } \\
\text { Square }\end{array}$ & Slope & $\begin{array}{c}\text { Intercept } \\
\text { (Btu/h) }\end{array}$ & $\begin{array}{c}\text { R- } \\
\text { Square }\end{array}$ \\
\hline 1028 & \multirow{7}{*}{ Storage } & 1.03 & 414 & 0.90 & 1.12 & 439 & 1.00 \\
\hline 1031 & & 0.99 & 542 & 0.95 & 1.13 & 392 & 1.00 \\
\hline 1027 & & 1.04 & 437 & 0.97 & 1.12 & 443 & 1.00 \\
\hline 1056 & & 0.57 & 764 & 0.34 & 1.11 & 617 & 1.00 \\
\hline 1061 & & 0.91 & 488 & 0.94 & 1.14 & 244 & 1.00 \\
\hline 1078 & & 1.08 & 253 & 0.89 & 1.11 & 284 & 0.98 \\
\hline 1026 & & 1.24 & 433 & 0.97 & 1.12 & 499 & 1.00 \\
\hline 1065 & \multirow{3}{*}{ TWH } & - & - & - & 1.19 & 314 & 0.99 \\
\hline 1030 & & 1.09 & 218 & 1.00 & 1.22 & 31 & 1.00 \\
\hline 1045 & & 1.07 & 72 & 1.00 & 1.19 & -196 & 1.00 \\
\hline 1062 & \multirow{3}{*}{ Hybrid } & 1.09 & 153 & 1.00 & 1.14 & 106 & 1.00 \\
\hline 1049 & & 1.02 & 286 & 1.00 & 1.08 & 220 & 1.00 \\
\hline 1054 & & 1.06 & 323 & 0.97 & 1.08 & 367 & 1.00 \\
\hline 1070 & \multirow{6}{*}{ Boiler } & 1.03 & 320 & 0.94 & 1.06 & 348 & 1.00 \\
\hline 1037 & & 1.17 & 165 & 1.00 & 1.22 & 137 & 1.00 \\
\hline 1047 & & - & - & - & 1.15 & 227 & 1.00 \\
\hline 1055 & & 1.33 & 28 & 0.99 & 1.23 & 308 & 0.96 \\
\hline 1052 & & 1.28 & 445 & 0.96 & 1.15 & 463 & 1.00 \\
\hline 1063 & & 1.24 & 391 & 0.98 & 1.10 & 535 & 1.00 \\
\hline
\end{tabular}

The relationships between the loads and environmental conditions were more strongly dependent upon occupant behavior and had weaker fits (see Table 9). Daily variance in occupant behavior affects the load. For example, the data showed variance in daily thermostat operation and homeowners indicated short-term variable occupancy, which changed the daily DHW load. Additionally, the relationship between DHW use and environment (inlet water temperature) was not statistically significant at sites with high variability in DHW use, low DHW loads, and/or small seasonal variance in inlet water temperature. In these cases, when the load does not vary with inlet water temperature, we used the average DHW. 
Table 9. Load Curves for Space and Water Heating

\begin{tabular}{|c|c|c|c|c|c|c|c|c|c|c|}
\hline \multirow[b]{2}{*}{$\begin{array}{c}\text { Site } \\
\text { Number }\end{array}$} & \multirow{2}{*}{$\begin{array}{c}\text { Heating } \\
\text { Plant } \\
\text { Type }\end{array}$} & \multicolumn{5}{|c|}{ DHW Output Versus Inlet Water Temperature } & \multicolumn{4}{|c|}{ Space Heating Output Versus OAT } \\
\hline & & Slope & $\begin{array}{c}\text { Intercept } \\
\text { (Btu/h) }\end{array}$ & $\begin{array}{c}\text { R- } \\
\text { Squared }\end{array}$ & $\begin{array}{c}\text { P- } \\
\text { Value }\end{array}$ & Signif? & Slope & $\begin{array}{c}\text { Intercept } \\
\text { (Btu/h) }\end{array}$ & $\begin{array}{c}\text { R- } \\
\text { Squared }\end{array}$ & $\begin{array}{c}\text { Balance Point } \\
\left({ }^{\circ} \mathbf{F}\right)\end{array}$ \\
\hline 1028 & \multirow{7}{*}{ SWH } & -3.52 & 325 & 0.09 & 1.000 & No & -311 & 21,017 & 0.95 & 68 \\
\hline 1031 & & -2.94 & 946 & 0.02 & 0.048 & No & -287 & 19,253 & 0.87 & 67 \\
\hline 1027 & & -21.53 & 2,300 & 0.17 & 0.010 & Yes & -344 & 21,081 & 0.83 & 61 \\
\hline 1056 & & -7.39 & 667 & 0.61 & 0.000 & Yes & -263 & 16,425 & 0.87 & 62 \\
\hline 1061 & & -16.42 & 1,762 & 0.36 & 0.000 & Yes & -422 & 27,220 & 0.91 & 65 \\
\hline 1078 & & -40.62 & 4,406 & 0.28 & 0.001 & Yes & -272 & 16,803 & 0.65 & 62 \\
\hline 1026 & & 2.64 & 547 & 0.00 & 0.820 & No & -497 & 31,767 & 0.85 & 64 \\
\hline 1065 & \multirow{3}{*}{ TWH } & 0.00 & 0 & 0.00 & 0.130 & No & -369 & 24,221 & 0.98 & 66 \\
\hline 1030 & & -30.85 & 3,994 & 0.45 & 0.000 & Yes & -245 & 16,052 & 0.42 & 65 \\
\hline 1045 & & -36.09 & 3,664 & 0.23 & 0.001 & Yes & -297 & 21,351 & 0.88 & 72 \\
\hline 1062 & \multirow{3}{*}{ Hybrid } & -13.14 & 1,521 & 0.03 & 0.274 & No & -315 & 18,822 & 0.86 & 60 \\
\hline 1049 & & -48.30 & 4,163 & 0.50 & 0.000 & Yes & -310 & 17,978 & 0.84 & 58 \\
\hline 1054 & & -3.80 & 452 & 0.04 & 0.207 & No & -230 & 13,654 & 0.64 & 59 \\
\hline 1070 & \multirow{6}{*}{ Boiler } & 0.74 & 61 & 0.02 & 0.384 & No & -239 & 15,479 & 0.72 & 65 \\
\hline 1037 & & -29.09 & 2,934 & 0.33 & 0.000 & Yes & -183 & 12,812 & 0.66 & 70 \\
\hline 1047 & & -24.02 & 1,643 & 0.00 & 0.898 & No & -439 & 27,709 & 0.85 & 63 \\
\hline 1055 & & -10.10 & 875 & 0.34 & 0.000 & Yes & -221 & 14,527 & 0.80 & 66 \\
\hline 1052 & & -3.61 & 520 & 0.03 & 0.289 & No & -309 & 20,536 & 0.84 & 67 \\
\hline 1063 & & -8.32 & 1,260 & 0.06 & 0.172 & No & -229 & 15,288 & 0.70 & 67 \\
\hline
\end{tabular}


We do not report efficiencies at four sites. These sites had data issues preventing full analysis of the combi systems. The occupants of sites 1047 and 1065 relocated before monitoring was completed. An additional space heating source was discovered at Site 1054 immediately prior to monitoring. The variability in secondary heat source use made the load difficult to characterize. Site 1055 had several instrumentation and installation issues, such as instrumentation installed in the wrong location and a heating plant wiring issues that caused atypical operation. These issues prevented data collection over an extended period.

Homes with statistically significant relationships between DHW load and inlet water temperatures had R-squared values between 0.17 and 0.63 . Occupant behavior had smaller impacts on the space heating load versus OAT relationships (R-squared from 0.42 to 0.98 ).

Summer Efficiency. The summer efficiency was the measured efficiency from July when space heating loads were nonexistent and there were only DHW loads. Summer or DHW-only efficiencies had a large variance from site to site (33\% to $90 \%)$. The summer efficiency was impacted by the heating plant type, household DHW load, and average cycle length.

Heating Plant Type. Standby loses were largely determined by the heating plant type. Systems with storage capacity kept water hot at all times. Poor insulation and/or large storage volumes increased the standby losses, which were previously tested in a laboratory (see Figure 14) (Schoenbauer et al. Upcoming). The higher volume SWHs had the highest standby loses. The hybrid WHs and boilers with storage (Rinnai) also had significant standby losses. The TWHs and low-mass boilers (Navien) had very small standby losses. The range of efficiency for the tankless units was due to hot water usage profile. The site with the highest efficiency $(90 \%$ at Site 1045) had a higher percentage of water usage from large draws; $91 \%$ of hot water volume was consumed in draws of greater than 3 gallons at Site 1045 compared to an average of $80 \%$ at the other sites. The impact of standby loss was higher in the lowest load homes.



Figure 14. Standby energy use for combi systems

DHW Load. Standby or idle time increased with lower DHW loads. The lower efficiency sites (1028, 1056, 1070, and 1052) were those that had a combination of: (1) heating plants with 
greater standby loss and (2) low DHW use (Table 10). Homes with less water heating usage reduce the summer efficiency for systems with hot water storage (see Figure 15). The efficiency of a condensing SWH from field data collected during the WH only mode is included for comparison purposes.

Table 10. DHW Loads at Each Site

\begin{tabular}{c|c|c|c}
\hline \multirow{2}{*}{$\begin{array}{c}\text { Site } \\
\text { Number }\end{array}$} & Heating Plant & \multicolumn{2}{|c}{ DHW Load } \\
\cline { 3 - 4 } & & $\begin{array}{c}\text { Energy } \\
\text { (Btu/h) }\end{array}$ & $\begin{array}{c}\text { Volume } \\
\text { (gpd) }\end{array}$ \\
\hline $\mathbf{1 0 2 8}$ & Polaris & 131 & 12.7 \\
$\mathbf{1 0 3 1}$ & Polaris & 790 & 42.3 \\
$\mathbf{1 0 2 7}$ & Polaris-Stress & 1,041 & 54.6 \\
$\mathbf{1 0 5 6}$ & Phoenix & 197 & 10.8 \\
$\mathbf{1 0 6 1}$ & Phoenix & 830 & 33.3 \\
\hline $\mathbf{1 0 7 8}$ & Phoenix-Stress & 2,115 & 89.0 \\
$\mathbf{1 0 2 6}$ & Vertex & 715 & 33.9 \\
$\mathbf{1 0 6 5}$ & Vertex & 337 & 19.5 \\
$\mathbf{1 0 3 0}$ & Rinnai TWH & 1,966 & 106.8 \\
$\mathbf{1 0 4 5}$ & Rinnai TWH & 1,726 & 81.1 \\
$\mathbf{1 0 6 2}$ & Rinnai TWH & 832 & 41.5 \\
$\mathbf{1 0 4 9}$ & Eternal & 1421 & 67.7 \\
$\mathbf{1 0 5 4}$ & Eternal & 251 & 13.5 \\
\hline $\mathbf{1 0 7 0}$ & Eternal & 101 & 5.7 \\
\hline $\mathbf{1 0 3 7}$ & Navien & 1,227 & 72.7 \\
\hline $\mathbf{1 0 4 7}$ & Navien & 768 & 23.7 \\
$\mathbf{1 0 5 5}$ & Navien & 264 & 16.5 \\
\hline $\mathbf{1 0 5 2}$ & Rinnai Boiler & 301 & 13.0 \\
\hline $\mathbf{1 0 6 3}$ & Rinnai Boiler & 789 & 34.0 \\
\hline
\end{tabular}




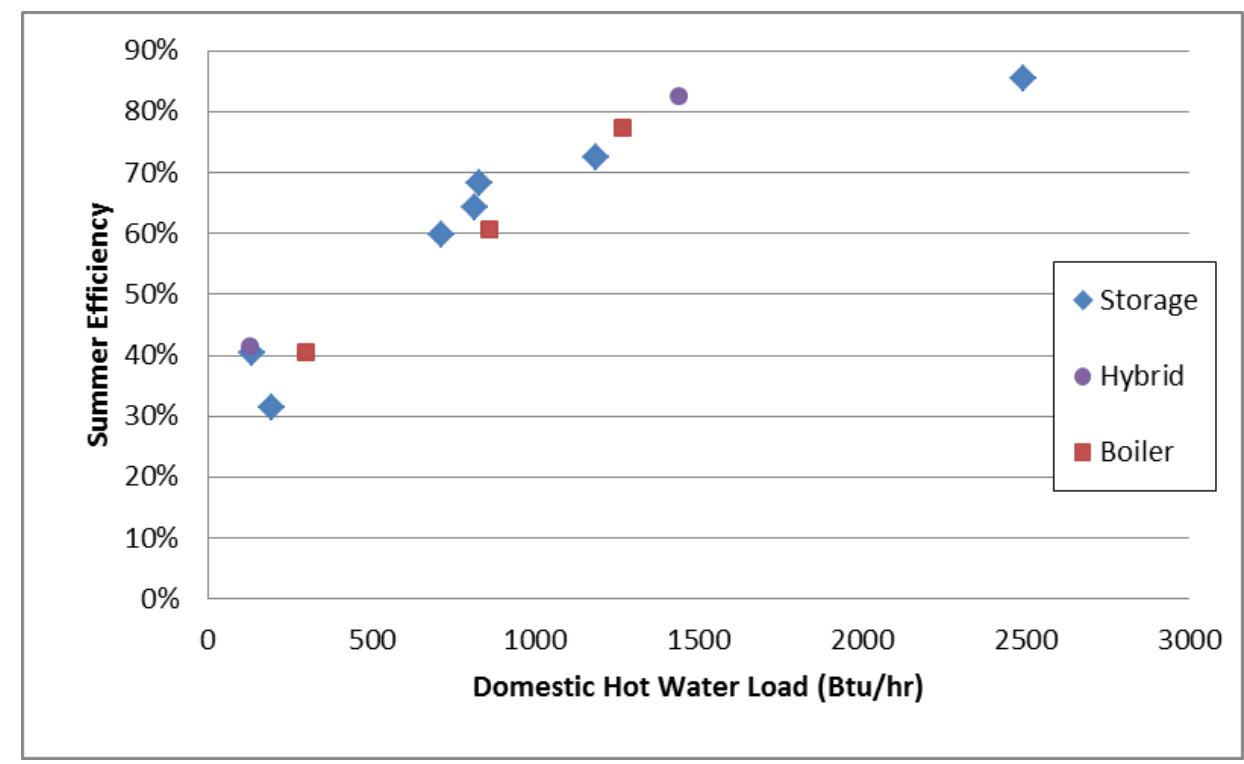

Figure 15. Combi system summer efficiency versus DHW load

Burner Cycle Length. Cycle length had a large impact on daily efficiencies for the low-mass systems (TWH and low-mass boiler), with shorter cycle length decreasing the daily efficiency. Low-mass systems require the heat exchanger and burner to heat up for each event; therefore, for short events a significant portion of the event energy was used to heat up the unit. Low-mass systems have no hot storage capacity; therefore, most of the energy at the beginning of a cycle is used to heat up the heat exchanger. If there are no additional draws soon after this short cycle, the heat dissipates to the surrounding area and has no useful effect. Because of this, days with short cycle lengths often have lower efficiencies than days with longer events where the startup effects were minimized (Figure 16).

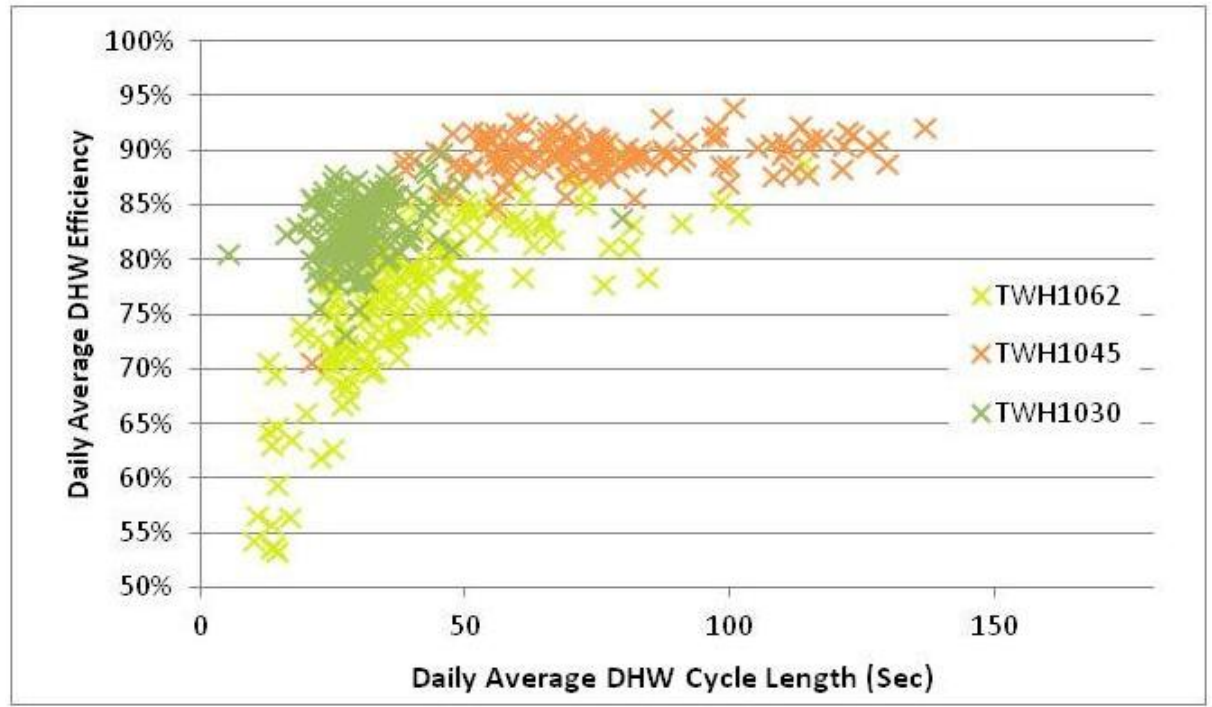

Figure 16. Impact of daily average event length on DHW efficiency 
Winter Efficiency. The winter efficiencies were calculated from January data. During this time space heating loads were much greater than DHW loads; making winter efficiency mostly dependent on space heating efficiencies. Winter efficiencies ( $87 \%$ on average) were higher than summer efficiencies (65\% on average) at most sites. Winter efficiencies had smaller site-to-site variances $(82 \%$ to $90 \%)$. Operational parameters, such as return water temperature and flow rate, have a high impact on space heating efficiency. Combi systems were installed carefully so that these parameters allowed for the best possible performance and were similar at each site. The variance in winter efficiency was mostly a result of differences in the heating load.

Heating Plant Type. System type had the largest impact on winter efficiencies. The hybrid WHs had the highest winter efficiencies in the field ( $92 \%$ on average). SWHs had slightly lower installed efficiencies $(87 \%)$. The TWH had lower space heating efficiencies $(85 \%)$. Laboratory testing, at the field installation condition of $105^{\circ} \mathrm{F}$ return water temperatures, showed the same rankings (Figure 5).

Boiler manufacturers required a primary/secondary loop plumbing configuration. The primary loop flow rates were controlled by an internal boiler pump. This configuration made proper installation and set up at two sites with boilers (1037 and 1052) difficult, resulting in an increased temperature of the return water and reduced the efficiencies ( $83 \%$ on average) (for more information see Butcher, 2010). At site 1063, optimization was more successful. The heating load and house characteristics allowed the system to achieve a lower return water and better efficiency, $87 \%$ during peak heating season.

Field and Lab Data Comparison. We compared winter efficiencies measured in the field to the system efficiencies measured in the laboratory for each system type (Figure 17 through Figure 19). Due to the constraints of real homes and loads, the steady-state laboratory conditions were not the same as the field installs. Despite the small differences in laboratory and field conditions the data were consistent. Laboratory data from previously completed testing (Schoenbauer et al. Upcoming) were used to verify field data. Laboratory tests of steady-state operation at $4 \mathrm{gpm}$ and $110^{\circ} \mathrm{F}$ return water temperature and idle tests were used to determine the laboratory input versus output relationship (Figure 17 through Figure 19). Standby results were used for the zero output intercept, and the steady-state test's measured input and output were used with the intercept to define the linear relationship. For comparison, we plotted field data from January when the ratio of space heating to DHW was highest. Field data from 12 of the 19 field sites fall within the \pm $3 \%$ efficiency bands, which was the combined uncertainty for the laboratory and field measurements, shown on each plot. And 16 of the 19 sites were within 5\%, while the remaining three sites had less than a 7\% difference. The average difference in the field and laboratory measurements was $0.1 \%$. In general, the data were consistent between the field and the laboratory, meaning that two laboratory tests, steady-state and standby, were enough to reasonably predict the installed performance. 


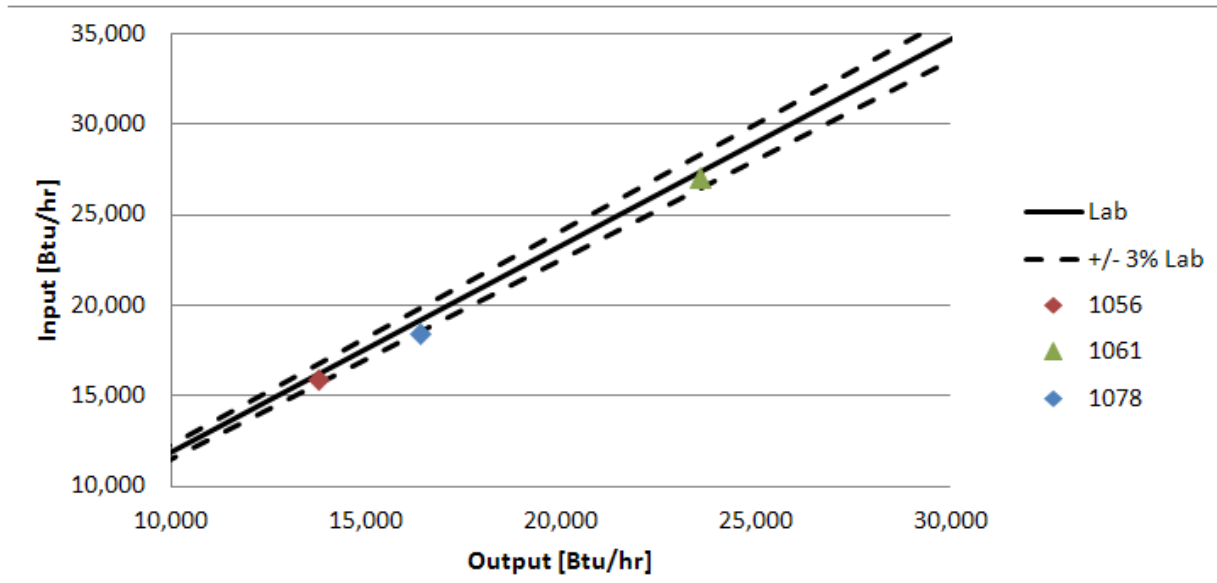

a) Phoenix

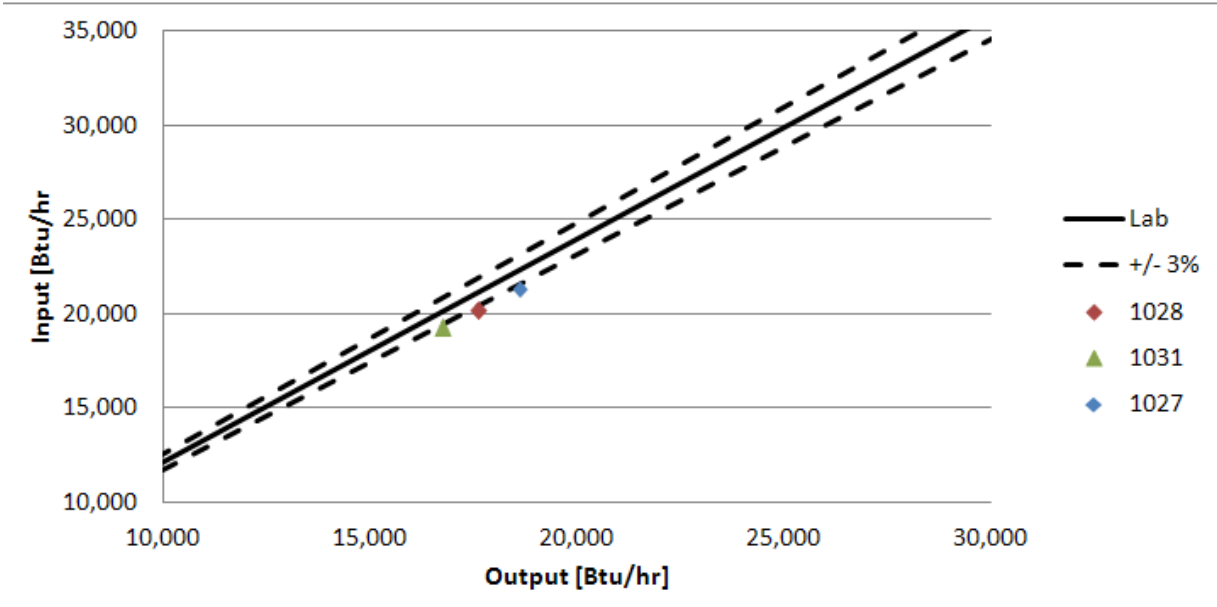

b) Polaris

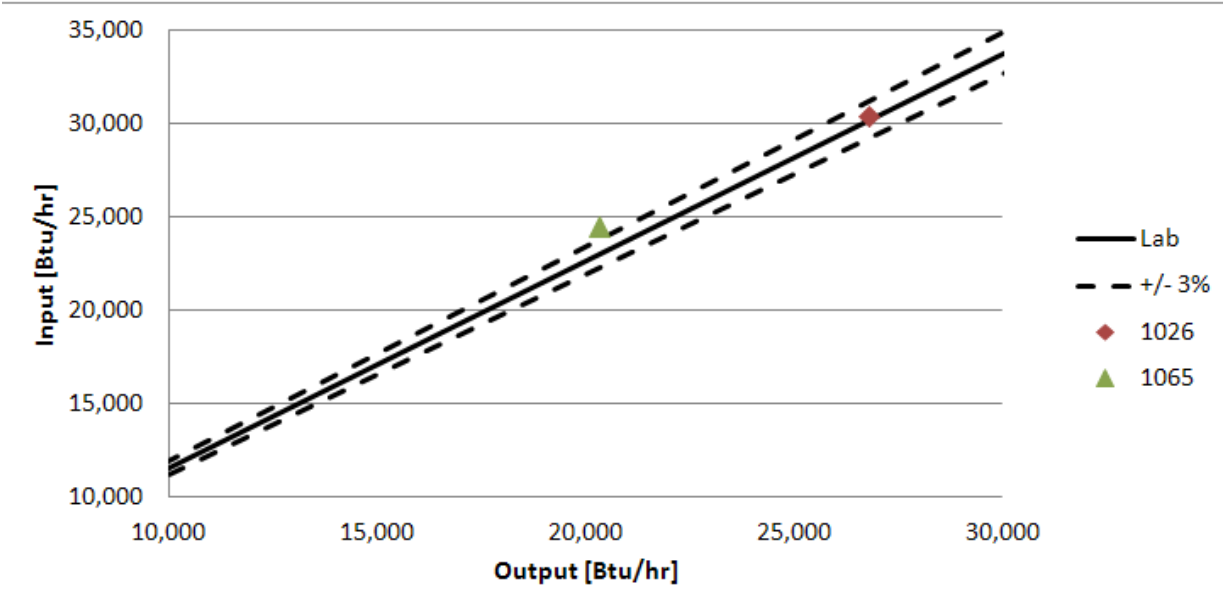

c) Vertex

Figure 17. Comparison of field and laboratory efficiencies for storage-based combi systems 


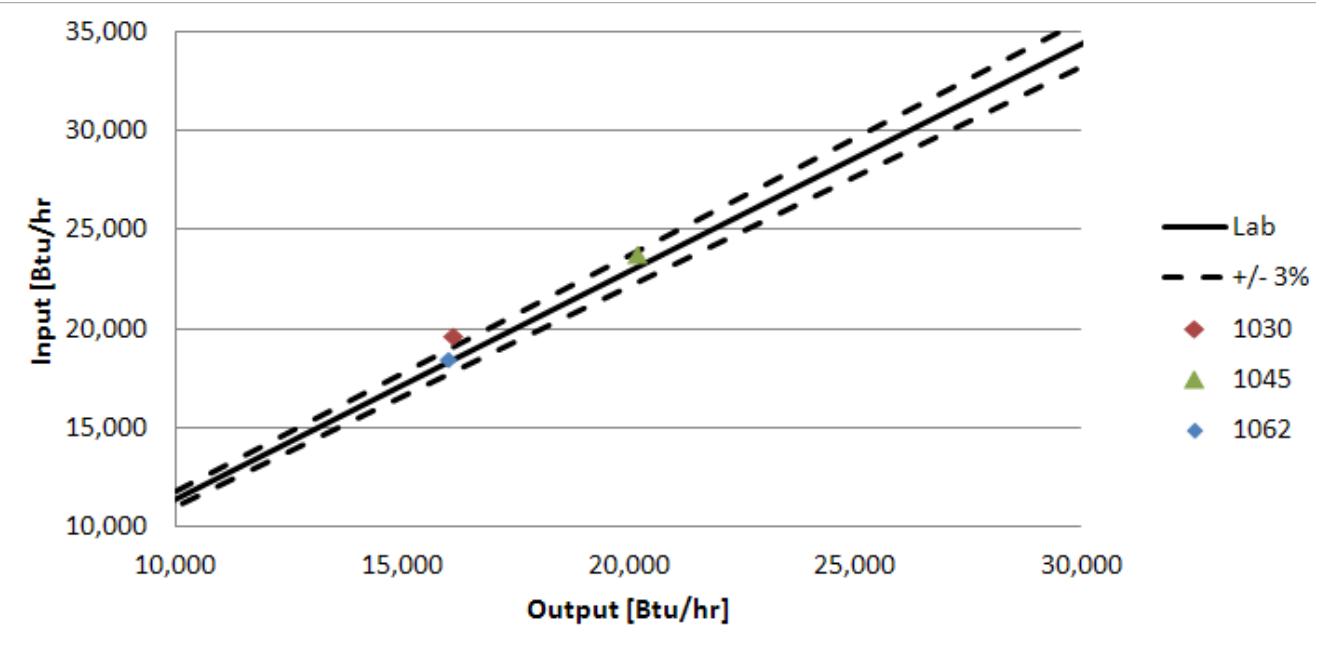

a) Rinnai $T W H$

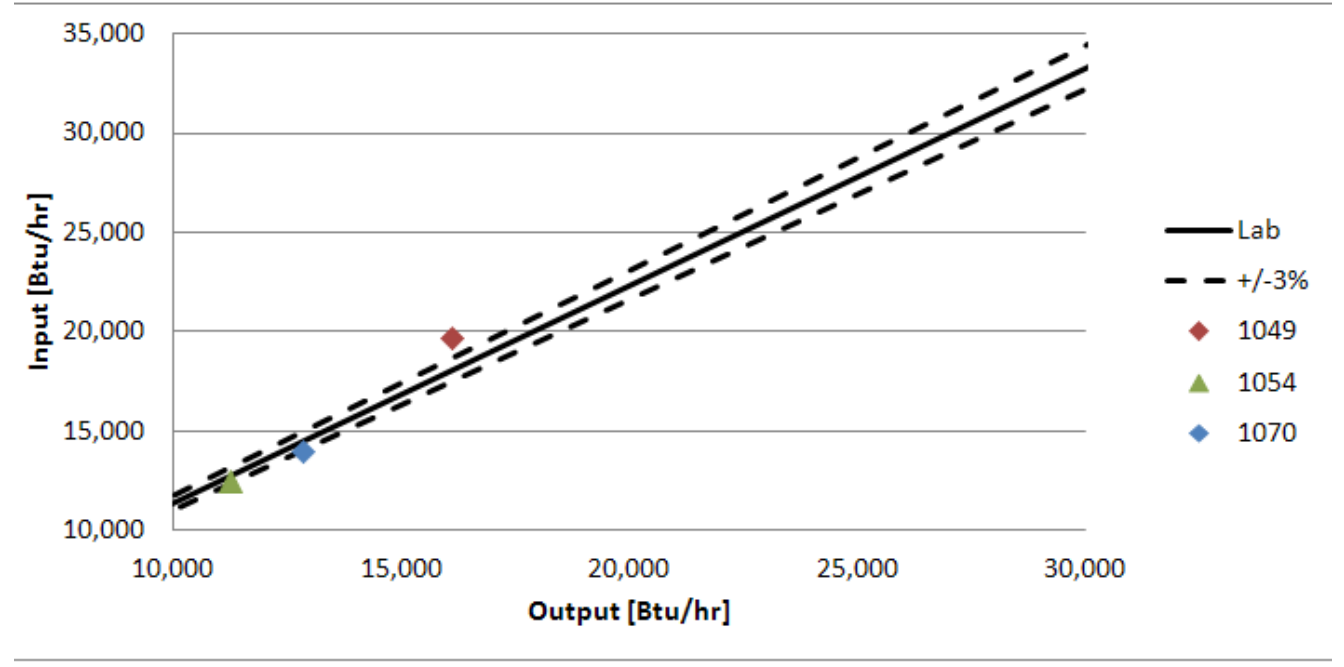

b) Eternal

Figure 18. Comparison of field and laboratory efficiencies for TWH and hybrid-based combi systems 


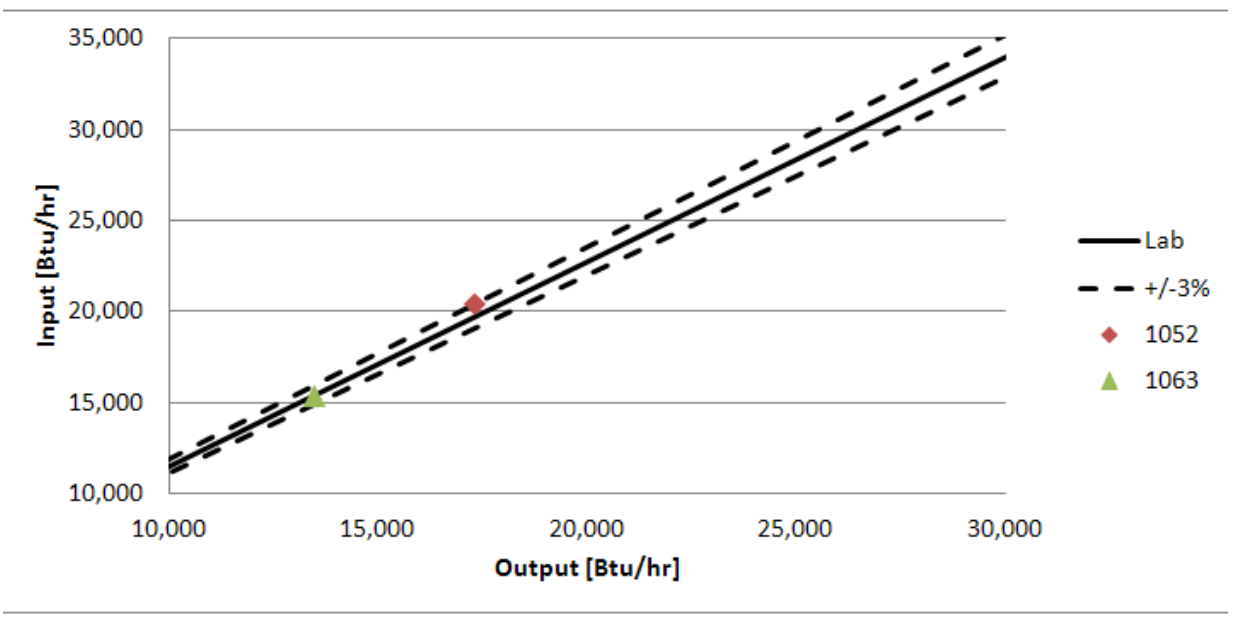

a) Rinnai Boiler

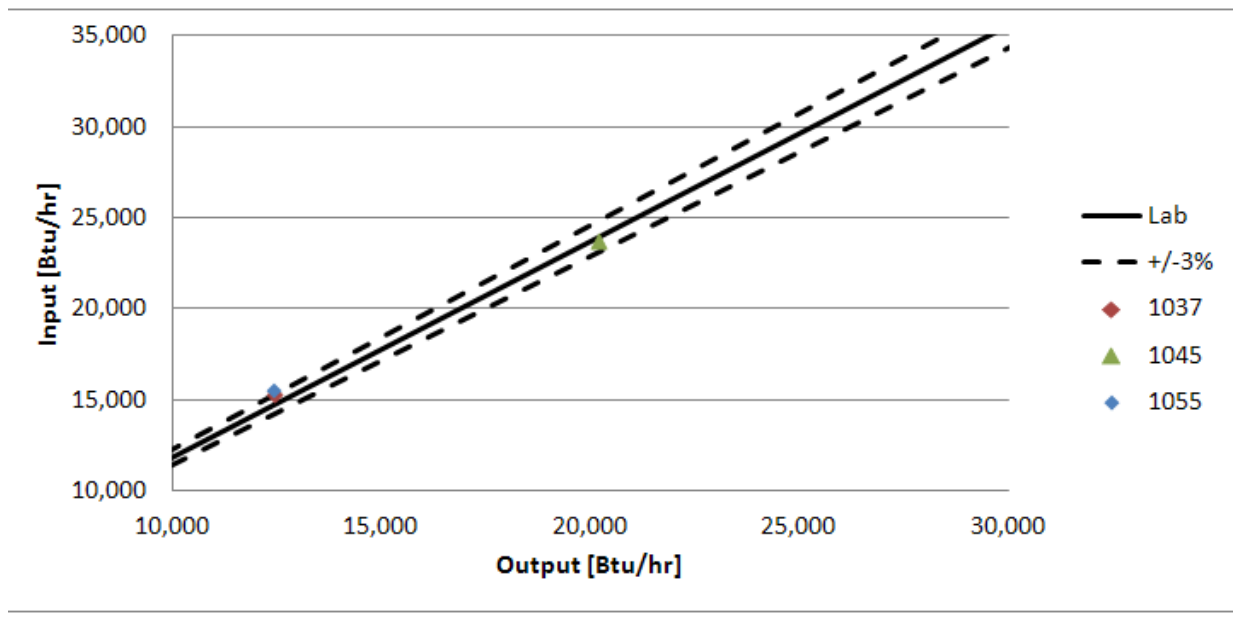

b) Navien

Figure 19. Comparison of field and laboratory efficiencies for boiler-based combi systems

Annual efficiencies were calculated by summing the total daily energy consumption and energy delivered by each system over a typical year. On average the annual efficacies of the combi systems were $87 \%$. Annual efficiencies ranged from $81 \%$ to $90 \%$. DHW (or summer)

efficiencies were lower than space heating (or winter) efficiencies for all systems other than the TWH combi systems. Combi system efficiencies were impacted by the size of the load. Systems with smaller loads were typically less efficient than those with larger loads. In general, the combi systems had high efficiency and performed well.

\subsection{Energy Savings}

We compared existing system and combi systems and found significant gas savings (Figure 20). Energy savings were computed as described in Section 3.2. Savings depended on:

- The existing equipment

- The quality of installation and setup of the combi system

- The space heating and water heating loads of the home. 


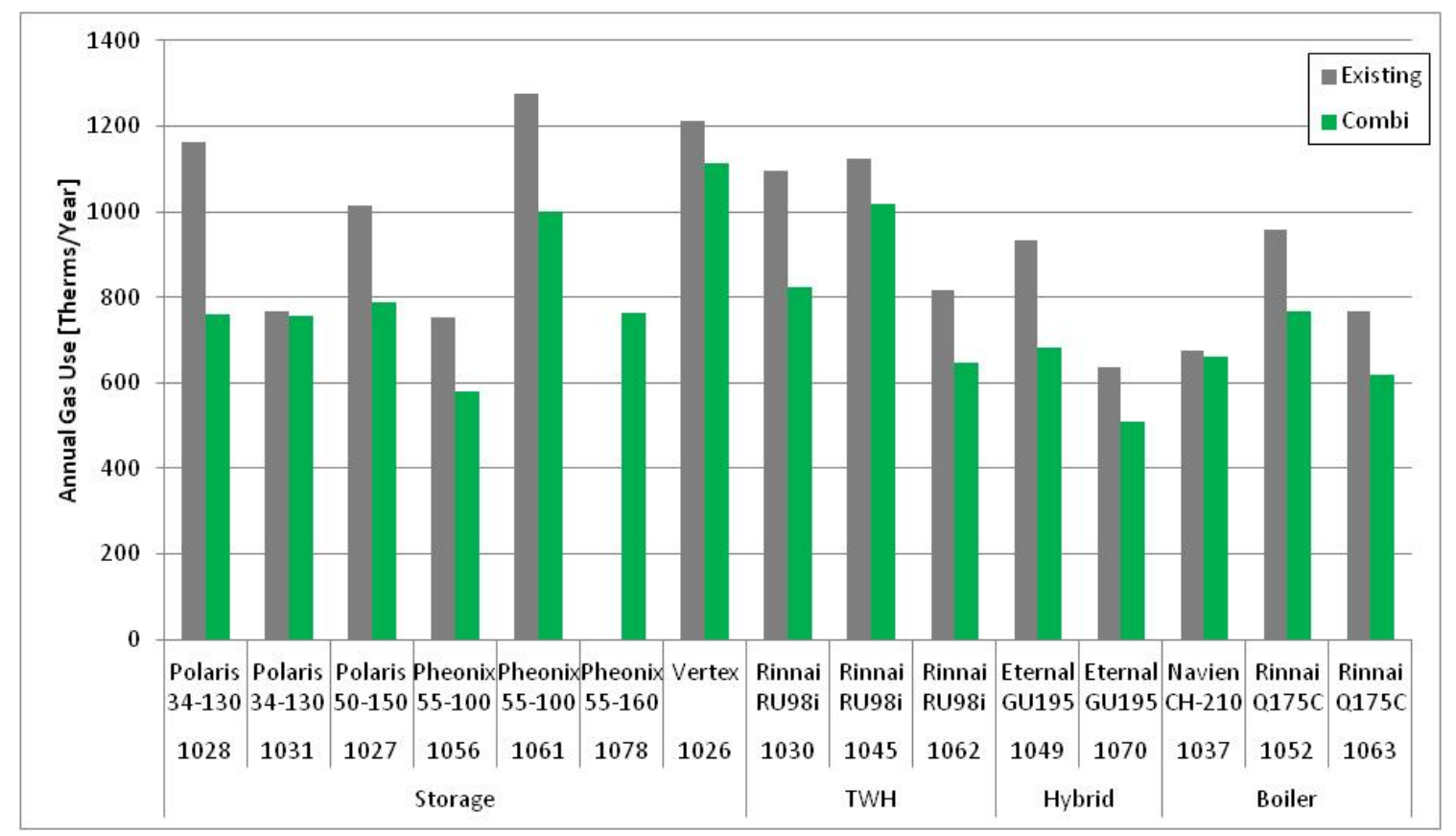

Figure 20. Annual natural gas consumption for space and water heating pre- and post-combination system installation

Figure 21 shows the percentage of natural gas that the combi systems saved. On average, the systems saved $18 \%$ of the natural gas previously required to provide space and water heating to these homes.

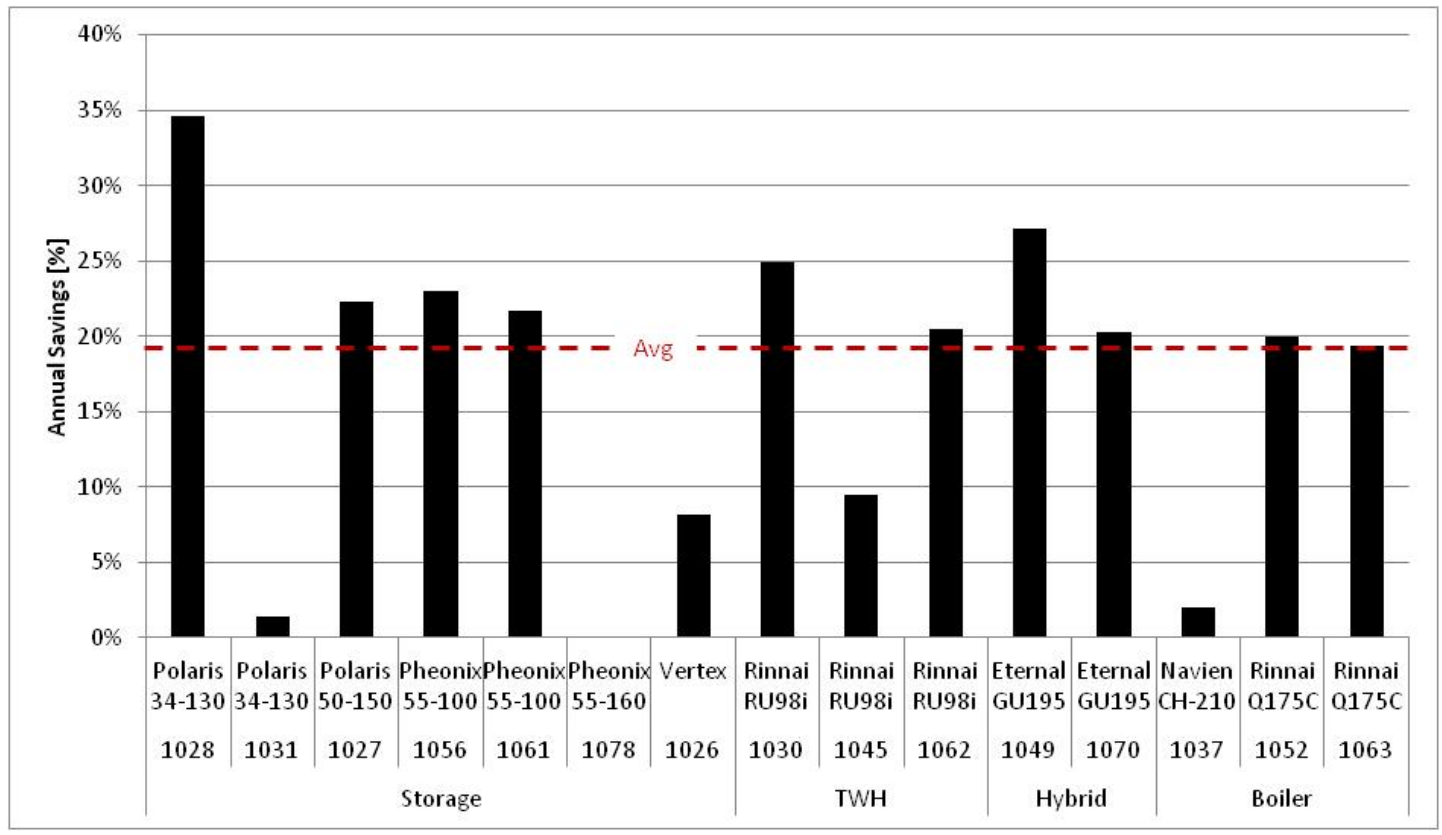

Figure 21. Natural gas savings at each site

Existing Equipment. The performance of the existing furnace had a large impact on the savings potential at two sites. The highest (35\%) and lowest (1\%) savings came from sites 1028 and 1031. At Site 1028, the existing furnace was the oldest of all the homes, likely dating to the early 
1980s. The unit's AFUE was not available, but its age suggests a rating of $70 \%-78 \%$. The large savings were likely due to a low AFUE (70\%) or the system was rated higher but had degraded over time. The existing furnace at Site 1031 was a condensing furnace. The furnace was eligible for replacement in this project because it was installed in 2004 and was nearing the end of the expected lifetime. Despite its age, the furnace had an AFUE rating of $93 \%$. The SWH combi system selected to replace the system had a 95\% thermal efficiency rating and an installed winter efficiency of $87 \%$. The high efficiency of the existing system reduced the potential for improvement and limited the savings to $1 \%$ at this site.

Quality of Installation. We found that it was challenging to balance multiple installation requirements (delivered air temperatures, loads, system configurations, and the conditions necessary to achieve high efficiency). At Site 1037, these difficulties resulted in low savings (only $2 \%$ over the existing system). The difficulties were accentuated by the additional installation requirements of boiler systems. Mixing between the loops resulted in water temperatures around $120^{\circ} \mathrm{F}$ entering the boiler during space heating, reducing performance.

Load. Homes with larger loads saved relatively more energy per year (see Figure 22). The percentage saved remained fairly constant; therefore, in general larger loads had greater savings. The homes available as test sites for this project had all undergone weatherization, greatly reducing their heating loads. There was concern at the outset of this project about combi system capacity, so the selection criteria favored homes with smaller total (DHW and space heating) loads. The results showed that initial capacity concerns were unwarranted and combi systems could have met much higher loads. Additionally, the actual space heating loads in the monitored homes were smaller than initially estimated. AHU maximum output was much greater than the measured space heating design loads (see Section 4.4). Additionally, analysis of the delivered water and air temperatures showed that adequate DHW and air temperatures were supplied to meet demands (see Section 4.5). The project's focus on low-load homes, limited the absolute annual savings, and impacted the cost effectiveness of these systems.

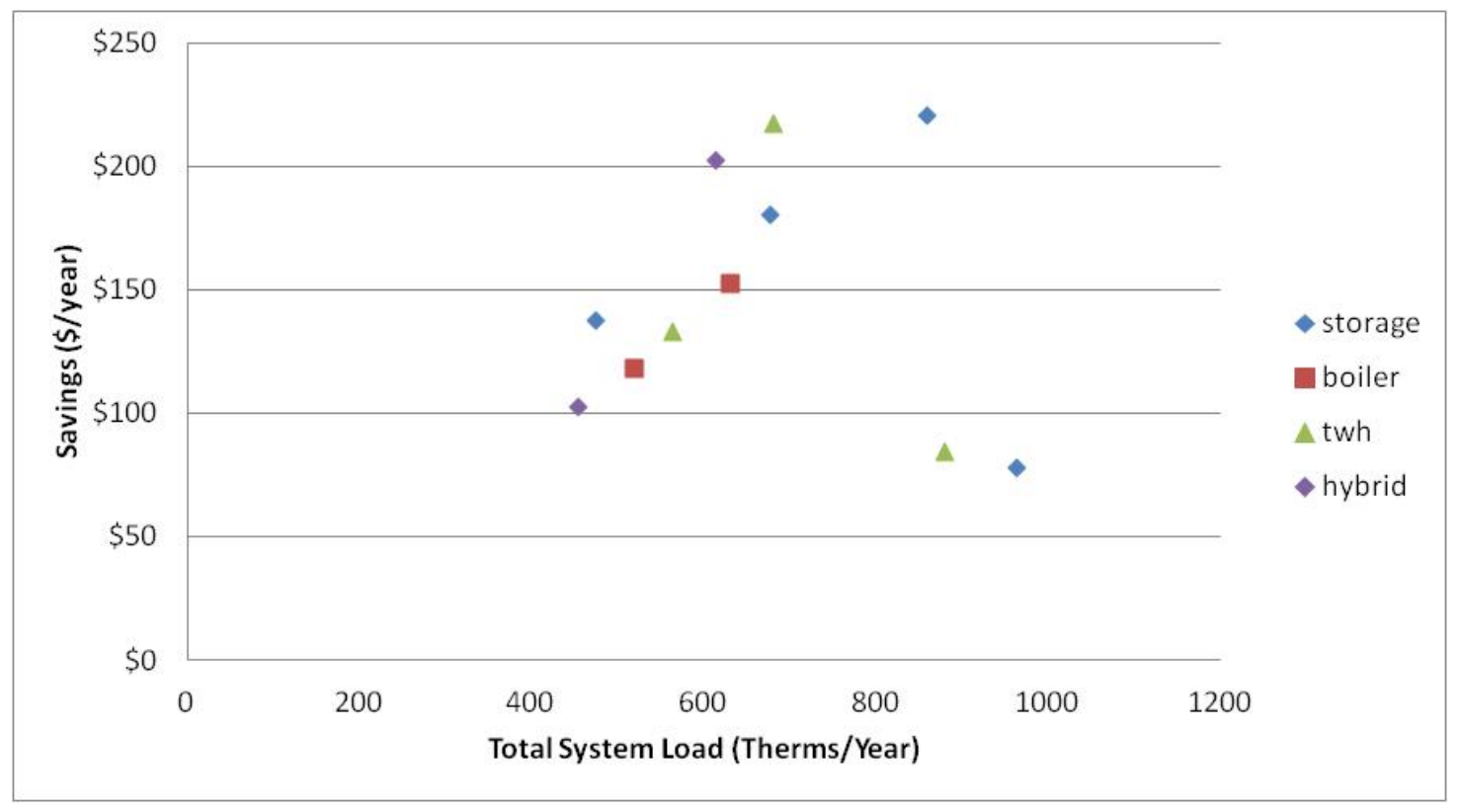

Figure 22. Natural gas savings per site by annual load 
Homes selected for this project had undergone low income weatherization prior to any monitoring. These homes were on average $1,540 \mathrm{ft}^{2}$ of conditioned space and had fully insulated $2 \times 4$ walls with R-50 insulation targets for open attics. This resulted in homes with low space heating loads.

\subsection{Cost Analysis}

An economic analysis determined how combi systems can increase energy efficiency and the effectiveness of energy efficiency programs. We analyzed installed cost, the savings to investment ratio (SIR), and simple paybacks.

Installation Costs. Detailed costs were recorded for 70 installations using a variety of heating plants and AHUs. Several factors influence the combi systems' installed costs:

- The installations were part of a large project.

- Jobs were sent out to bid separately with multiple contractors bidding each install.

- The number of contractors changed over the course of the project.

- The pressure on contractors for low bids changed over time.

- Contractors installed the same system several times and became more familiar with the equipment.

- Several of the factors that influenced the installation costs for these systems were specific to this project.

Figure 23 shows how the costs of systems changed over the course of the project, initial bids tended to be lower, and bids near the end of the project were typically higher in the price range. Figure 23 shows the installed costs for the three heating plants with the most installations. Other systems did not have sufficient installations to see cost trends. The figure shows the bids for two contractors over time. In general, initial low bids were likely due to contractors' desire to be awarded jobs. The contractors knew of the potential for a large number of jobs, allowing them to reduce their typical profit per job. Over time, only two contactors continued to bid on jobs. The contractors became more familiar with the costs of the installs and what bids were winning jobs. Additionally, at the onset of the combi installation project reducing costs was of high concern. However, the goal for the total number of installations was reduced toward the end of the project, which increased the weatherization agencies' allowable cost per job. Contractors were not informed of this directly, but pressure from the weatherization agency to keep costs down decreased and higher priced bids started to be accepted. 


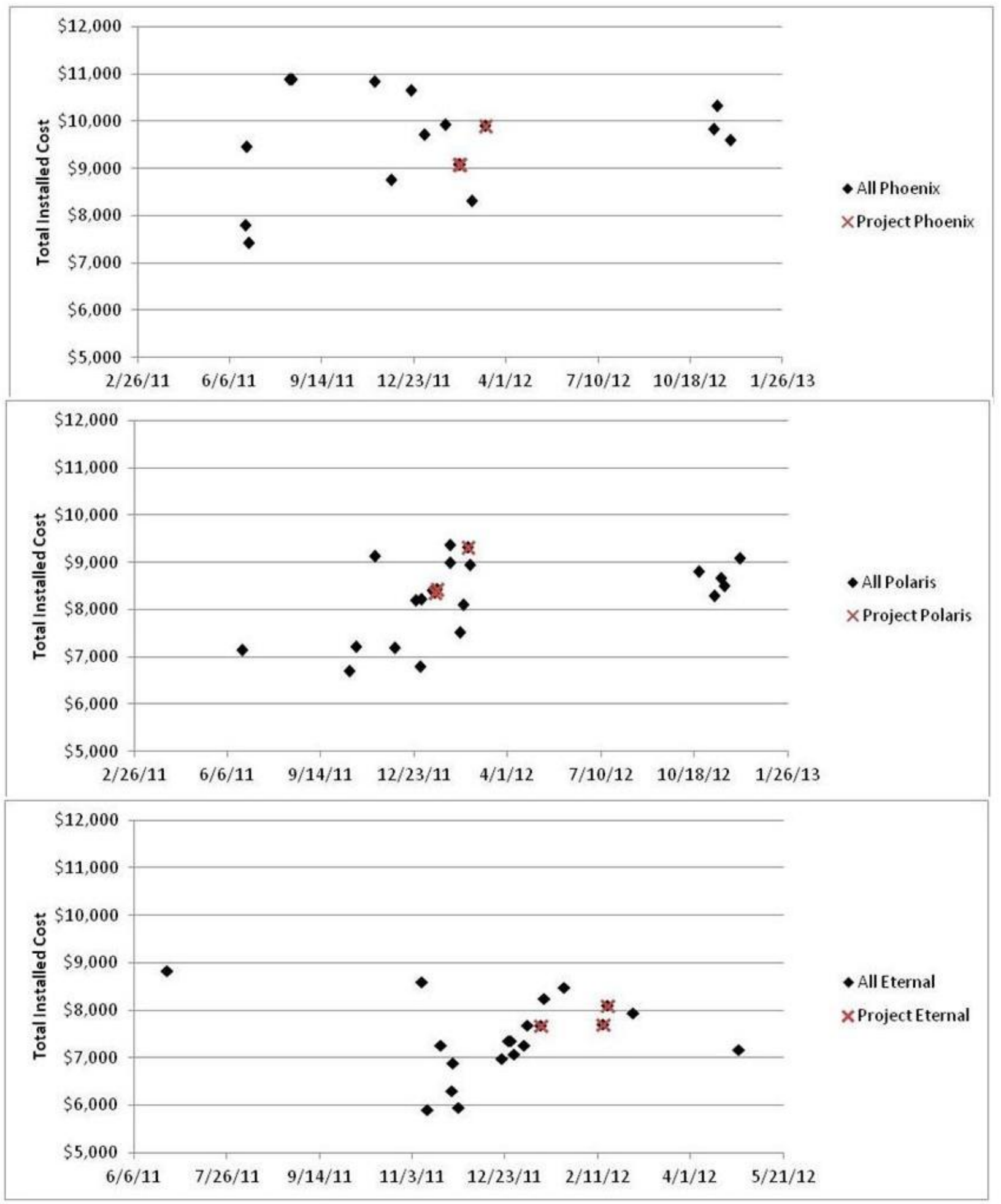

Note: Figures show installed costs for similar heating plants installed as part of the 200 home implementation project ("All") and the detailed monitoring project ("Project").

Figure 23. Cost changes over time for the most installed systems

(Phoenix, Polaris, and Eternal) 
Table 11 shows the average costs by system type. There were differences in how the installers broke down prices into different categories. It was common for several jobs with similar equipment to have similar total costs, but there could be big differences in the breakdown between heating plant cost, labor costs, and miscellaneous materials costs. The total costs were known to be accurate and were used for the cost analysis. The tankless and hybrid systems were generally less expensive to install and the storage tanks were the most expensive. In general, total installed cost scaled with the equipment costs.

Table 11. Average Installation Costs From Implementation Project

\begin{tabular}{c|c|c|c|c|c|c|c|c}
\hline System & n & $\begin{array}{c}\text { Heating } \\
\text { Plant }\end{array}$ & \multirow{2}{*}{$\begin{array}{c}\text { AHU } \\
\mathbf{( \$ )}\end{array}$} & \multirow{2}{*}{$\begin{array}{c}\text { Misc } \\
\mathbf{( \$ )}\end{array}$} & $\begin{array}{c}\text { Labor } \\
\mathbf{( \$ )}\end{array}$ & \multicolumn{3}{|c}{ Cost } \\
\cline { 7 - 9 } & & $\mathbf{( \$ )}$ & & & & Average & Min & Max \\
\hline Storage-Vertex & 3 & 3,223 & 2,345 & 1,280 & 1,943 & 8,792 & 8,120 & 9,505 \\
Storage-Polaris & 21 & 4,175 & 2,186 & 476 & 1,369 & 8,207 & 6,495 & 9,375 \\
Storage-Phoenix & 15 & 4,397 & 2,081 & 650 & 2,479 & 9,607 & 7,135 & 11,000 \\
TWH-Rinnai & 4 & 2,521 & 2,421 & 1,025 & 1,616 & 7,584 & 6,945 & 8,445 \\
Hybrid-Eternal & 22 & 2,815 & 2,323 & 590 & 1,562 & 7,289 & 5,696 & 8,751 \\
Boiler-Navien & 5 & 4,129 & 2,375 & 495 & 1,124 & 8,123 & 6,650 & 8,840 \\
\hline
\end{tabular}

Installed costs of combi systems were compared to other systems types (see Figure 23). Several different costs were considered for this comparison. Low income weatherization agencies in Minnesota have installed a large number of power vented WHs and condensing furnaces. The large volume of installations has resulted in a price break for these agencies (see Table 12). Local contractors were contacted for their typical pricing structures for open market installations. These costs were used for the analysis in this project. The least expensive space and water heating option would be an ND furnace and an ND SWH. This inexpensive option is still common in some northern climate states, and was useful for replacement comparisons. Typical costs for this base system are around $\$ 3,075$ ( $\$ 1,875$ for the furnace and $\$ 1,200$ for the WH). A common system upgrade consisted of a condensing gas furnace (with an average AFUE of 94\%) and power vent WH (EF of 0.60). This was the system typically installed by Minnesota low income weatherization programs. On the open market this system costs $\$ 6,350$ to install $(\$ 4,250$ for a condensing furnace and $\$ 2,100$ for the WH), which includes local utility rebates. Local weatherization paid, on average, $\$ 3,500$ for a condensing furnace and $\$ 1,800$ for the WH. A homeowner seeking high efficiency space and water heating could install a condensing furnace and condensing SWH (thermal efficiencies of 95\%) or condensing TWH (EF of 0.90 to 95\%). Open market installation costs for a condensing SWH were found to be $\$ 5,300$ and previous research (Schoenbauer et al. 2011) showed condensing TWHs with installed costs of $\$ 4,000$. Condensing combi systems were the lowest cost method of providing both condensing water heating and space heating (Table 13). Costs of installing a condensing furnace and power vent WH are lower, but only provide water heating with a $0.60 \mathrm{EF}$ rating. Contractors also had little experience with combi systems and their costs will likely change over time if the numbers of installations were increased. Combi system equipment can currently have three different ratings (EF, AFUE, and thermal efficiency). Confusion surrounding multiple ratings has prevented local utilities from rebating combi systems, which ultimately make them a less desirable option. Condensing furnaces, power vent WHs, TWHs, and condensing SWHs are more mature technologies with better defined costs. 


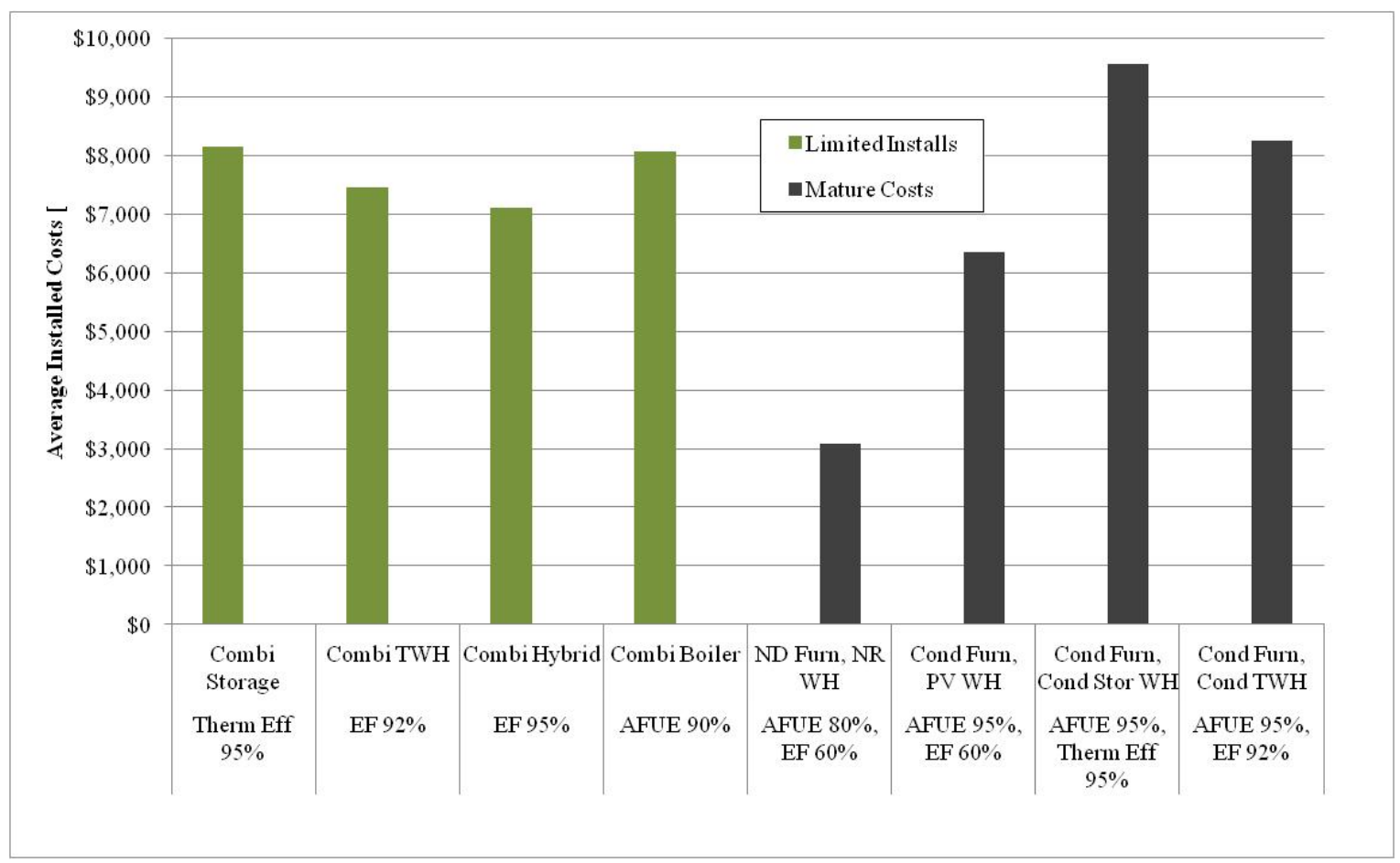

Figure 24. Installation costs for residential HVAC systems

Table 12. Installation Costs for Furnaces and WHs

\begin{tabular}{c|c|c|c}
\hline & $\begin{array}{c}\text { Program or High Volume } \\
(\mathbf{\$})\end{array}$ & $\begin{array}{c}\text { Open Market } \\
(\mathbf{\$})\end{array}$ & $\begin{array}{c}\text { BEoptE+ v1.01 } \\
\mathbf{( \$ )}\end{array}$ \\
\hline Condensing Furnace & 3,500 & 4,250 & 3,318 \\
Minimum Efficiency Furnace & - & 1,875 & 1,408 \\
Photovoltaic WH & 1,800 & 2,100 & 970 \\
\hline Condensing SWH & $5,100^{*}$ & 5,350 & - \\
Condensing TWH & - & - & 1,800 \\
\hline
\end{tabular}

* Price was based on the installed cost of a photovoltaic WH and the increased cost of a condensing SWH 
Table 13. SIR for Combi Systems

\begin{tabular}{|c|c|c|c|c|c|c|c|}
\hline $\begin{array}{c}\text { Site } \\
\text { Number }\end{array}$ & Heating Plant & AHU & $\begin{array}{l}\text { Cost } \\
(\$)\end{array}$ & $\begin{array}{c}\text { Space } \\
\text { and WH } \\
\text { Savings } \\
(\$ / y r)\end{array}$ & $\begin{array}{c}\text { Lifetime } \\
\text { (years) }\end{array}$ & $\begin{array}{c}\text { Wx } \\
\text { Program } \\
\text { SIR }\end{array}$ & $\begin{array}{l}\text { Install Cost } \\
\text { Needed for } \\
\text { SIR }=1 \\
\text { (\$) }\end{array}$ \\
\hline 1028 & Polaris & Rinnai 75 & 8,410 & 321 & 15 & 0.6 & 4,820 \\
\hline 1031 & Polaris & Enerzone 70 & 8,840 & $9^{a}$ & 15 & 0.2 & 1,365 \\
\hline 1027 & Polaris-Stress & Enerzone 70 & 9,760 & 181 & 15 & 0.3 & 2,712 \\
\hline 1056 & Phoenix & Enerzone 70 & 9,535 & 138 & 15 & 0.2 & 2,076 \\
\hline 1061 & Phoenix & Enerzone 70 & 9,535 & 221 & 15 & 0.3 & 3,315 \\
\hline 1026 & Vertex & Enerzone 100 & 9,000 & 79 & 15 & 0.1 & 1,184 \\
\hline 1030 & Rinnai TWH & Enerzone 70 & 7,605 & 218 & 15 & 0.4 & 3,266 \\
\hline 1045 & Rinnai TWH & Enerzone 70 & 6,760 & 85 & 15 & 0.2 & 1,280 \\
\hline 1062 & Rinnai TWH & Enerzone 70 & 7,850 & 134 & 15 & 0.3 & 2,006 \\
\hline 1049 & Eternal & Enerzone 70 & 8,500 & 203 & 15 & 0.4 & 3,047 \\
\hline 1070 & Eternal & Enerzone 70 & 8,155 & 103 & 15 & 0.2 & 1,549 \\
\hline 1037 & Navien & Enerzone 70 & 9,200 & 11 & 15 & 0.0 & 163 \\
\hline 1052 & Rinnai Boiler & Enerzone 70 & 12,500 & 153 & 15 & 0.2 & 2,297 \\
\hline 1063 & Rinnai Boiler & Enerzone 70 & 12,507 & 119 & 15 & 0.1 & 1,785 \\
\hline \multicolumn{3}{|c|}{ Condensing Furnace $(A F U E=95 \%)^{b}$} & 3,500 & 105 & 20 & 0.6 & 2,098 \\
\hline
\end{tabular}

Simple Paybacks. Payback calculations were used to determine the number of years the combi systems would take to pay off the incremental cost of the update. These calculations assumed that equipment needed to be replaced (which was not the case for the SIR). For these simple paybacks the savings are compared to the incremental cost for the system, because a new system was necessary. The equipment could be replaced with a baseline system non-condensing furnace and ND SWH ( $\$ 3,075$ install cost), a condensing furnace and power vent SWH $(\$ 6,350$ install cost), a condensing furnace and condensing WH ( $\$ 8,250$ install cost with a TWH or $\$ 9,550$ install cost with a SWH), or a condensing WH-based combi system $(\$ 7,300$ to $\$ 8,000$ average install cost). Installed performance was not available for all options. The energy consumption of combi systems, non-condensing furnaces, and condensing SWHs were determined from the field data collected for this project. The energy consumption of condensing TWHs, power vent WHs, and ND SWHs were characterized in a previous field monitoring project (Schoenbauer et al. 2011). Condensing furnace performance was assumed to match the performance of the space heating combi systems, an assumption that was supported by the data collected for a condensing furnace in this project (Site 1031). Assuming the space heating performance of a combi system matched the installed performance of a condensing furnace; the remaining benefit would be from water heating savings. The final column of Table 14 addressed this scenario with comparison to condensing furnaces. The paybacks versus a condensing furnace system are long because the only savings come from DHW, where the load was small. The installation costs of combination systems were lower than the cost of installing a condensing furnace and a condensing $\mathrm{WH}$ in most cases making the payback immediate.

Future research is underway to improve installation costs and performance of the systems. Section 6 discussed the planned continuation of combi system work. Research will include control optimization to improve system efficiency and/or increase space heating capacity. For 
example, properly configured outdoor resets could increase space heating capacity using the same hydronic coil with no change or improved efficiency. Improving capacity may allow for smaller systems to be used for more installations, reducing the equipment costs.

Table 14. Simple Payback for Combi Systems

\begin{tabular}{|c|c|c|c|c|}
\hline \multirow{2}{*}{$\begin{array}{c}\text { Combination } \\
\text { System }\end{array}$} & \multirow[b]{2}{*}{ Load } & \multirow{2}{*}{$\begin{array}{c}\text { Average } \\
\text { Install Cost } \\
\text { (\$) }\end{array}$} & \multicolumn{2}{|c|}{ Simple Payback } \\
\hline & & & $\begin{array}{c}\text { AFUE }=80 \%, \\
E F=60 \%\end{array}$ & $\begin{array}{c}\text { AFUE }=95 \%, \\
E F=60 \%\end{array}$ \\
\hline \multirow{2}{*}{ Storage WH } & Low & 8200 & 47 & 185 \\
\hline & High & 8800 & 23 & 136 \\
\hline \multirow{2}{*}{ TWH } & Low & 7600 & 44 & 28 \\
\hline & High & 7600 & 21 & 20 \\
\hline \multirow{2}{*}{ Hybrid WH } & Low & 7300 & 30 & 23 \\
\hline & High & 7300 & 13 & 11 \\
\hline
\end{tabular}

Notes:

AFUE $80 \%$, EF 0.6: Refers to an ND furnace and WH

AFUE 95\%, EF 0.6: Refers to a condensing furnace and power vent WH

Listed install costs are total costs, but the incremental cost is used to calculate the payback

Boiler systems had a limited number of installations over a range of costs and were excluded from this analysis.

\subsection{Calculated Space Heating Loads}

Careful consideration was taken to size the combi system for each home. System parameters were set to minimize return water temperature while meeting or exceeding the required design OAT load and $115^{\circ} \mathrm{F}$ supply air temperature. We used two methods to determine the design load for space heating prior to each installation. Contractors were asked to perform a Manual J calculation and weatherization staff used house data to model each home in the NEAT software.

The contractor's design condition space heating load calculations were compared to the load for the home using the measured data and temperature to determine the actual load at design conditions (Figure 25 and Table 15). For each site, both contractors calculated a higher design load than the measured design load. For two of 19 sites, Contractor A's computed load was within $20 \%$ of the measured load (10\%-20\% is a typical oversize factor used by the industry). Contractor B had three sites within $20 \%$. In contrast, the NEAT models overpredicted the design heating load at 17 of the 19 sites and were within a $20 \%$ oversize factor at two other sites (Figure 26).

Table 16 shows the percent difference of space heating load calculations and the measured design load of each home. The results indicate that the design heating loads were typically significantly overestimated. The average Contractor A heating load estimate was more than $100 \%$ oversized. Personnel for Contractor B were a little closer, about $80 \%$ oversized on average. The NEAT modeling software was the closest to actual loads, overpredicting by $51 \%$ on average. The NEAT software required several hours of data collection and entry to determine the estimated load, while the contractor's personnel spent significantly less time conducting their Manual J calculations; therefore, it was expected that the NEAT software would be more accurate. Finally, the agencies do not use a comparison of modeled and utility bill annual gas use to modify NEAT model parameters. Applying that process could further improve NEAT design load estimates. 
Table 15. Space Heating Load Comparisons

\begin{tabular}{c|c|c|c|c|c}
\hline $\begin{array}{c}\text { Site } \\
\text { Number }\end{array}$ & $\begin{array}{c}\text { Contractor A } \\
\text { (Btu/h) }\end{array}$ & $\begin{array}{c}\text { Contractor B } \\
\text { (Btu/h) }\end{array}$ & $\begin{array}{c}\text { NEAT } \\
\text { (Btu/h) }\end{array}$ & $\begin{array}{c}\text { Measured Data } \\
\text { (Btu/h) }\end{array}$ & $\begin{array}{c}\text { Uncertainty } \\
\text { (Btu/h) }\end{array}$ \\
\hline $\mathbf{1 0 6 2}$ & 46,103 & 40,476 & 41,966 & 16,104 & 1,688 \\
\hline $\mathbf{1 0 5 6}$ & 52,368 & 36,440 & 26,112 & 17,797 & 1,705 \\
$\mathbf{1 0 6 5}$ & 51,893 & 44,820 & 35,136 & 18,504 & 3,245 \\
$\mathbf{1 0 7 8}$ & 40,400 & 58,753 & 40,320 & 19,415 & 2,165 \\
$\mathbf{1 0 6 1}$ & 54,359 & 41,916 & 37,368 & 19,785 & 1,748 \\
$\mathbf{1 0 4 9}$ & - & 46,154 & 36,277 & 20,466 & 5,438 \\
$\mathbf{1 0 3 0}$ & 41,106 & 35,004 & 32,064 & 21,167 & 1,145 \\
$\mathbf{1 0 3 7}$ & 40,723 & 36,948 & 28,534 & 21,699 & 2,657 \\
$\mathbf{1 0 5 5}$ & 43,502 & 42,466 & 30,729 & 23,549 & 1,555 \\
$\mathbf{1 0 2 7}$ & 53,058 & 41,736 & 38,774 & 24,422 & 1,002 \\
$\mathbf{1 0 5 4}$ & 55,909 & 53,828 & 40,101 & 24,498 & 1,961 \\
$\mathbf{1 0 7 0}$ & 55,140 & 41,097 & 29,111 & 26,092 & 1,695 \\
$\mathbf{1 0 2 6}$ & 58,014 & 45,524 & 46,248 & 26,621 & 1,002 \\
$\mathbf{1 0 5 2}$ & 61,305 & 45,819 & 33,474 & 26,690 & 1,042 \\
$\mathbf{1 0 2 8}$ & 46,984 & 42,343 & 35,716 & 27,280 & 2,061 \\
\hline $\mathbf{1 0 4 7}$ & 55,917 & 52,961 & 42,636 & 30,855 & 4,990 \\
\hline $\mathbf{1 0 3 1}$ & 38,541 & 38,900 & 38,260 & 34,815 & 1,450 \\
\hline $\mathbf{1 0 6 3}$ & 56,420 & 36,800 & 32,640 & 35,609 & 3,391 \\
\hline $\mathbf{1 0 4 5}$ & 42,955 & 47,693 & 31,461 & 40,709 & 2,891 \\
\hline
\end{tabular}

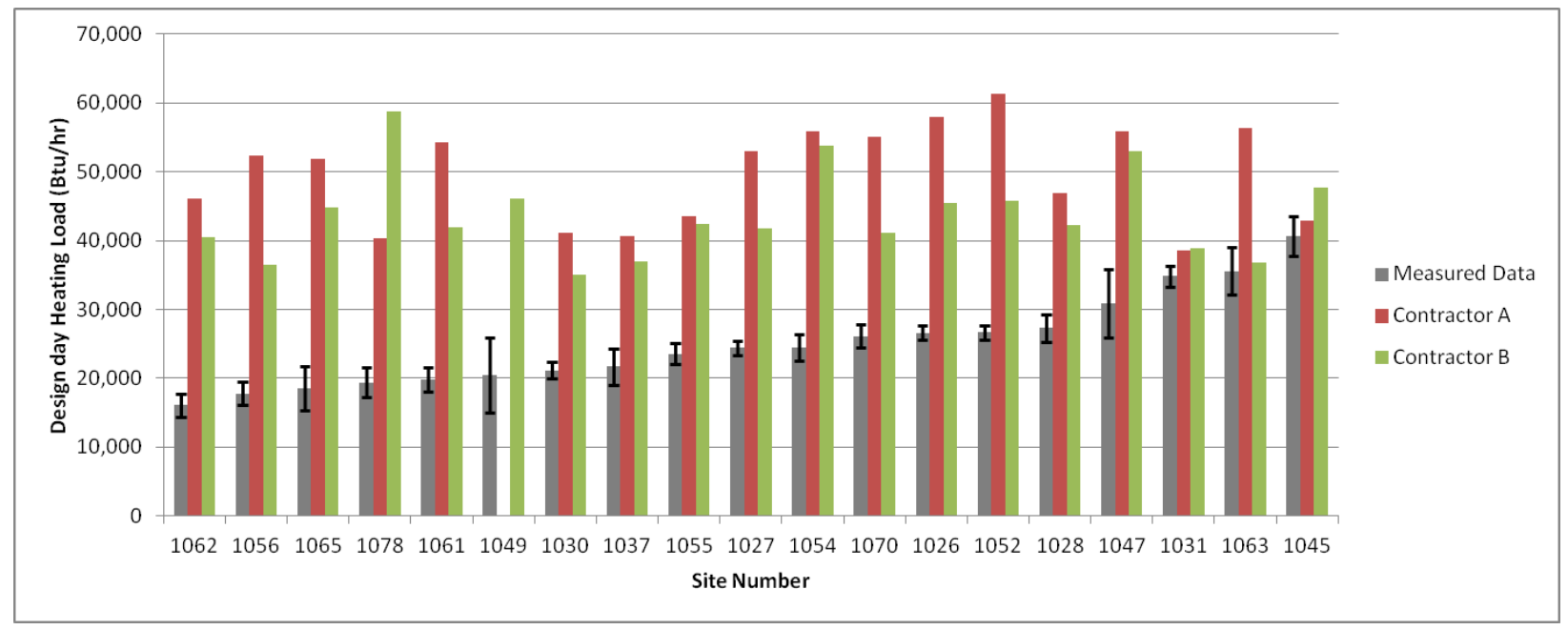

Figure 25. Comparison of the measured space heating load and the contractors estimates 


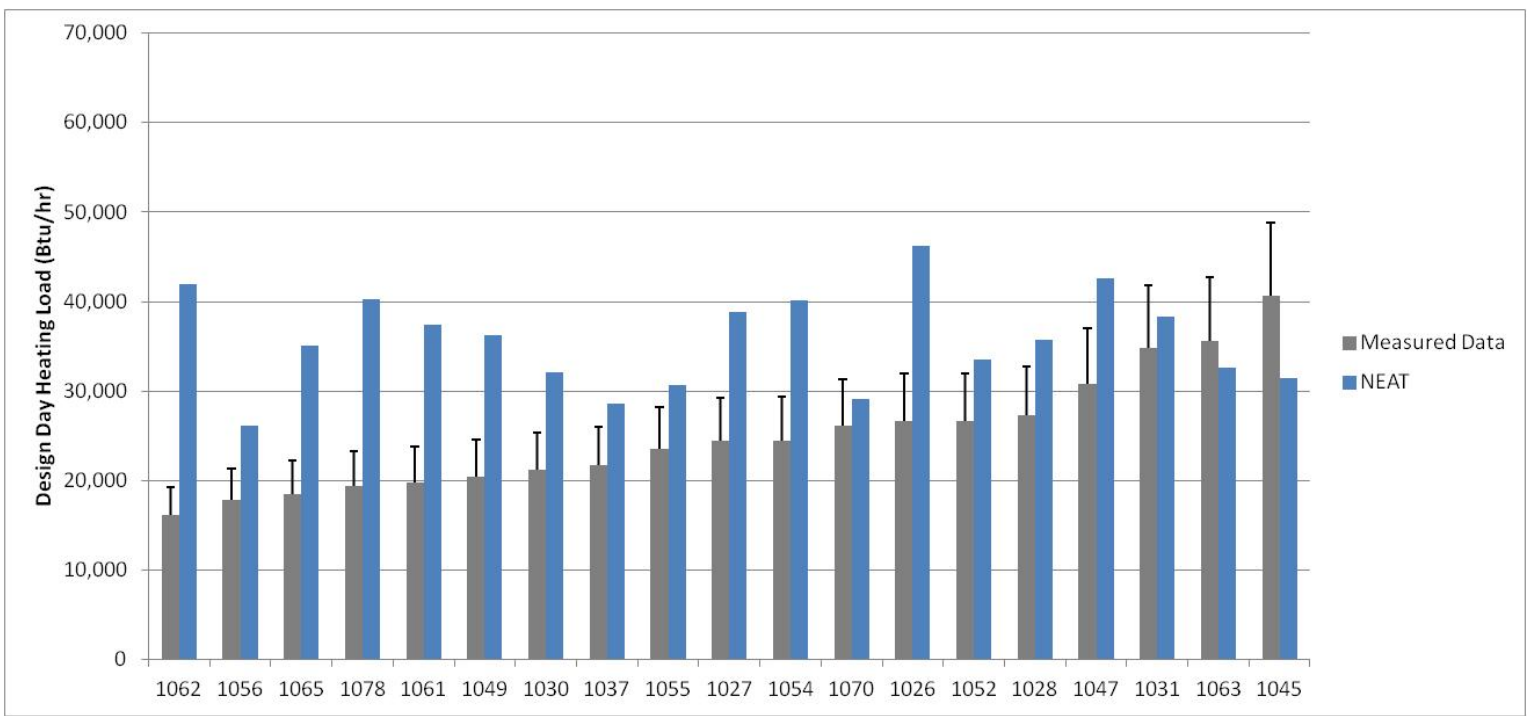

Figure 26. Comparison of the measured space-heating load and the NEAT software

Table 16. Overprediction of Space-Heating Loads

\begin{tabular}{c|c|c|c}
\hline \multirow{2}{*}{$\begin{array}{c}\text { Site } \\
\text { Number }\end{array}$} & \multicolumn{3}{|c}{ Percentage Difference From Measured } \\
\cline { 2 - 4 } & $\begin{array}{c}\text { Contractor A } \\
(\mathbf{\%})\end{array}$ & $\begin{array}{c}\text { Contractor B } \\
\mathbf{( \% )}\end{array}$ & $\begin{array}{c}\text { NEAT } \\
(\mathbf{\%})\end{array}$ \\
\hline $\mathbf{1 0 6 2}$ & 186 & 151 & 161 \\
\hline $\mathbf{1 0 5 6}$ & 194 & 105 & 47 \\
\hline $\mathbf{1 0 6 5}$ & 180 & 142 & 90 \\
\hline $\mathbf{1 0 7 8}$ & 108 & 203 & 108 \\
\hline $\mathbf{1 0 6 1}$ & 175 & 112 & 89 \\
\hline $\mathbf{1 0 4 9}$ & - & 126 & 77 \\
\hline $\mathbf{1 0 3 0}$ & 94 & 65 & 51 \\
\hline $\mathbf{1 0 3 7}$ & 88 & 70 & 31 \\
\hline $\mathbf{1 0 5 5}$ & 85 & 80 & 30 \\
\hline $\mathbf{1 0 2 7}$ & 117 & 71 & 59 \\
\hline $\mathbf{1 0 5 4}$ & 128 & 120 & 64 \\
\hline $\mathbf{1 0 7 0}$ & 111 & 58 & 12 \\
\hline $\mathbf{1 0 2 6}$ & 118 & 71 & 74 \\
\hline $\mathbf{1 0 5 2}$ & 130 & 72 & 25 \\
\hline $\mathbf{1 0 2 8}$ & 72 & 55 & 31 \\
\hline $\mathbf{1 0 4 7}$ & 81 & 72 & 38 \\
\hline $\mathbf{1 0 3 1}$ & 11 & 12 & 10 \\
\hline $\mathbf{1 0 6 3}$ & 58 & 3 & -8 \\
\hline $\mathbf{1 0 4 5}$ & 6 & 17 & -23 \\
\hline Mean & 108 & 84 & 51 \\
\hline Median & 110 & 72 & 47 \\
\hline $\mathbf{1}^{\text {st }}$ Quartile & 82 & 61 & 28 \\
\hline $\mathbf{3}^{\text {rd }} \mathbf{Q u a r t i l e}$ & 126 & 108 & 69 \\
\hline
\end{tabular}




\subsection{Occupant Comfort}

\subsubsection{Delivered Air Temperature}

A common concern with space heating systems has been occupants feeling "cold blow," discomfort from moving air that, while warmer than the air in the room, feels cold when blowing directly on a person. For new systems cold blow can be avoided by delivering higher air temperatures and avoiding air blowing directly on occupants. Because ductwork and grilles were not retrofitted in this project, we could not change the location or type of supply registers to minimize the occurrence of air blowing directly on occupants. Instead, we focused on achieving higher supply air temperatures by setting a steady-state delivered air temperature guideline of $115^{\circ} \mathrm{F}$. Each of the four system types had slightly different delay times to achieve steady-state temperatures performance.

An alternative solution to the "cold blow" discomfort is a control strategy of delaying the blower initiation after the call for heat to allow the temperature to ramp up before airflow begins. This control strategy is common is forced air applications, but was not available for most hydronic air handling units.

SWHs. Almost half of the SWH-based combi systems achieved a median supply air temperature of $115^{\circ} \mathrm{F}$. The average supply air temperatures of combi systems using storage-type WHs was $109^{\circ}-120^{\circ} \mathrm{F}$ (Figure 27 and Table 17 ). The median supply air temperature was $112^{\circ} \mathrm{F}$ or greater for all of the systems and $115^{\circ} \mathrm{F}$ or greater for three of the seven systems. For storage-based systems it was more difficult to set the supply air temperature due to the variability in the stored water temperature. The SWHs had different sized dead bands for temperature control, resulting in different ranges in the minimum/maximum stored water temperatures and delivered air temperatures. On a call for heat from the thermostat, hot water immediately circulated through the hydronic coil. The AHU fan turned on at the same time as the circulation pump and the delivered air temperature raised as the coil came up to temperature (Figure 28). The delivered air temperature reached $110^{\circ} \mathrm{F}$ around 45 seconds on average.

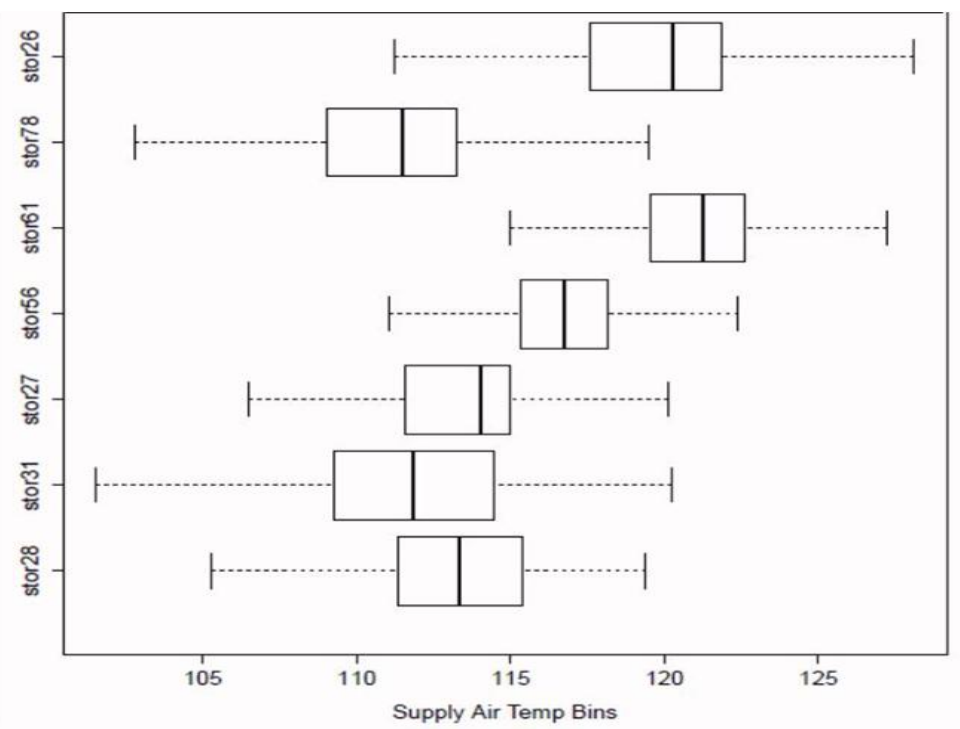

Figure 27. Supply air temperature distributions for SWH-based combi systems 


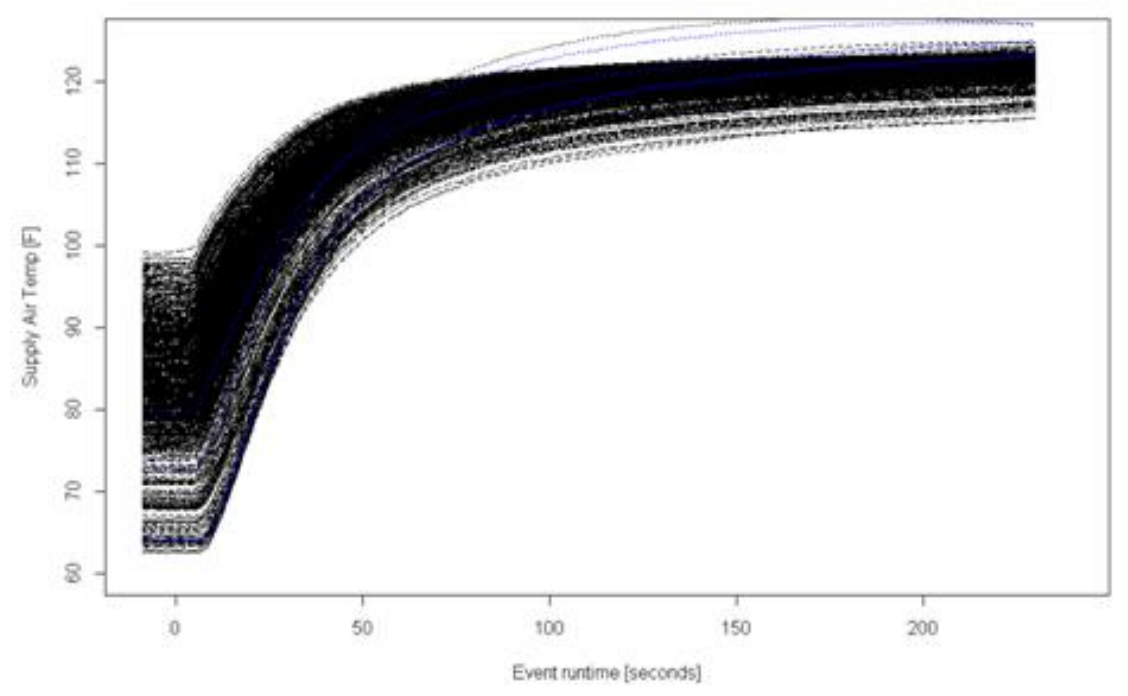

Figure 28. Delivered air temperature of each space-heating event at Site 1061 with a SWH-based combi system

TWHs. Combi systems using TWHs had average delivered air temperatures of $113^{\circ}-118^{\circ} \mathrm{F}$ and median air temperatures of $115^{\circ}-119^{\circ} \mathrm{F}$ (Figure 29). TWHs control the steady-state outlet temperature to a small range of allowable temperatures, making the outlet water temperature more constant. The fairly constant water temperature made it possible to more accurately set the supply air temperature to the desired value. As a result, all three systems had a median supply air temperature at or slightly above the desired value of $115^{\circ} \mathrm{F}$. Since the TWHs had no storage capacity and heated water as necessary when space heat was called for, cold water circulated through the hydronic coil until the WH came up to temperature. This control strategy resulted in the TWH-based combi system taking a relatively long time of about 100 seconds to reach $110^{\circ} \mathrm{F}$ (Figure 30).

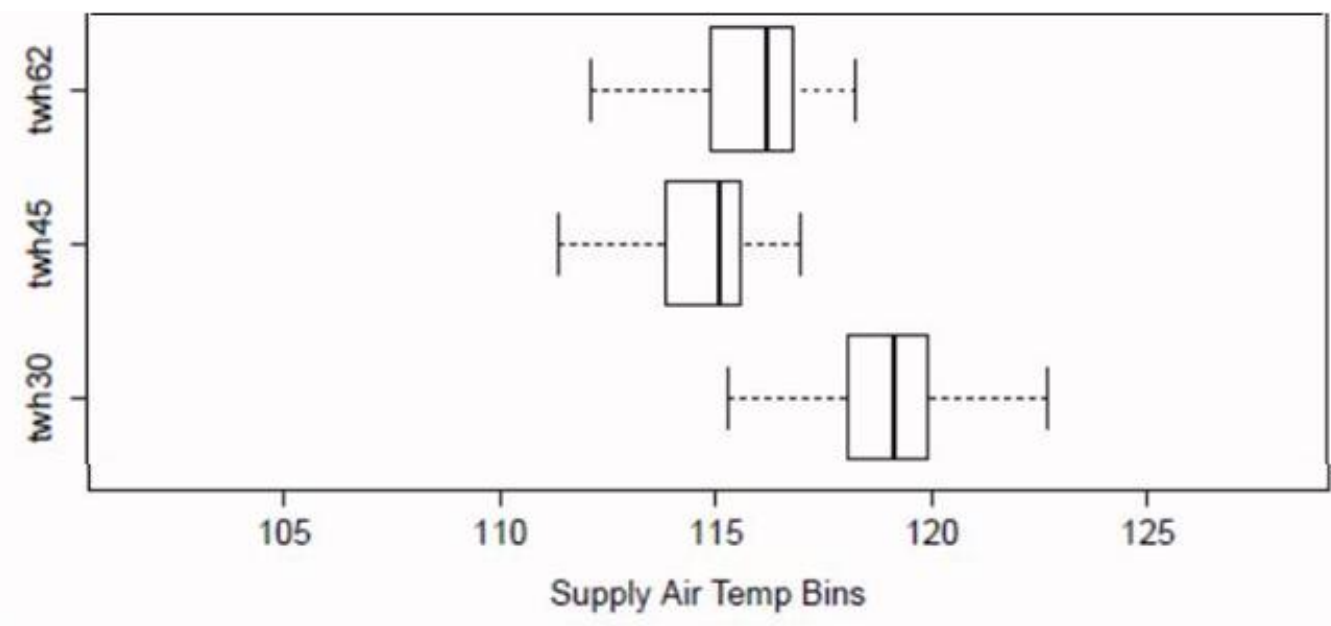

Figure 29. Supply air temperature distributions for TWH-based combi systems 


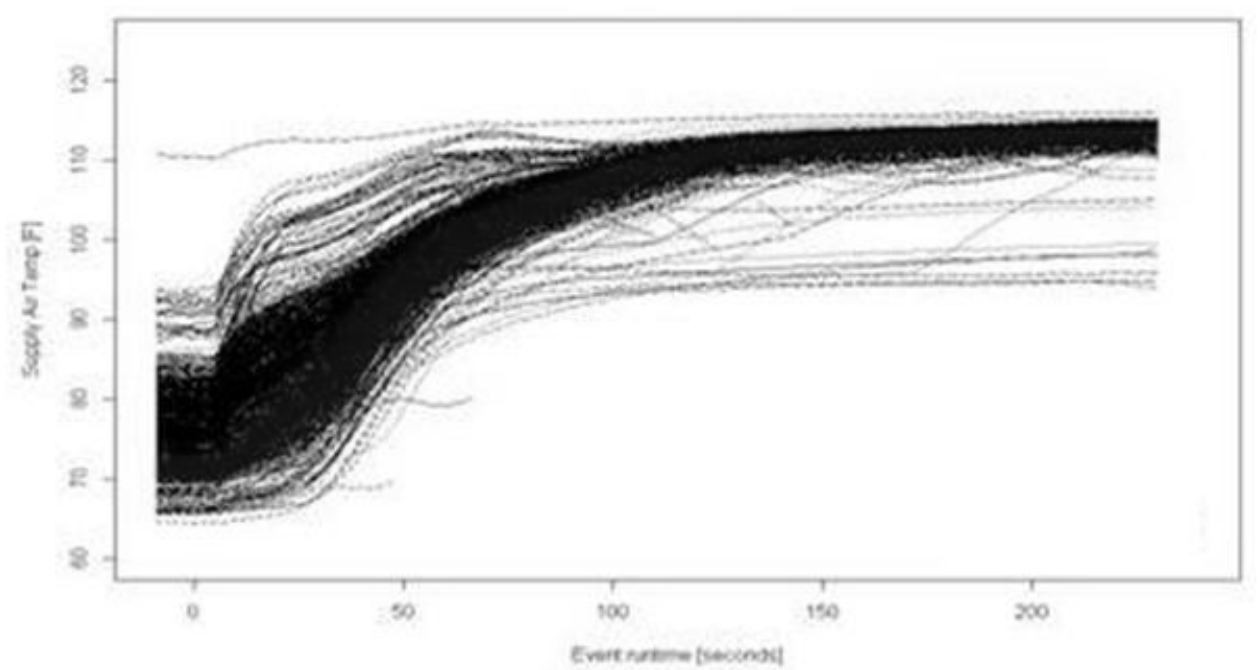

Figure 30. Delivered air temperature of each space-heating event at Site 1045 with a TWH-based combi system

Hybrid WHs. Combi systems that used hybrid WHs had average delivered air temperatures of $115^{\circ}-117^{\circ} \mathrm{F}$ with median air temperatures of $116^{\circ} \mathrm{F}$ and $119^{\circ} \mathrm{F}$ (see Figure 31 ). Like tankless units, the hybrid WHs had a tight range of delivered water temperatures, allowing steady-state air temperatures to be set up easily. These units had 2 gallons of storage, and this quantity of hot water helped to bridge the gap between a call for space heating and the burner reaching steadystate. On average, hybrids delivered $110^{\circ} \mathrm{F}$ air 50 seconds after a call for heat.

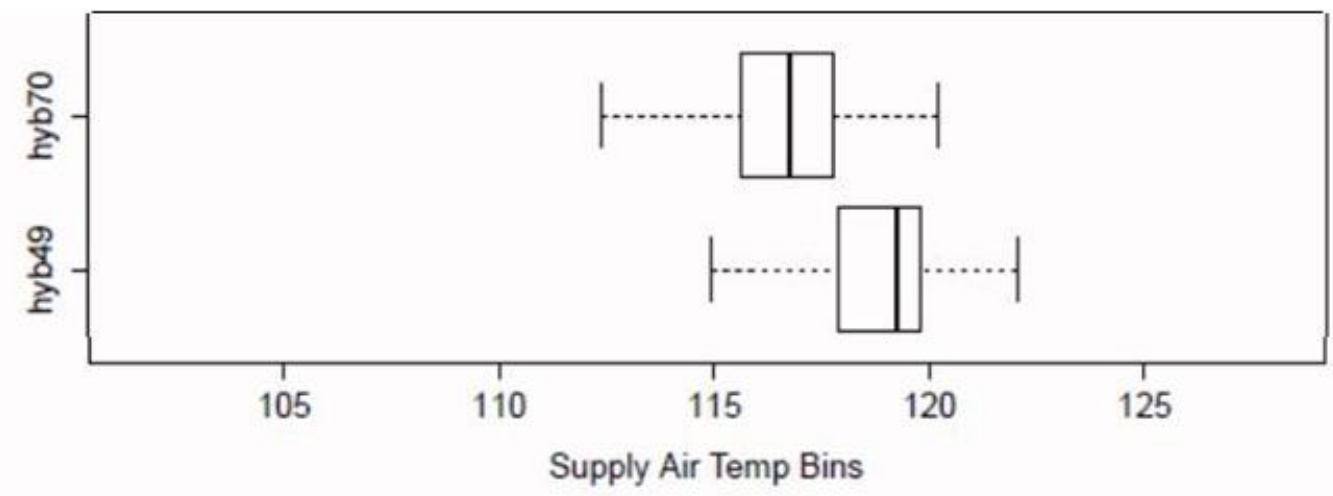

Figure 31. Supply air temperature distributions for hybrid WH-based combi systems 


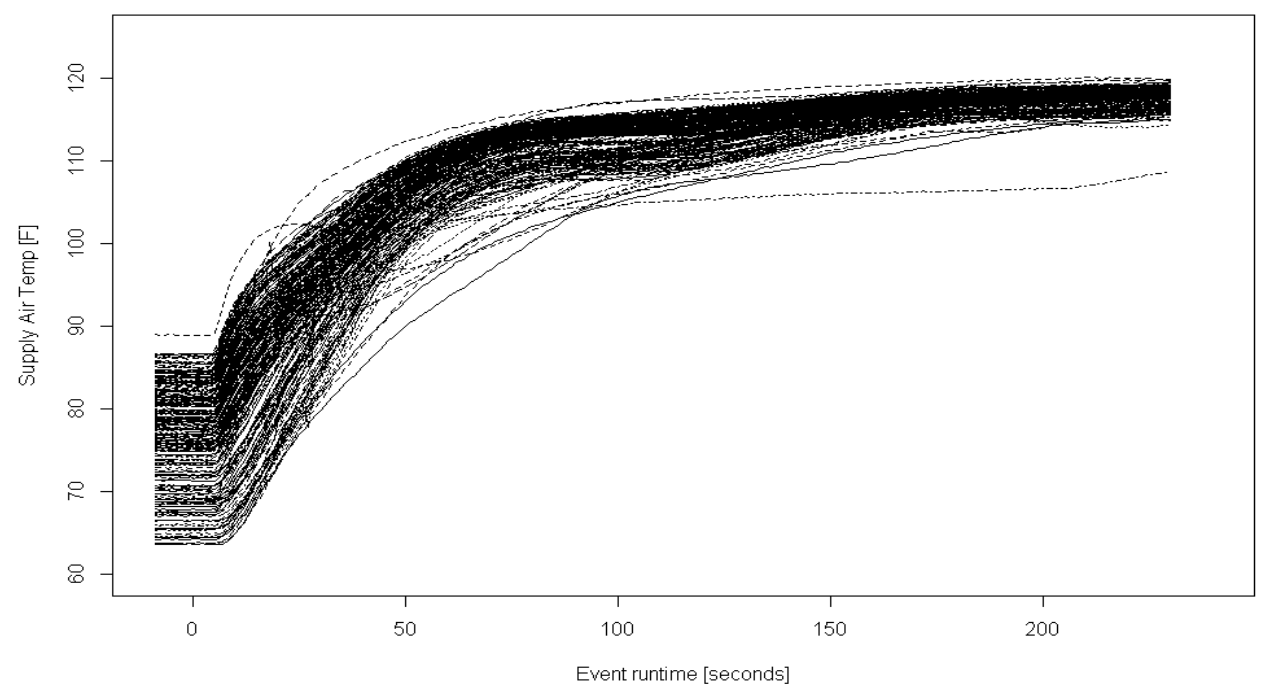

Figure 32. Delivered air temperature of each space-heating event at Site 1049 with a hybrid WH-based combi system

Boilers. Most boiler-based combi systems, both low-mass systems and those with storage capacity, had delivered air performance similar to that of other combi units: $116^{\circ}-120^{\circ} \mathrm{F}$ average temperature (Figure 33). However, one boiler (a Rinnai at Site 1063) used an OAT reset control that reduced the delivered water temperature as the OAT increased. This resulted in the delivered air temperature being reduced in the shoulder seasons, which resulted in a larger inter-quartile range than for other systems. Low-mass boilers have no storage capacity, and these performed similarly to a TWH. These systems took around 110 seconds to reach $110^{\circ} \mathrm{F}$ (Figure 34 ). A boiler with storage capacity (Site 1063) performed similar to storage-based system. Air temperatures reached $110^{\circ} \mathrm{F}$ around 40 seconds into the event (Figure 35). 


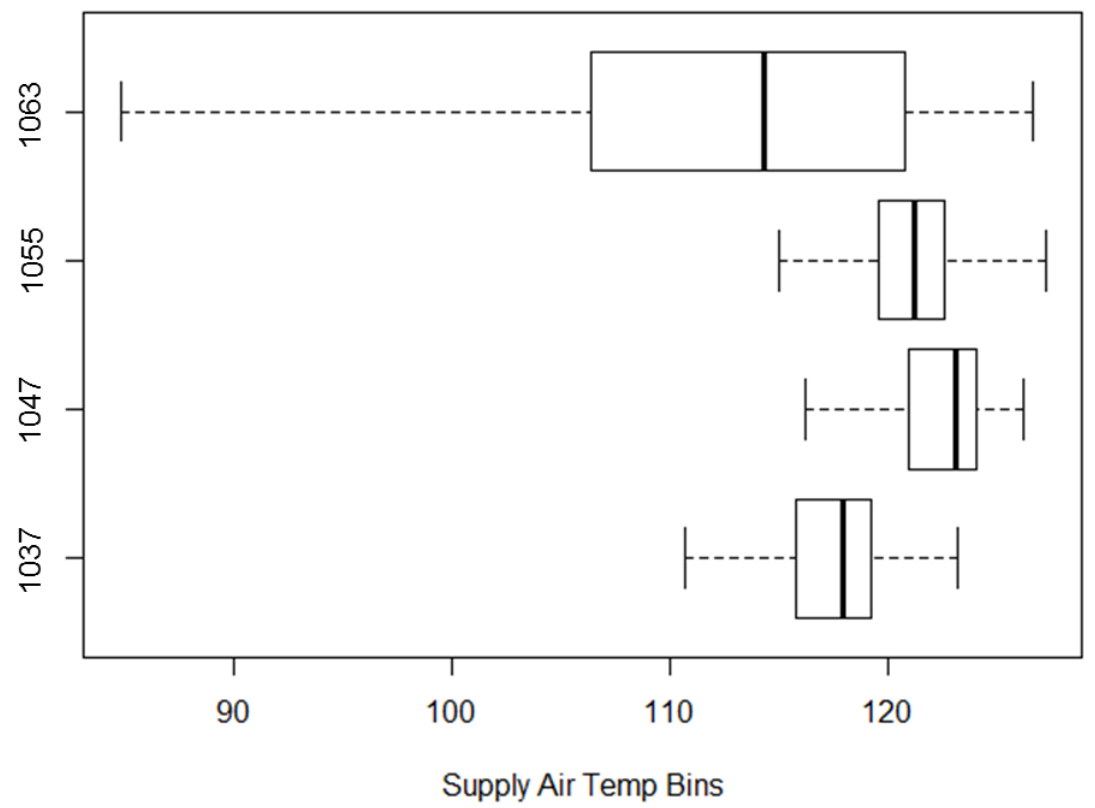

Figure 33.Supply air temperature distributions for boiler-based combi systems

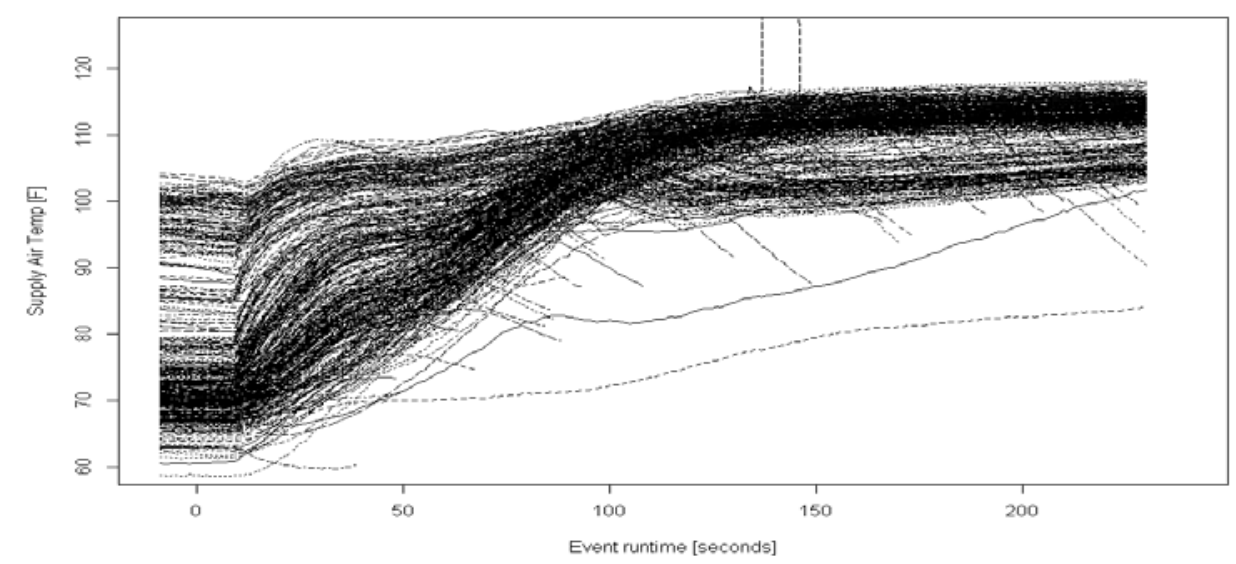

Figure 34. Delivered air temperature of each space-heating event at Site 1037 with a low-mass boiler-based combi system 


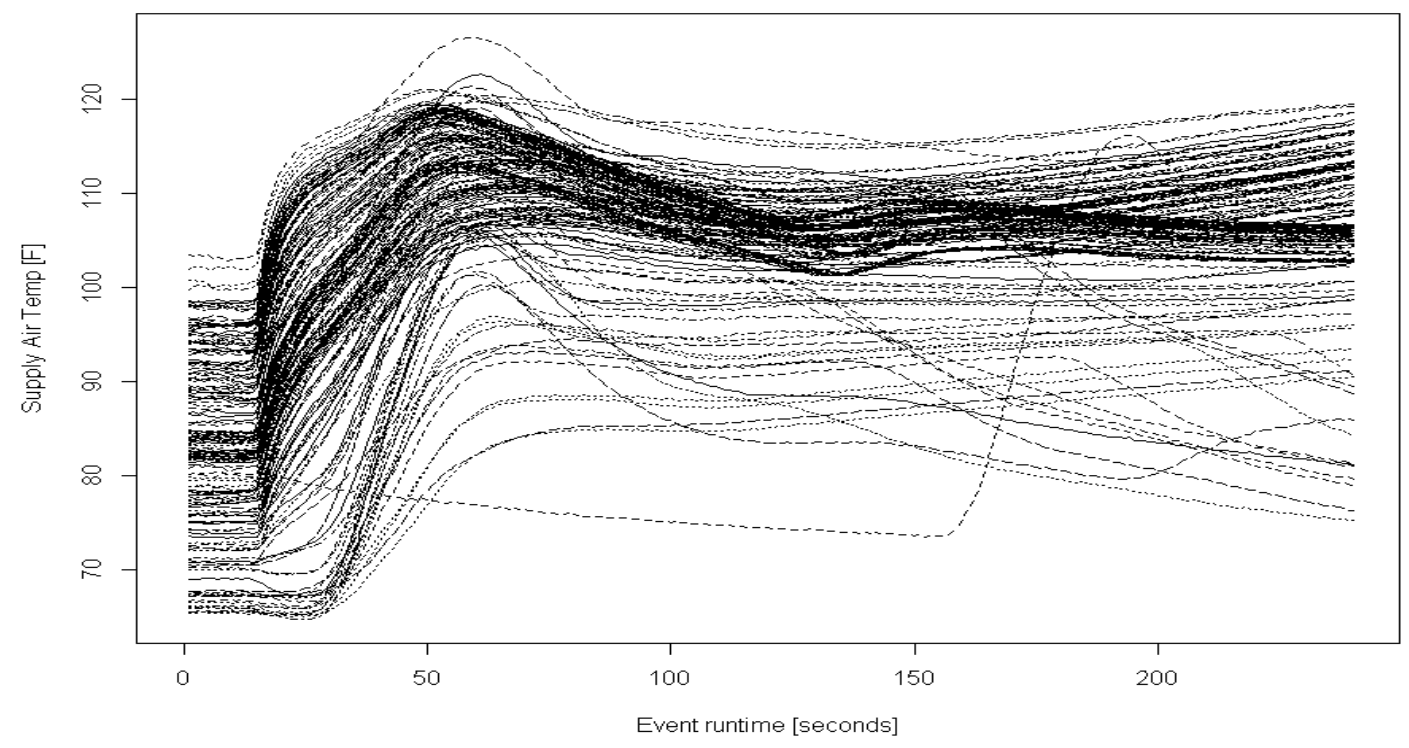

Figure 35. Delivered air temperature of each space-heating event at Site 1063 with a boiler-based combi system

Table 17. Supply Air Temperature Distribution Characteristics

\begin{tabular}{|c|c|c|c|c|c|}
\hline \multirow[b]{2}{*}{$\begin{array}{c}\text { Site } \\
\text { Number }\end{array}$} & \multirow[b]{2}{*}{$\begin{array}{c}\text { Combination Appliance } \\
\text { Heating Plant }\end{array}$} & \multicolumn{4}{|c|}{ Supply Air Temperature } \\
\hline & & $\begin{array}{c}1^{\text {st }} \text { Quartile } \\
\left({ }^{\circ} \mathrm{F}\right)\end{array}$ & $\begin{array}{l}\text { Median } \\
\left({ }^{\circ} \mathrm{F}\right)\end{array}$ & $\begin{array}{l}\text { Mean } \\
\left({ }^{\circ} \mathbf{F}\right)\end{array}$ & $\begin{array}{l}3^{\text {rd }} \text { Quartile } \\
\left({ }^{\circ} \mathrm{F}\right)\end{array}$ \\
\hline 1028 & Polaris & 111 & 113 & 113 & 115 \\
\hline 1031 & Polaris & 109 & 112 & 111 & 114 \\
\hline 1027 & Polaris & 112 & 114 & 111 & 115 \\
\hline 1056 & Phoenix & 115 & 117 & 116 & 118 \\
\hline 1061 & Phoenix & 120 & 121 & 120 & 123 \\
\hline 1078 & Phoenix & 109 & 112 & 109 & 113 \\
\hline 1026 & Vertex & 118 & 120 & 119 & 122 \\
\hline 1030 & Rinnai TWH & 118 & 119 & 118 & 120 \\
\hline 1045 & Rinnai TWH & 114 & 115 & 113 & 116 \\
\hline 1062 & Rinnai TWH & 115 & 116 & 114 & 117 \\
\hline 1054 & Eternal & 118 & 119 & 117 & 120 \\
\hline 1070 & Eternal & 116 & 117 & 115 & 118 \\
\hline 1037 & Navien & 116 & 118 & 116 & 119 \\
\hline 1047 & Navien & 121 & 123 & 121 & 124 \\
\hline 1055 & Navien & 120 & 120 & 120 & 123 \\
\hline 1052 & Rinnai Boiler & 106 & 114 & 111 & 121 \\
\hline
\end{tabular}

Comparisons Between Combi Systems and Other Space Heating Systems. Delivered air temperatures for combi systems were compared to those for other system types. The existing furnaces that were ND non-condensing furnaces had a preset time delay between burner fire and 
the fan turning on. Figure 36 shows that these furnaces (time equals 0 when the fan turns on) compared to the combination systems. The existing furnaces reached $110^{\circ} \mathrm{F}$ about $15-20$ seconds after the fan turned on. The existing non-condensing ND furnaces also had higher steady-state delivered air temperatures. The furnaces monitored in this study had air temperatures of $125^{\circ}$ $150^{\circ} \mathrm{F}$. Other projects have shown that condensing gas furnaces typically deliver air temperature of $115^{\circ}-130^{\circ} \mathrm{F}$. Heat pump systems have air temperatures of $77^{\circ}-115^{\circ} \mathrm{F}$ (Natural Resources Canada 2009). These systems have had significant numbers of installations without occupant complaints of discomfort.

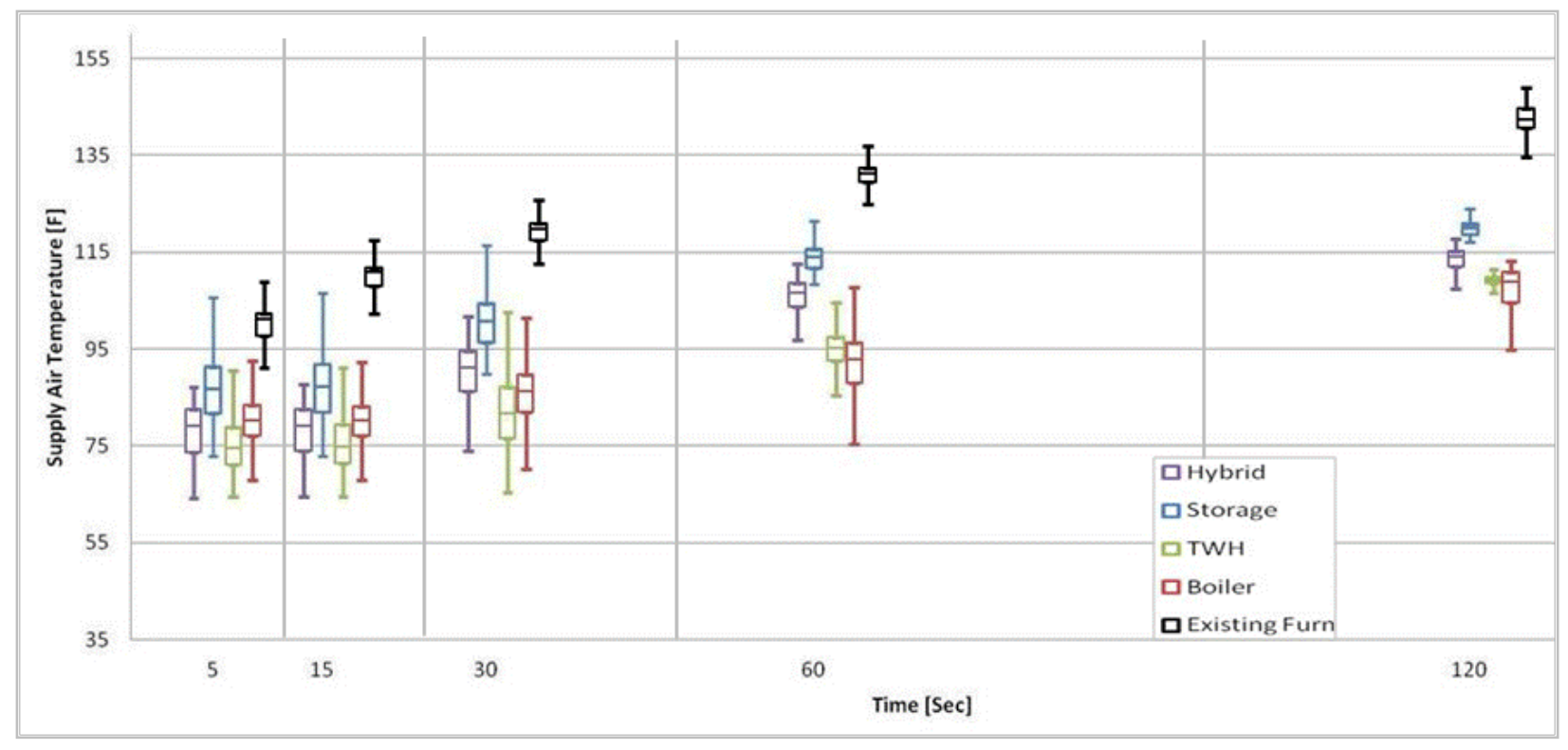

Figure 36.Time series discharge air temperatures for combi systems

The $115^{\circ} \mathrm{F}$ supply air design temperature was considered to achieve good occupant comfort without modifications to ductwork or delivery grilles. Combi systems have air temperatures similar to other high efficiency space heating systems (e.g., condensing furnaces and heat pumps). The combi system with outdoor reset (Site 1063) and large numbers of heat pump systems have provided sufficient capacity and comfort at temperatures below $115^{\circ} \mathrm{F}$, with longer runtimes at lower temperatures and flow rates while avoiding blowing directly on people. Delivered air temperatures of combi systems could potentially be lowered. The air temperature would be lowered by reducing the heating plant water temperature thus lowering return water temperature and improving efficiency.

\subsubsection{Hot Water Delivery Capabilities}

There were differences in the capabilities of each combi system to provide hot water. Three areas were analyzed to identify the origins of these differences. The first and most significant was the ramp up time, the time between hot water being turned on and hot water leaving the system. The second was the range of the steady-state water temperatures. The third was the percentage of time that water delivered was usable (temperature greater than $105^{\circ} \mathrm{F}$ ). The delivered water temperature of each system was measured approximately 6 in. downstream of the mixing valve. Each system was initially set to deliver $120^{\circ} \mathrm{F}$ water from the mixing valve, but occupants were allowed to adjust the system to meet their needs. This allowance for adjustment meant that not all systems were set for the same steady-state water temperature. 
SWHs. Figure 37 shows the water temperatures exiting the mixing valve for a combi system with a condensing SWH. Within about 5 seconds of the draw starting, the water leaving the mixing valve reached its steady-state temperature-in this case about $125^{\circ} \mathrm{F}$. The control mechanism for SWHs allowed the stored water to cool before firing to reheat. This resulted in a range (about $10^{\circ}-15^{\circ} \mathrm{F}$ ) of steady-state delivered water temperatures. Excluding Site 1028, for SWHs, $91 \%$ of the time when there was a hot water draw the delivered temperature was greater than $105^{\circ} \mathrm{F}$, the temperature water is typically assumed to become usable (Figure 38 ). The Phoenix WH (sites 1078, 1056, and 1061) had greater variance in delivered water temperature than the other two heaters. This was likely due to a difference in (1) the reduction of temperature variance allowed in the tank before reheat; (2) temperature measurement technique that allows greater variance in temperature; and (3) stratification in the tank or a combination of these effects. The homeowner atSsite 1028 preferred much cooler water and had lowered the water delivery temperature. At this site only $31 \%$ of the time was the temperature greater than $105^{\circ} \mathrm{F}$. The average delivered water temperatures for the SWHs varied from $105^{\circ} \mathrm{F}$ to $135^{\circ} \mathrm{F}$.

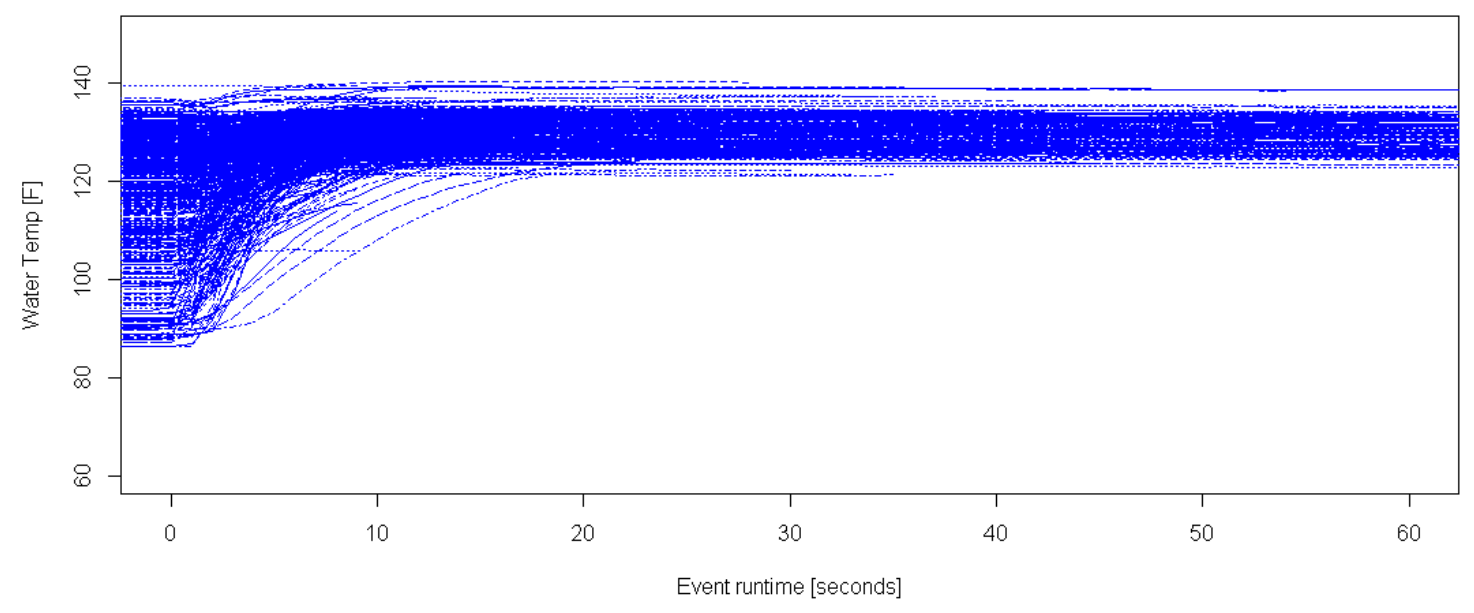

Figure 37. Time series plots of DHW temperatures after mixing valve of the SWH at Site 1078 


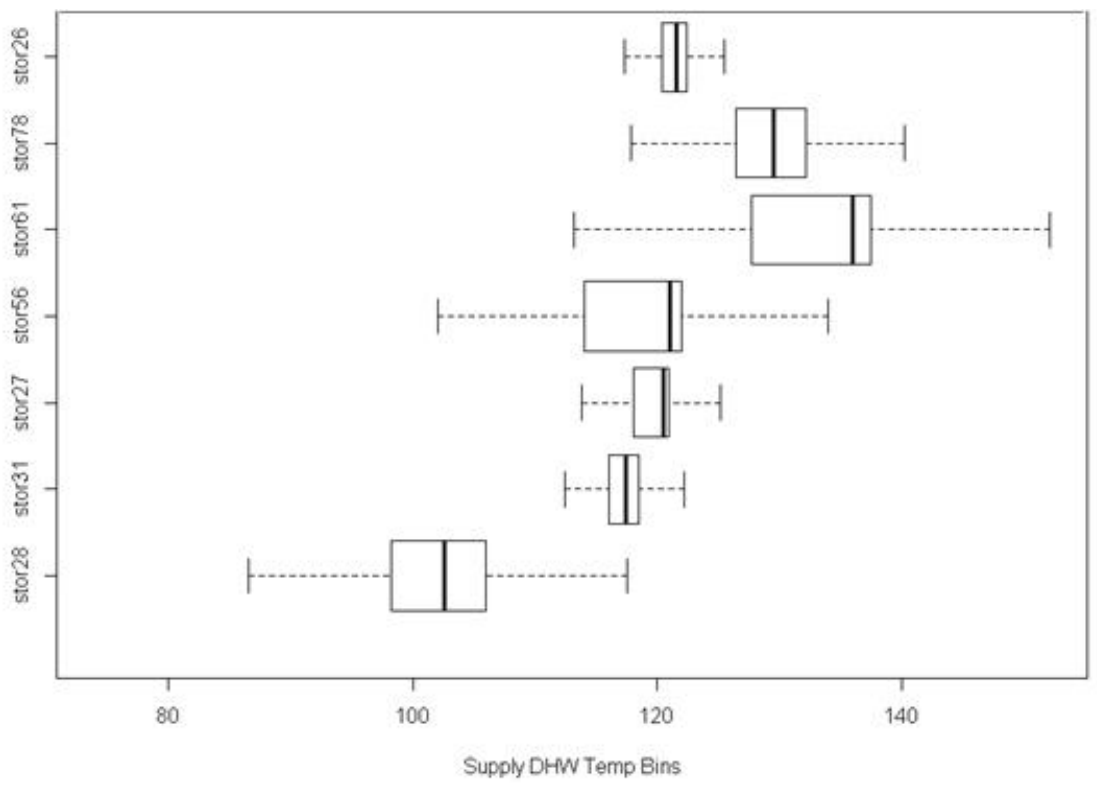

Figure 38. Delivered water temperatures for the storage-based combi systems

TWHs. TWHs initiate heating when a hot water draw is sensed (Figure 39). Not surprisingly, these systems had slower ramp-up times, typically taking 20-30 seconds longer to reach the desired temperature than the systems using SWHs. The delay time increased at lower flow rates and the figure shows some draws that took longer than 60 seconds to reach steady-state temperature. In addition, the unit would not produce hot water when flow rates fell below the minimum fire rate of the TWH $(\sim 0.5 \mathrm{gpm})$. Variance in a site's delivered water temperature increased with low water flow rates, long idle periods between events, and large seasonality in inlet water. At Site 1030, low water flow rates caused increased delay time, making WH ramp-up time a larger percentage of the total runtime and increasing the temperature variance. However, once the system reached steady-state, the continuous burner modulation allowed the WH to provide a very consistent temperature over a range of flow rates. At steady-state temperature, variance was typically less than $2^{\circ} \mathrm{F}$ (Figure 40). The occupants using the TWH systems kept the settings close to $120^{\circ} \mathrm{F}$ (Figure 40 ). Outlet water temperatures were greater than $105^{\circ} \mathrm{F} 84 \%$ of the time hot water was being used, and were $8 \%$ lower than the percentage of time for the SWHs. 


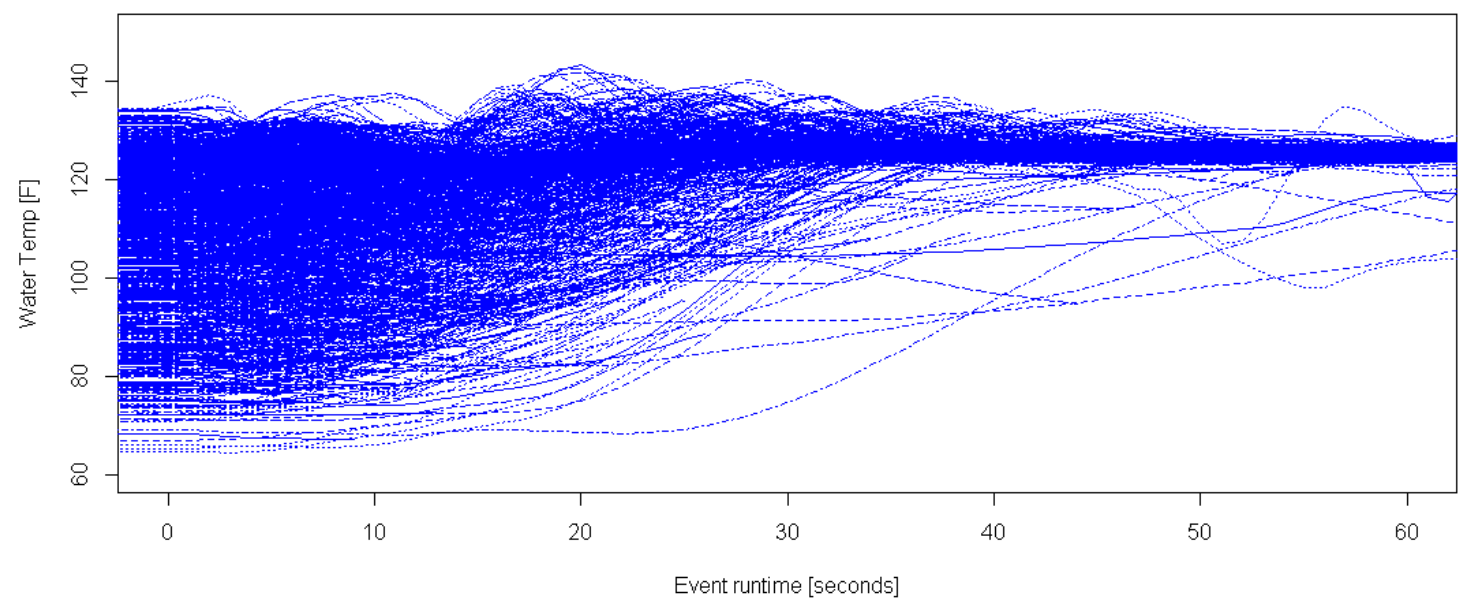

Figure 39. Time series plots of DHW temperatures after mixing valve of the TWH at Site 1030

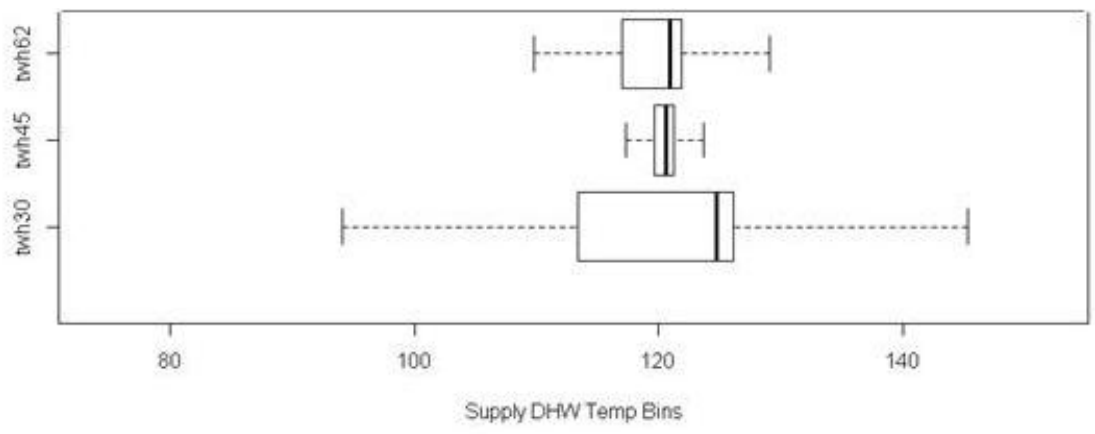

Figure 40. Delivered water temperatures for the TWH-based combi systems

Hybrid WHs. We found a clear benefit for added storage volume of the combi system using a hybrid WH (Figure 41). The 2-gallon storage volume provided usable hot water while the heater came up to temperature. The water temperature leaving the mixing valve reached the steady-state temperature about 5-10 seconds after the start of a water draw. This was comparable to a system using a SWH and an improvement over systems using a TWH. The hybrid system also provided hot water for low flow draws below $0.5 \mathrm{gpm}$, but delivered water temperatures were reduced as the draw continued until the stored water temperature dropped enough to require the tank to reheat (Figure 42). There were several events where the heater generated hot water 10-15 seconds into the event and then cooled before heating up again. The modulating burner allowed the hybrid unit to provide very consistent steady-state water temperatures (within $2^{\circ} \mathrm{F}$ ).

Temperatures were greater than $105^{\circ} \mathrm{F}$ on average $84 \%$ of the active time (Figure 42 ). None of these sites changed water delivery set point from $120^{\circ} \mathrm{F}$ design. 


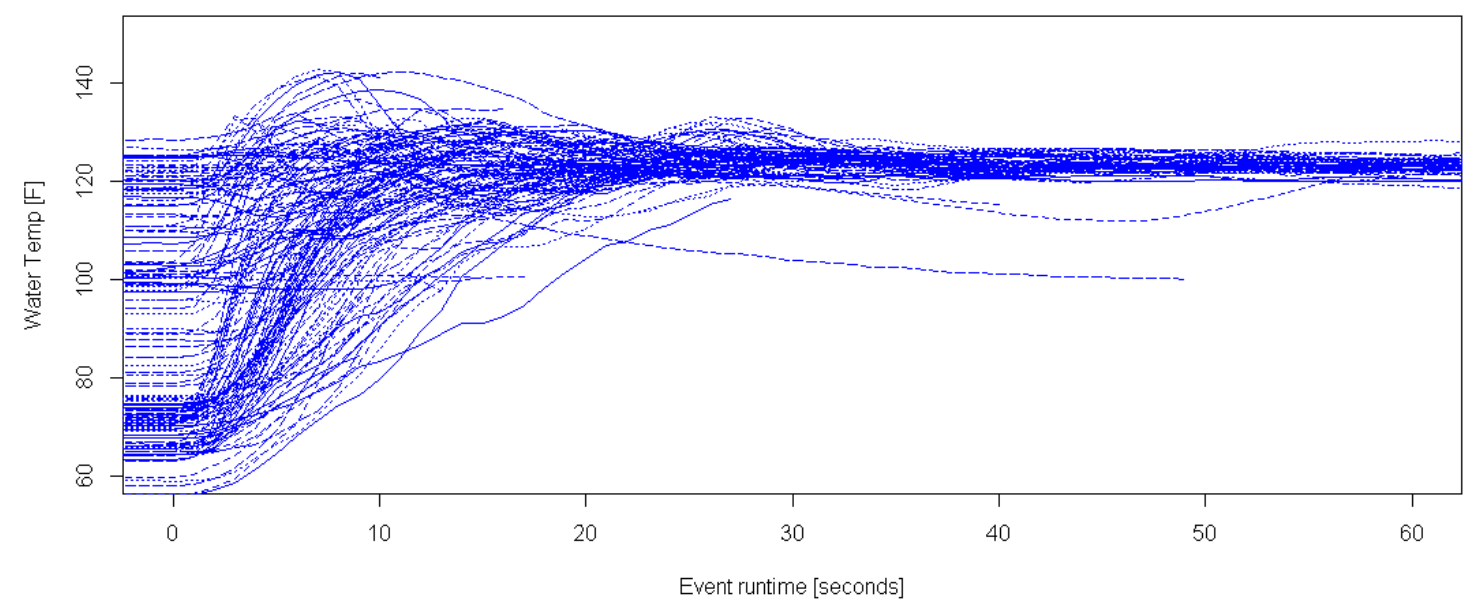

Figure 41.Time series plots of DHW temperatures after mixing valve of the hybrid WH at Site 1070

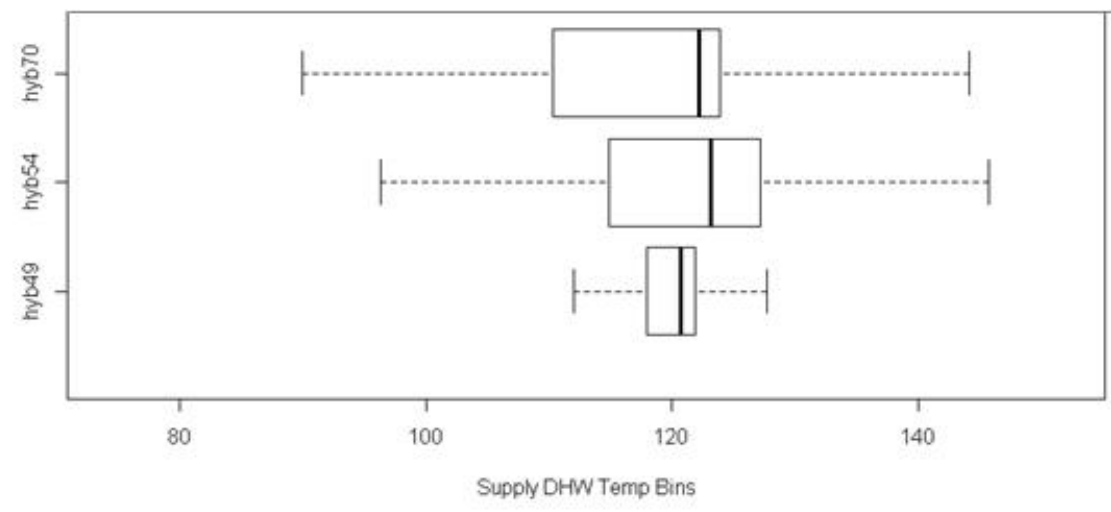

Figure 42. Delivered water temperatures for the hybrid WH-based combi systems

Boilers. The mechanism for setting the delivered water temperature was different for the boiler combi systems than for those based on WHs. Whereas each of the WHs was set at $140^{\circ} \mathrm{F}$ to provide enough heat for space heating and mixed with cold water for hot water use, each boiler had an internal mixing valve that was set to the desired DHW temperature.

Combi systems based on low-mass boilers (Sites 1037, 1047, and 1055) did not have any storage capacity and created hot water as needed. The systems used a digital set point control and internal mixing valve. Testing of the unit prior to installation left some concerns about the unit's ability to control the DHW temperature; therefore, the same mixing valves were installed for the other combi systems were also installed on the boiler combi systems. The water delivery performance of a low-mass combi boiler was similar to that of a TWH (Figure 43). These boilers had the slowest ramp up time of any DHW system tested taking 20-40 seconds to reach temperature. The low-mass boilers had steady-state water temperatures that fluctuated $5^{\circ}-10^{\circ} \mathrm{F}$ often up to 2 minutes into events. 


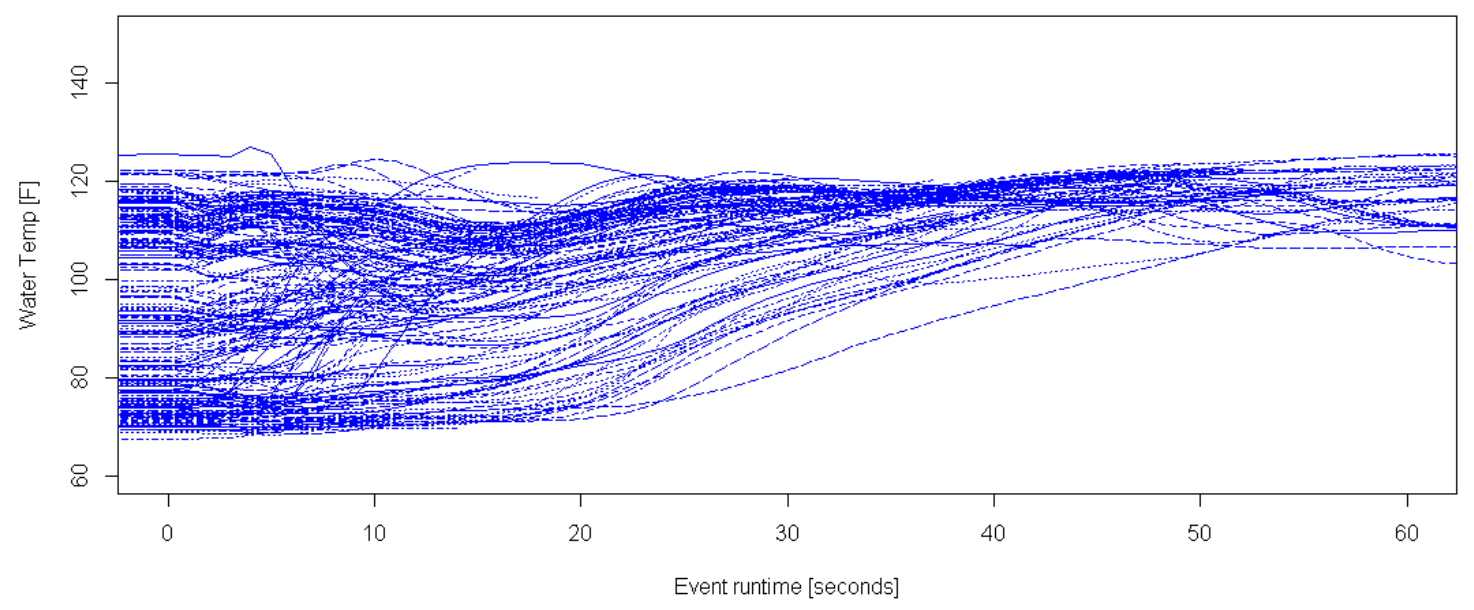

Figure 43.Time series plots of DHW temperatures after mixing valve of the low-mass boiler at Site 1055

The boilers installed at sites 1052 and 1063 had internal storage tanks with an approximately 12gallon capacity. The storage temperature of these tanks was fixed by the manufacturer, and an internal mixing valve was used to reduce the DHW temperature. Both sites had consistent water delivery (interquartile ranges less than $5^{\circ} \mathrm{F}$ ). Average temperatures were $128^{\circ} \mathrm{F}$ at each site, which was greater than the $120^{\circ} \mathrm{F}$ design, meaning that occupants increased the water temperature set point. Twelve gallons of storage capacity yielded DHW performance similar to an SWH with 5- to 10-second ramp-up time (Figure 44). The combi boilers with internal storage had a range of steady-state temperatures of $10^{\circ} \mathrm{F}$.

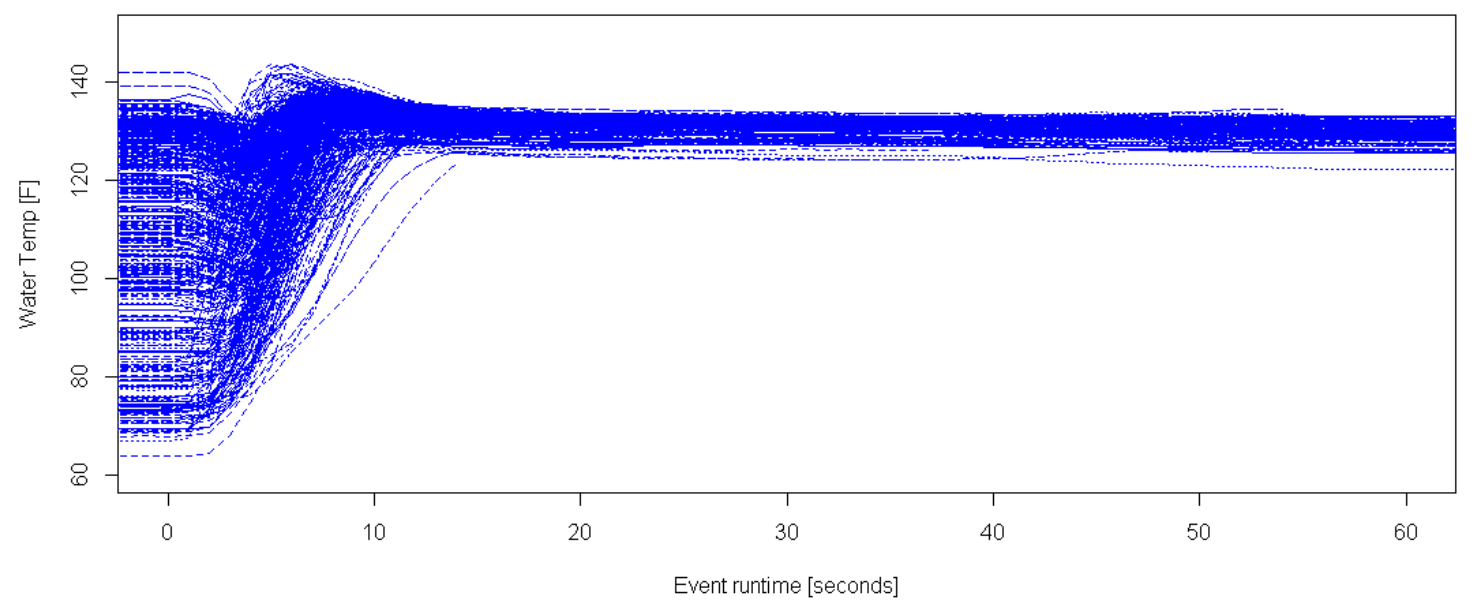

Figure 44. Time series plots of DHW temperatures after mixing valve of the boiler at Site 1063

The average delivered water temperatures show a significant difference between the low-mass boilers and boilers with internal storage. The low-mass boilers had an average delivered water temperature of $109^{\circ} \mathrm{F}$ (Figure 45) with a steady-state temperature of $120^{\circ} \mathrm{F}$. The boilers with 
storage capacity had an average delivered water temperature of $128^{\circ} \mathrm{F}$, with a steady-state temperature of $130^{\circ} \mathrm{F}$ (both occupants increased the set point temperature). The quick ramp-up time with storage capacity made the average temperature much closer to the steady-state temperature.

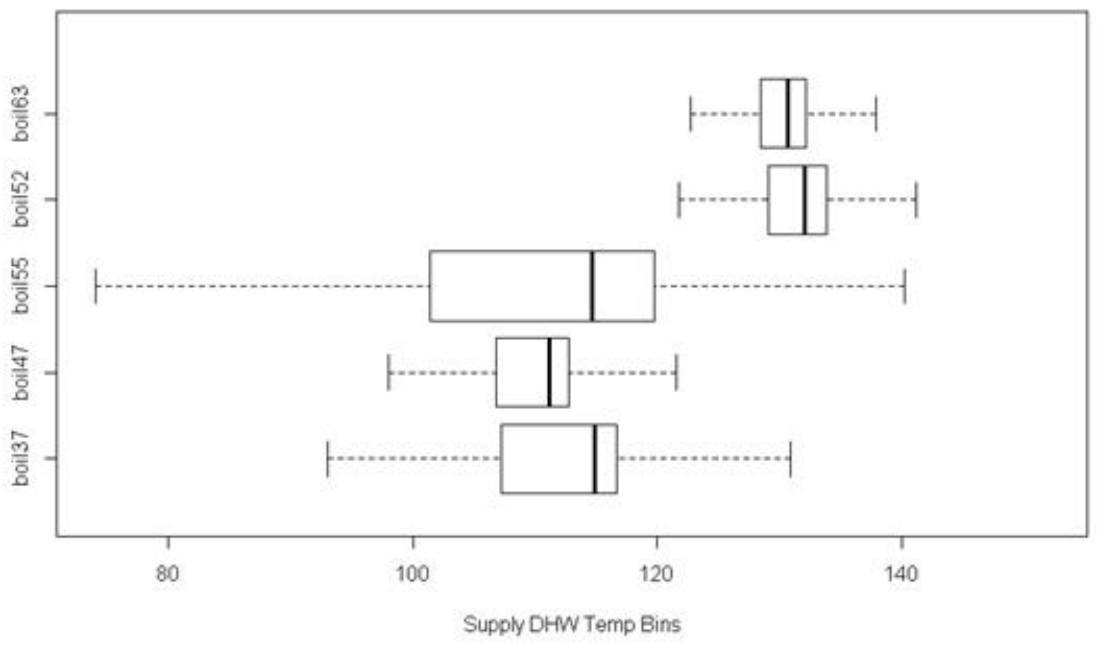

Figure 45. Delivered water temperatures for the boiler-based combi systems measured 6 inches after the mixing valve

For comparison, Figure 46 shows the delivery capability of a standard natural-draft SWH, a system that was monitored in a previous study (Schoenbauer, Hewett, and Bohac 2011). The ramp-up time was about 2 seconds. This installation did not require a mixing valve, reducing the ramp-up temperatures by a couple of seconds. The ramp-up time for this system was very similar to that of the storage-based combi system. This system has a wide range (about $30^{\circ} \mathrm{F}$ ) of steadystate water temperatures. This range of temperatures was much greater than any of the combi systems.

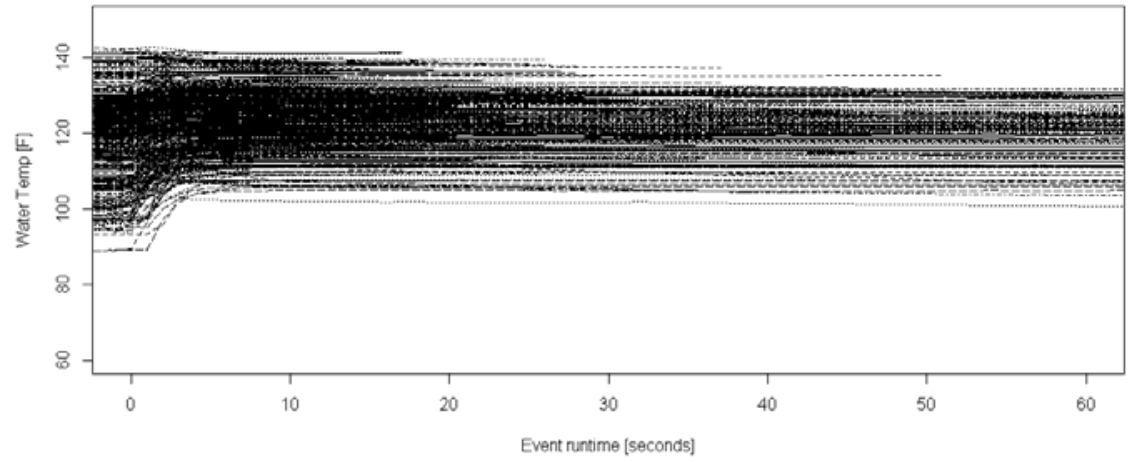

Figure 46. Time series plots for DHW temperatures at outlet of WH for an ND storage tank WH 


\section{Conclusions}

The field research conducted for this project has demonstrated that forced air natural gas combination systems can be used to provide high efficiency space and water heating for residential retrofits in a cold climate. These systems had acceptable occupant comfort and DHW capabilities. Combi systems provided on average a 19\% natural gas savings over ND forced air furnaces and ND SWHs (AFUE $\sim 80 \%$ and EF 58\%). Combination systems provided annual space heating at $85 \%-92 \%$ efficiency and improved domestic water heating efficiency at every site. Summer DHW efficiencies ranged from 35\%-90\% depending on water usage and system type. Several homes in the study had very low usage, resulting in storage tanks operating almost totally in standby mode.

Despite good savings and occupant comfort, two hurdles to widespread implementation were discovered. The technology has not matured enough to be cost competitive with condensing forced air furnaces that have almost complete penetration in cold climates. The second hurdle was the dependence on a proper installation to ensure good performance. The systems installed for this project were supported by a large laboratory research project. Knowledge from that project was used to inform the installation and setup the operating parameters of these systems. Without careful attention to detail in these areas, systems would not be able to perform to the levels measured in this report. 


\section{Future Work}

Future work will build on the results from this research showing that combi systems utilizing condensing WHs and boilers can provide both space and water heating with efficiencies of $90 \%$. However, combi systems, using condensing equipment, are still relatively new to the market and both end users and contractors are not familiar with their installation and performance. Future work will concentrate on system control options to improve ease of installation and use, reduce on-site design and engineering, improve system efficiency, and increase system capacity.

Monitoring results have highlighted areas for potential improvement. A preliminary list of control measures to evaluate in the laboratory includes temperature set point control (outdoor reset, turn down after heating season), space heating modulation (both water flow and airflow) and DHW priority.

The set point temperature reset varied by outdoor air control method and has been widely used for both commercial and residential boilers. This control method has potential benefits for combi systems as well. Past projects have required WHs be kept constant at $140^{\circ} \mathrm{F}$ to meet design space heating loads. Reducing the set point temperature to $130^{\circ} \mathrm{F}$ or below in the shoulder heating season and summer would increase the thermal efficiency of all the combi appliances and it would reduce the standby losses of SWHs. Initial laboratory testing showed an increase in efficiency for one condensing SWH from $86 \%$ to $93 \%$ with a $10^{\circ} \mathrm{F}$ reduction in the setback temperatures. These effects combine to create estimates 50 therms/year savings for a very simple outdoor reset control. These types of controls can increase performance, save energy, and improve the sizing and design process. Detailed laboratory and field testing is needed to determine the best control options and the impacts on the occupants. Laboratory testing will be used to determine the balance point between efficiency tradeoffs and reductions in runtime that can lead to short cycling.

Controlling air and water flow modulation would also improve combi systems. Current equipment requires air and water flow, which can only be manually modulated and typically remains fixed through the product's lifetime. Full modulation or multiple step modulation would allow the combi to operate at different optimized output rates depending on demand. There are several potential benefits from this approach:

- Lower output rates will increase run times, reducing the impacts of short-cycling, and improving comfort.

- Preliminary laboratory testing indicates that lower output rates may yield lower temperatures of return water, improving efficiency.

- Multiple firing rates can result in downsizing equipment. Large air coils are required to achieve high efficiency at peak loads. However, if a combi system with a smaller coil were optimized for less than peak load with flow modulation, it could be ramped up to peak load at a slightly lower efficiency. Because most hours of operation for a space heating system occur well below the design load, the system would operate at max efficiency for more hours with a small reduction in efficiency for the few hours at peak design loads. 
- This process would also reduce some of the site-specific optimization and engineering. Modulation control would allow the combi system to change the output based on the home's need, thus reducing the dependence on optimizing for the specific conditions of the home. 


\section{References}

Bohac, D.; Hancock, M.; Dunsworth, T.; Makredes,S. (1995). Energy Savings and Field Experiences with Dual Integrated Appliances. Proceedings paper. Minneapolis, MN: Center for Energy and Environment, August 1, 1995. http://aceee.org/proceedingspaper/ss94/panel03/paper02.

Bohac, D.L. (2002). "Results from House Air Leakage and Appliance Safety Tests Conducted on Single Family Houses Undergoing Sound Insulation.” In Santa Cruz, CA.

Bohac, D.L.; Cheple, M. (2002). "Ventilation and Depressurization Information for Houses Undergoing Remodeling.” DE-FG45-96R530335. St. Paul, MN: Minnesota Department of Commerce. http://doa.wi.gov/docview.asp?docid=2235\&locid=0.

Burch, J.; Christensen, C. (2007). "Towards Development of an Algorithm for Mains Water Temperature". Golden, CO: National Renewable Energy Laboratory. http:/www.energystar.gov/ia/partners/prod_development/new_specs/downloads/water_heaters/ AlgorithmForMainsWaterTemperature.pdf.

Butcher, T.; Arena, L. (2011). "The DHW Performance of Heating Boilers" presented at the ACEEE Hot Water Forum, May 11, Berkeley, CA. www.aceee.org/files/pdf/conferences/hwf/2011/7A\%20-\%20Tom\%20Butcher.pdf.

Comstock, O. (2013). “Gas Furnace Efficiency Has Large Implications for Residential Natural Gas Use.” U.S. Energy Information Administration. Today in Energy. www.eia.gov/todayinenergy/detail.cfm?id=14051.

Natural Resources Canada. (2009). "Air Source Heat Pumps." Office of Energy Efficiency. http://oee.nrcan.gc.ca/publications/residential/heating-heat-pump/4608.

Rudd, A. (2012). "Measure Guideline: Combination Forced-Air Space and Tankless Domestic Hot Water Heating Systems.” Washington, D.C.: Building America.

http://apps1.eere.energy.gov/buildings/publications/pdfs/building_america/measure_guide_comb i_systems.pdf $\% 20$.

Schoenbauer, B.; Bohac, D.; Hewett, M. (2012a). "Measured Residential Hot Water End Uses.” ASHRAE Transactions 119 (Part 1).

Schoenbauer, B.; Bohac, D.; Huelman, P.; Olsen, R.; Hewett, M. (2012b). Retrofitting Combined Space and Water Heating Systems: Laboratory Tests. Golden, CO: National Renewable Energy Laboratory. www.nrel.gov/docs/fy13osti/55482.pdf. Accessed February 2014.

Schoenbauer, B.; Hewett, M.; Bohac, D. (2011). “Actual Savings and Performance of Natural Gas Instantaneous Water Heaters.” ASHRAE Transactions 117 (Part 1): 657-672. 
Steven Winter Associates, Inc. Building America Systems Evaluations: In-Field Performance of Condensing Boilers in Cold Climate Region. Downloaded March 2012 from: http://carbswa.com/articles/advanced\%20systems\%20research/Condensing\%20Boiler\%20Final\%20Report. pdf.

Thomas, M.; Hayden, A.C.S.; Entchev, E.; Mackenzie, D.; Glouchkow, J.; Gusdorf, J.; Szadkowski, F.; Sager, J.; Swinton, M.; Armstrong, M.; Edwards, P.; Tikiryan, H. (2011). Combination Systems Good or Bad? presented at the ACEEE Water Heating Forum 2011, May 10, Berkeley, CA. www.aceee.org/files/pdf/conferences/hwf/2011/7A\%20\%20Martin\%20Thomas.pdf. Accessed February 2014. 


\section{Appendix A}

Daily average relationships for each field monitoring site. The layout of each page is shown below.

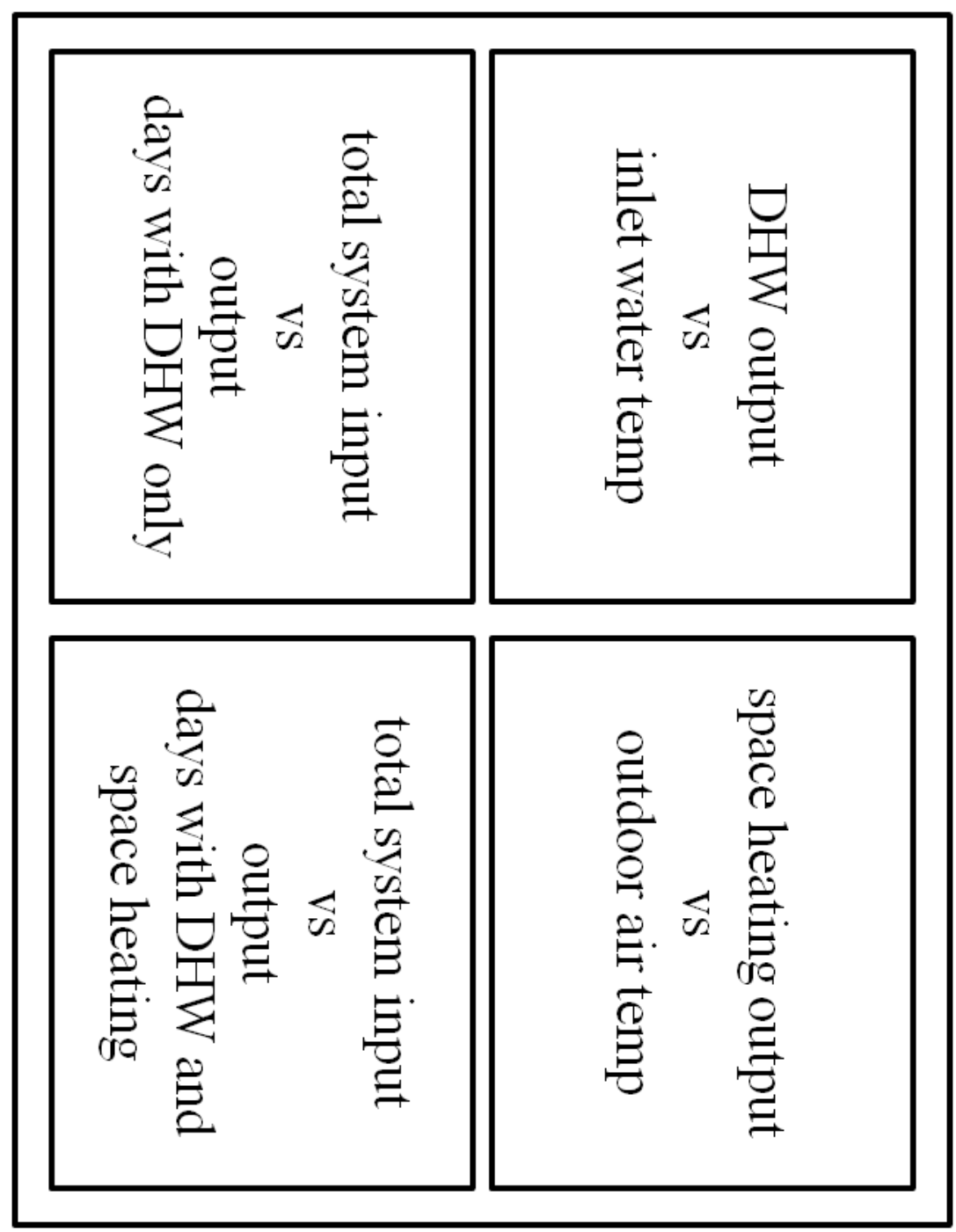



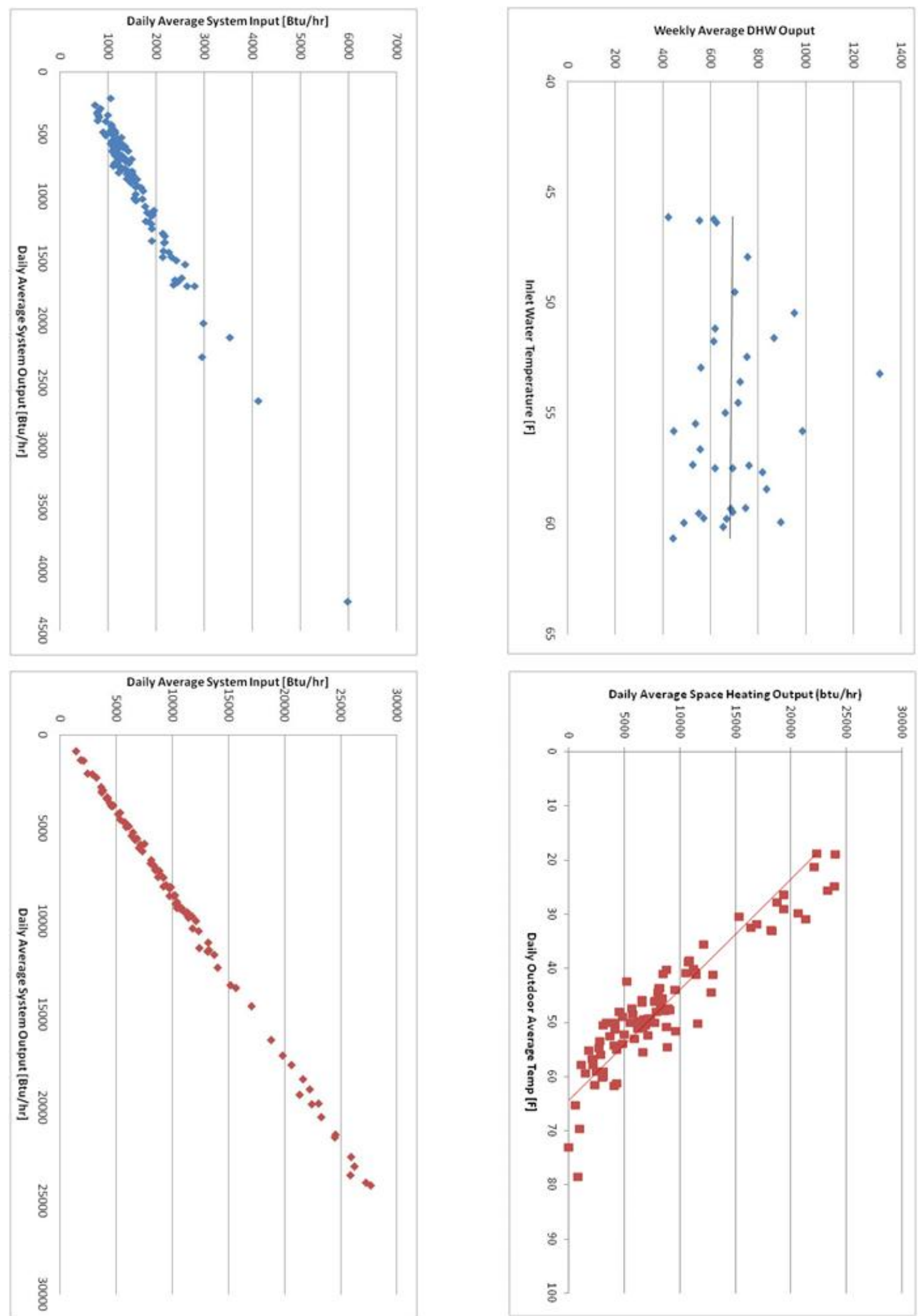

Site $\mathbf{1 0 2 6}$ 

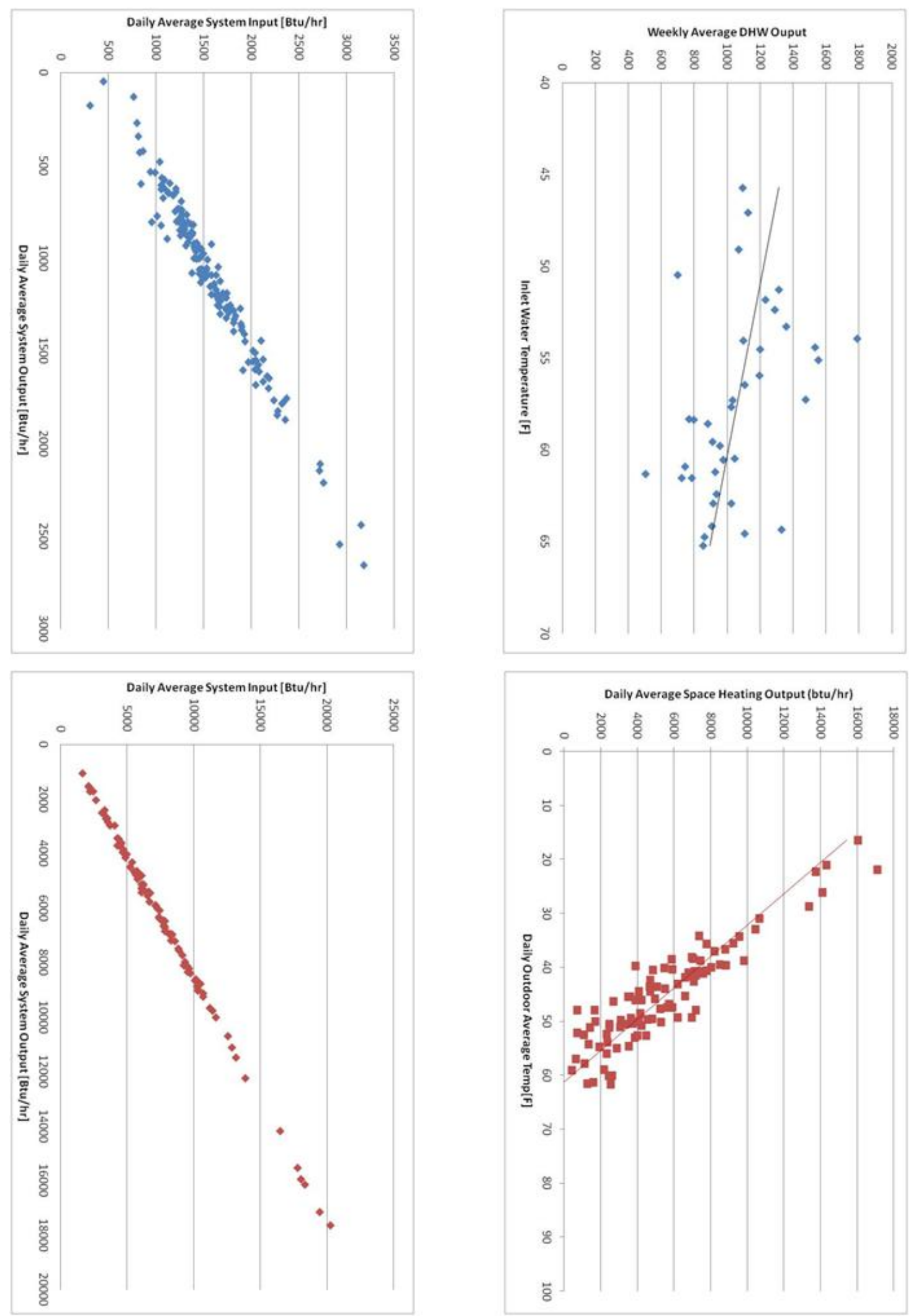

Site 1027 

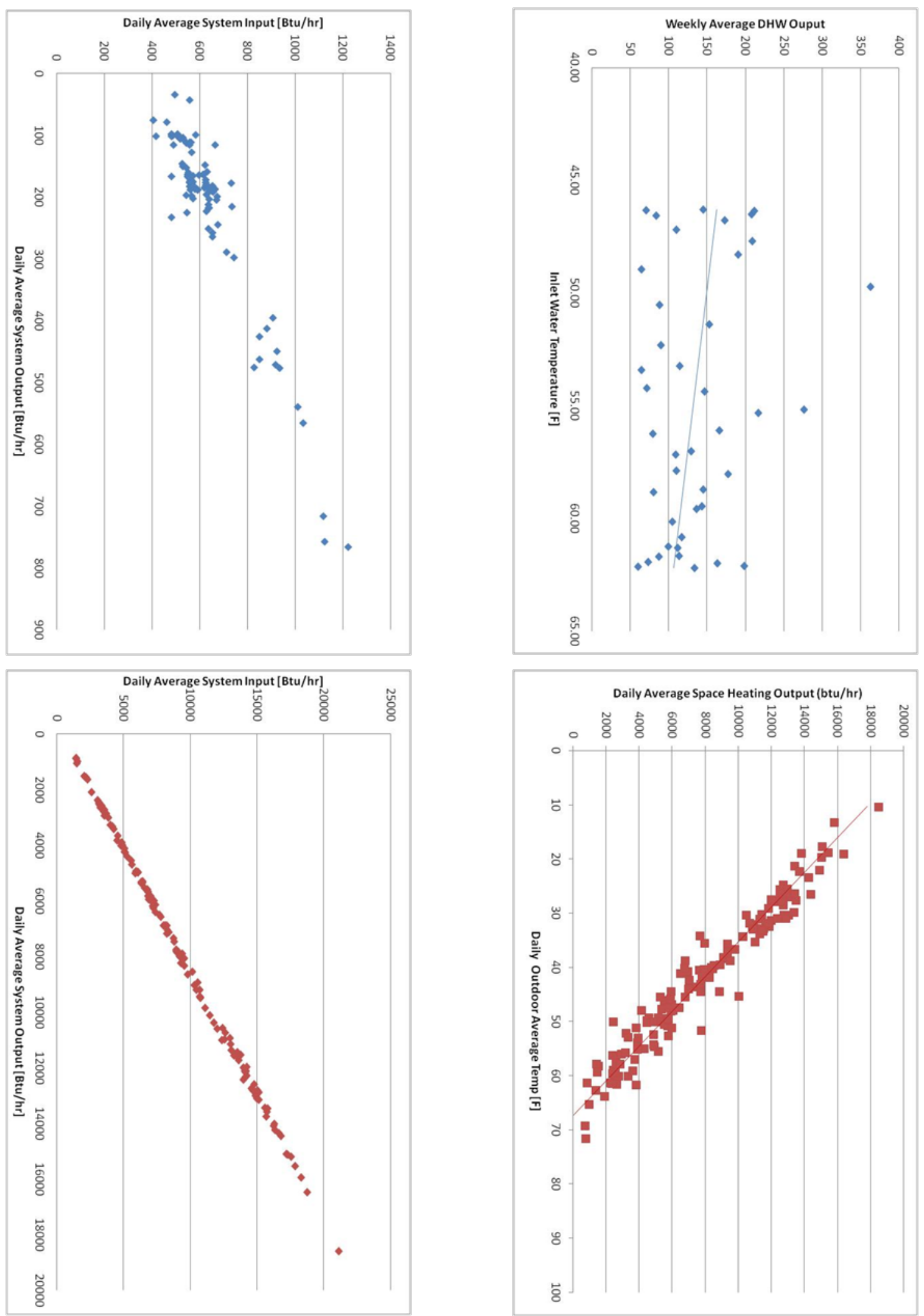

Site 1028 

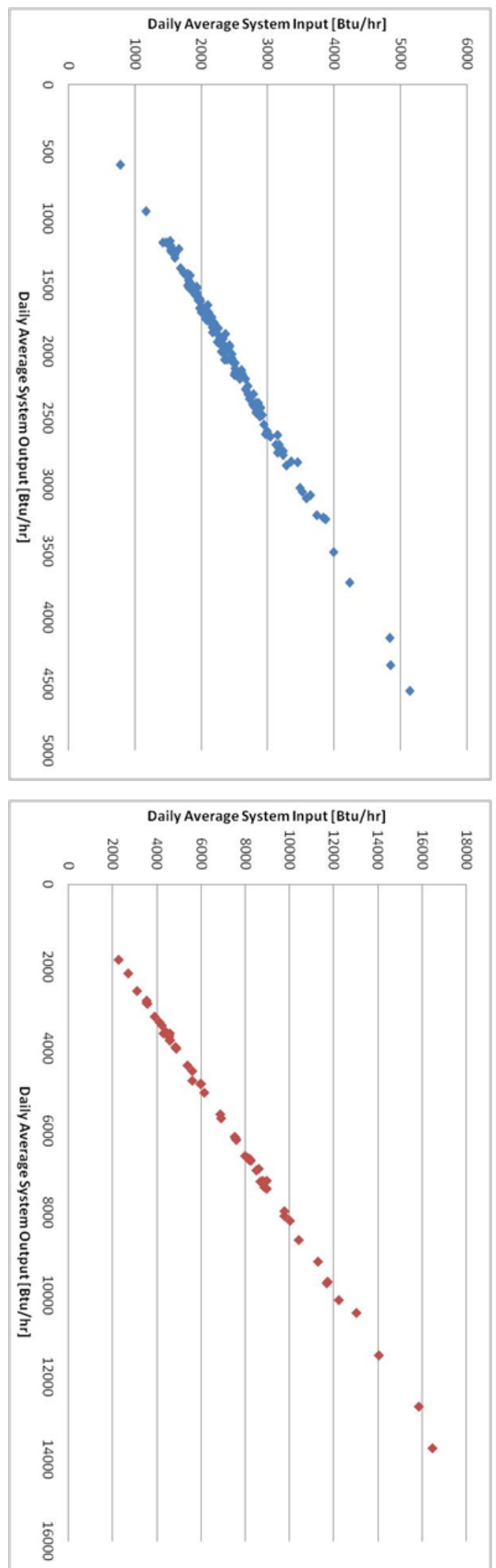
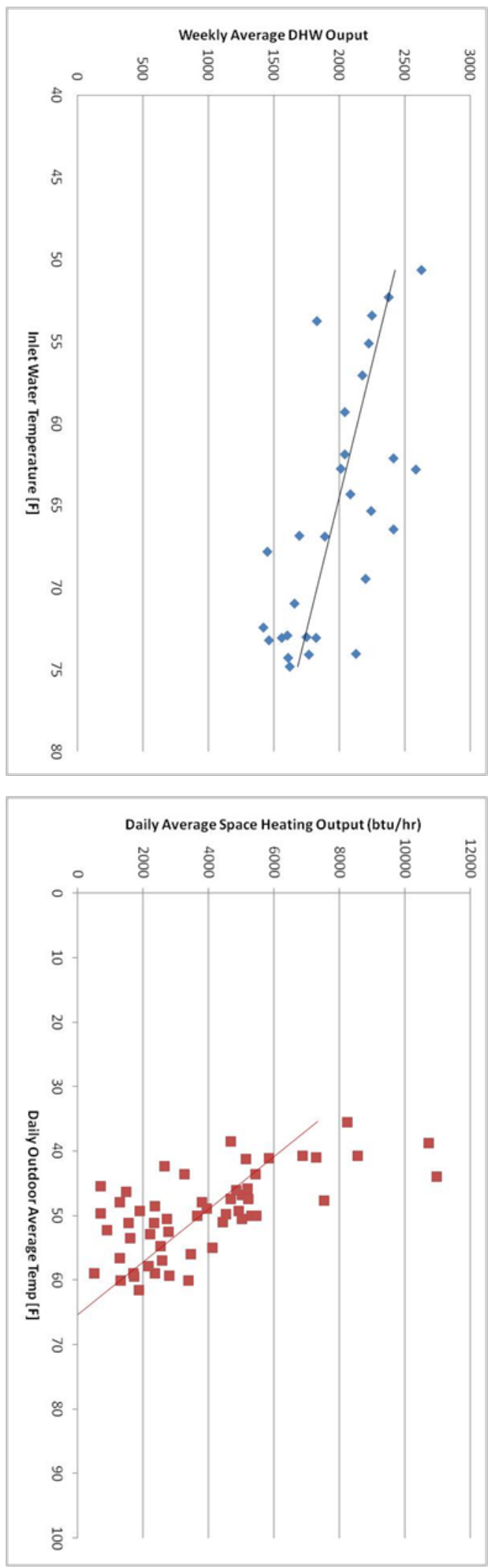

Site 1030 

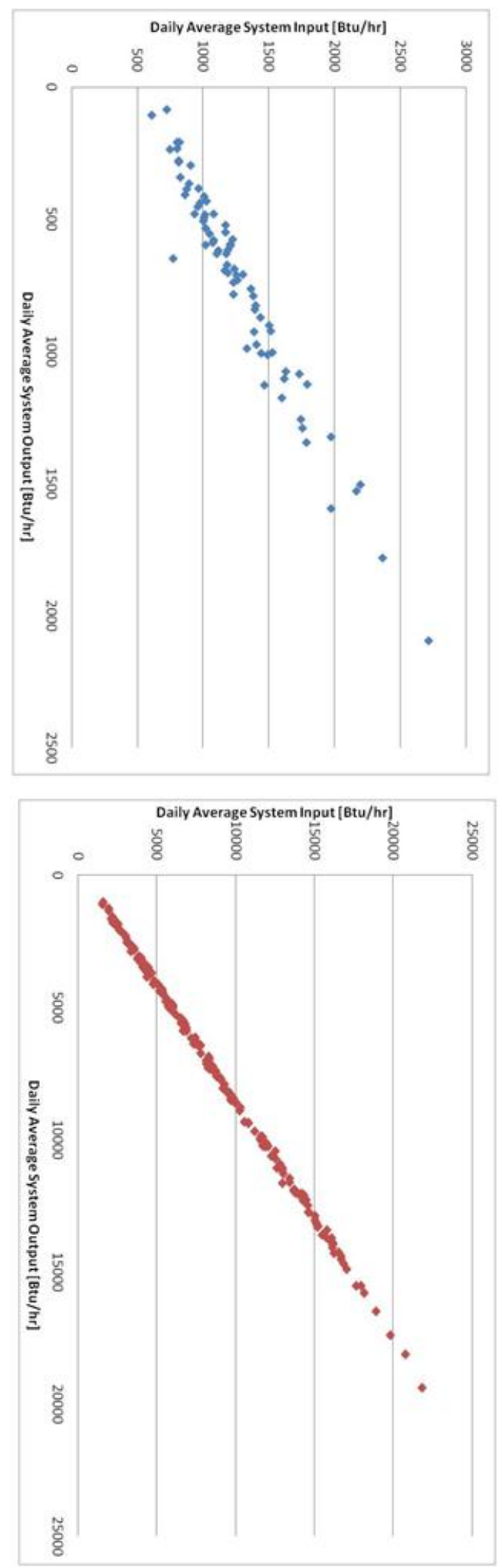
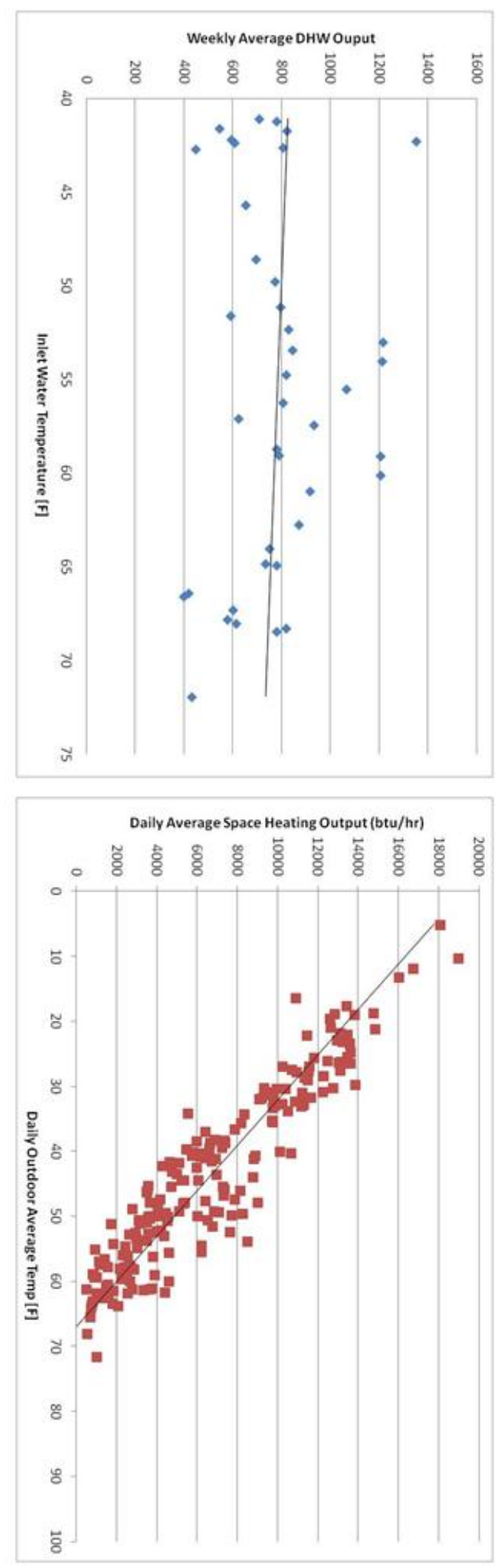

Site 1031 

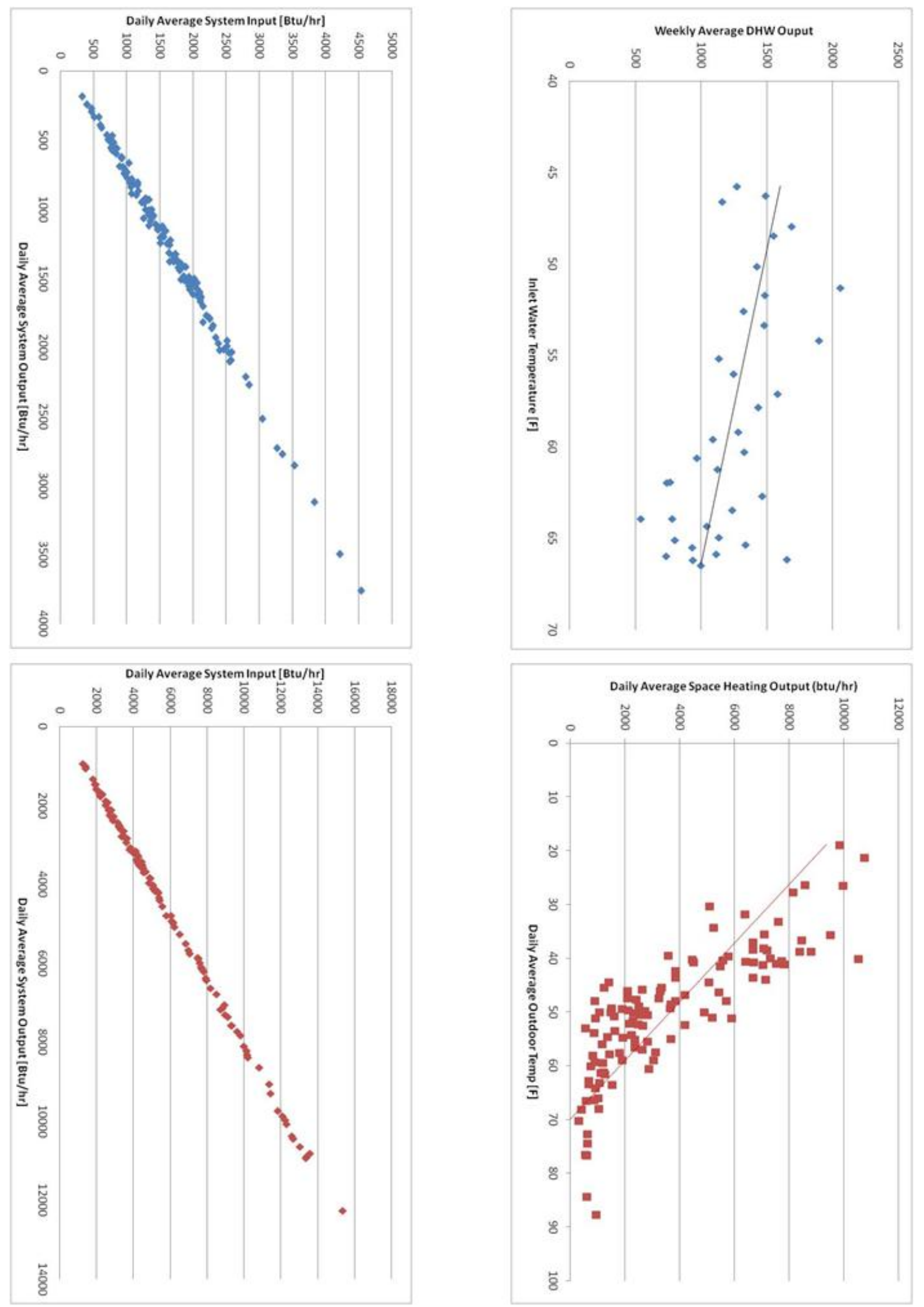

Site 1037 

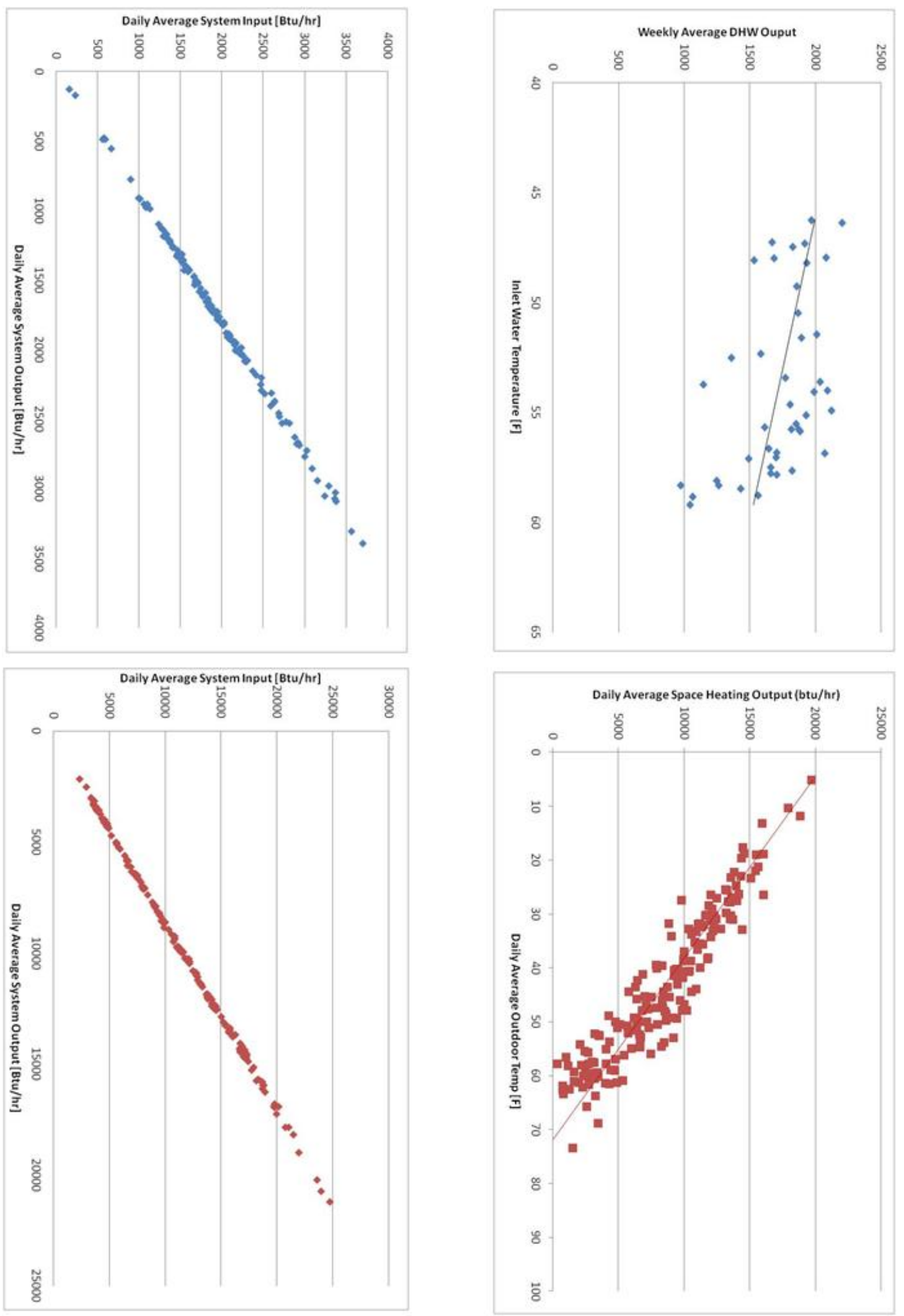

Site 1045 

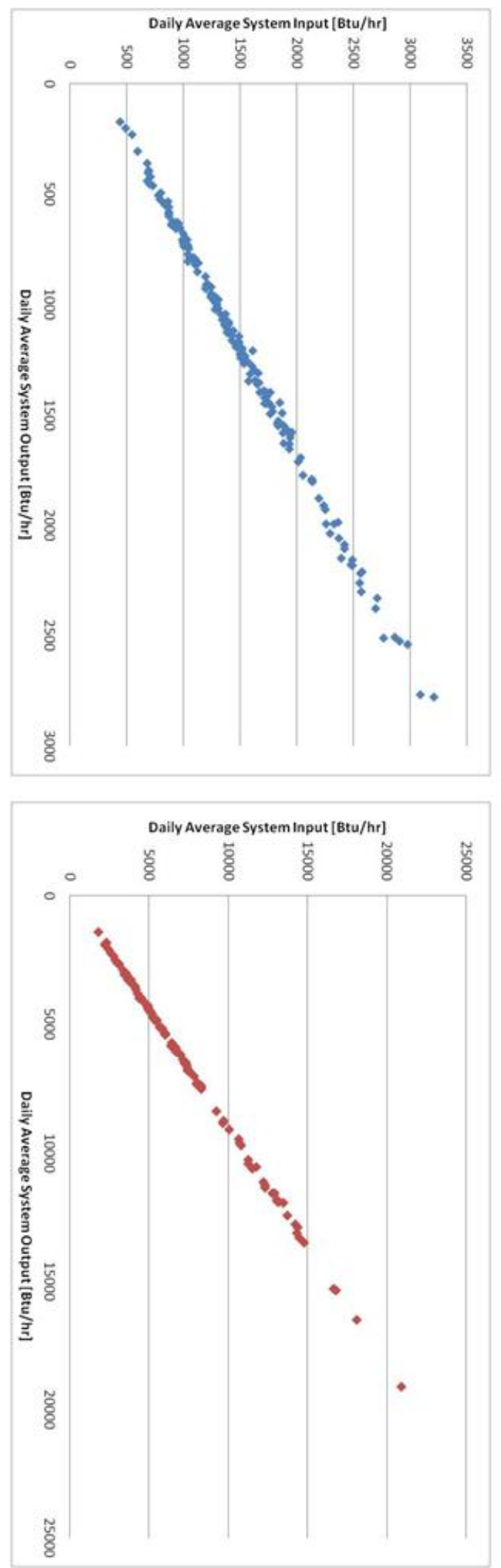
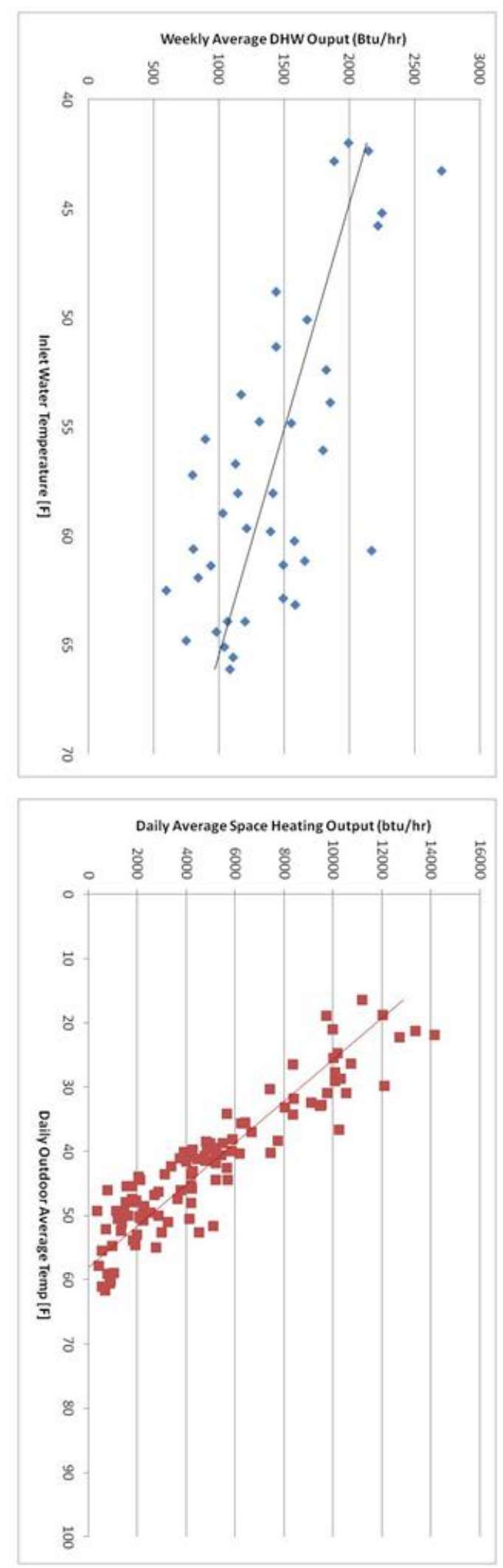

Site 1049 

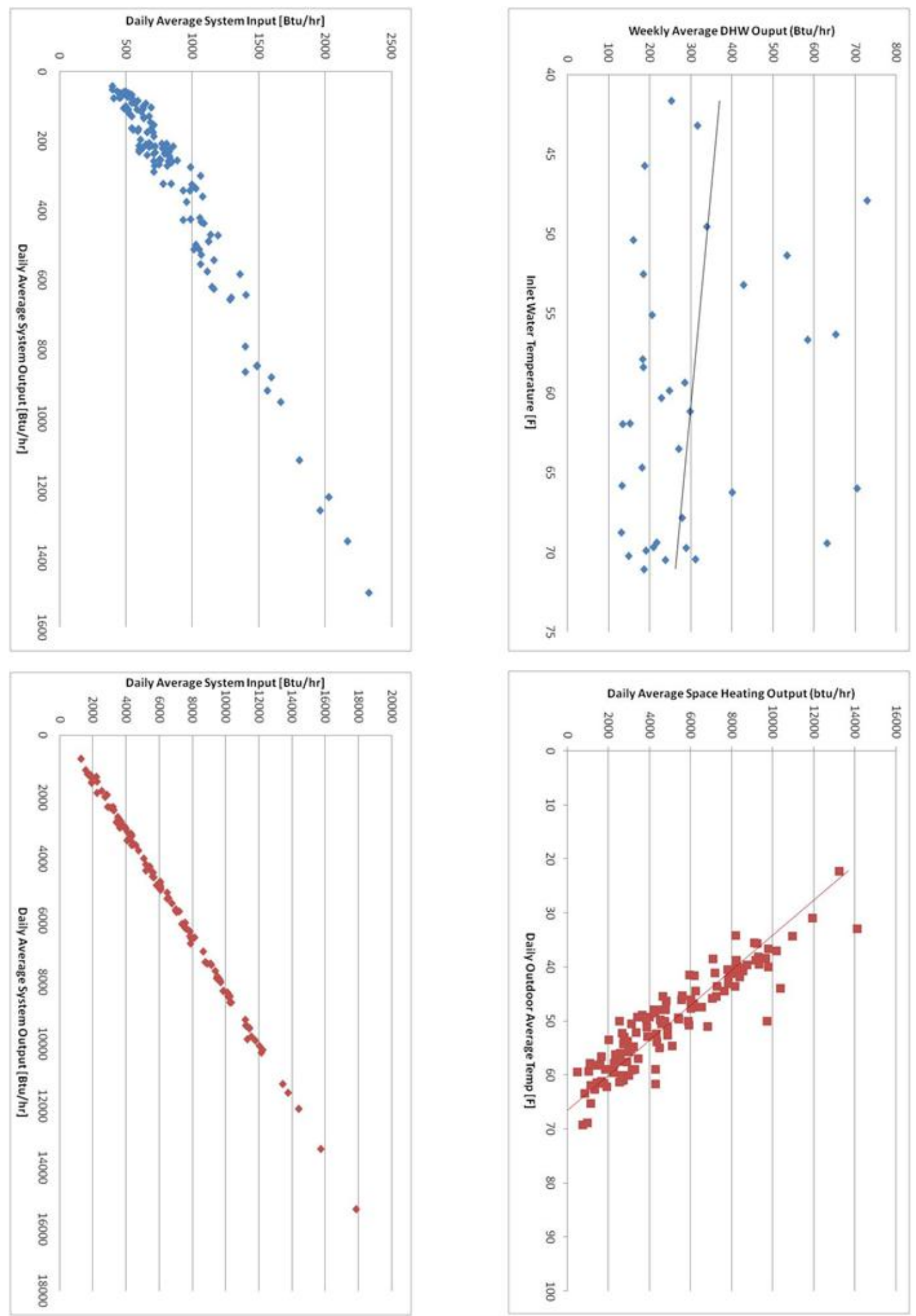

Site 1052 

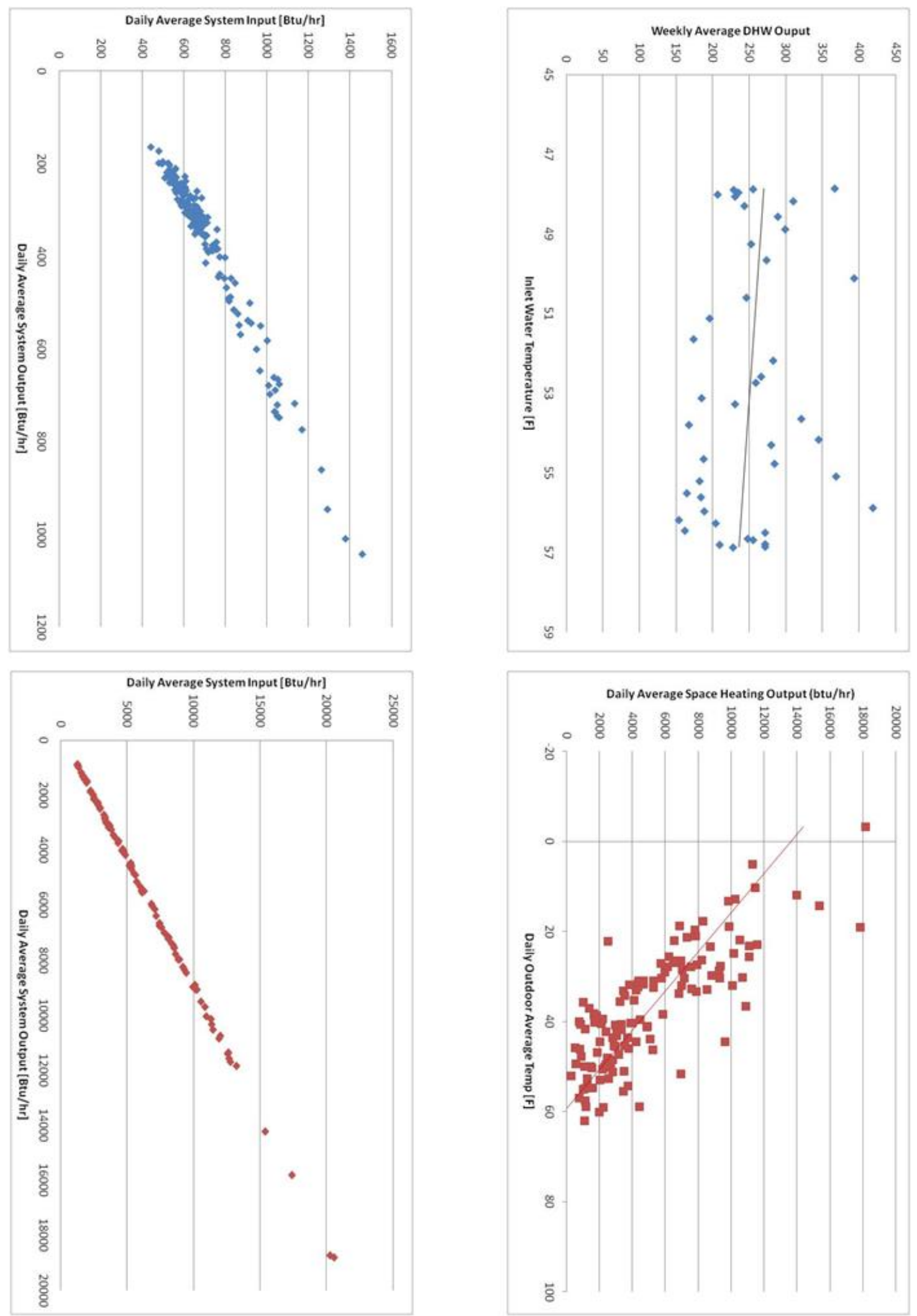

Site 1054 

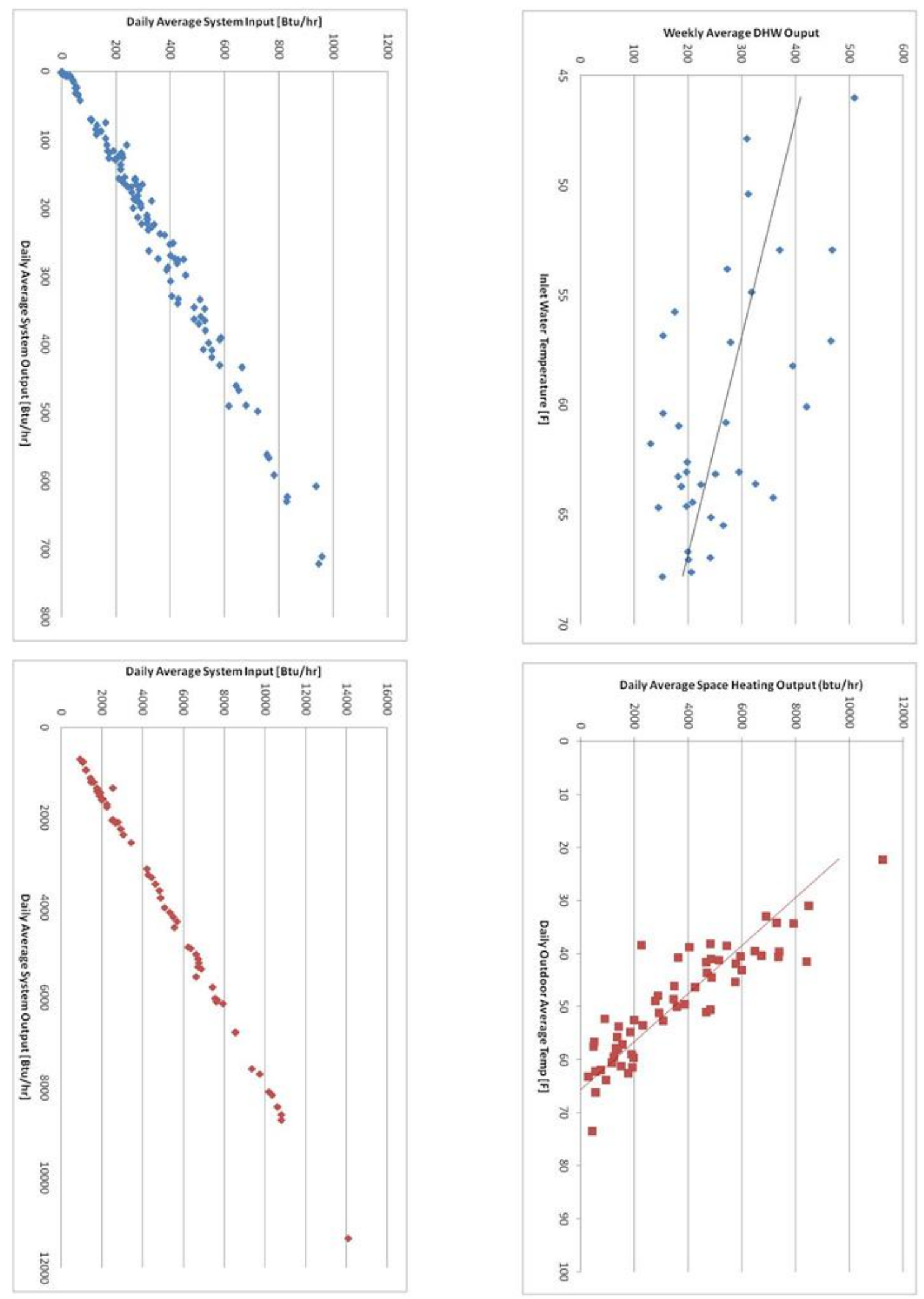

Site $\mathbf{1 0 5 5}$ 

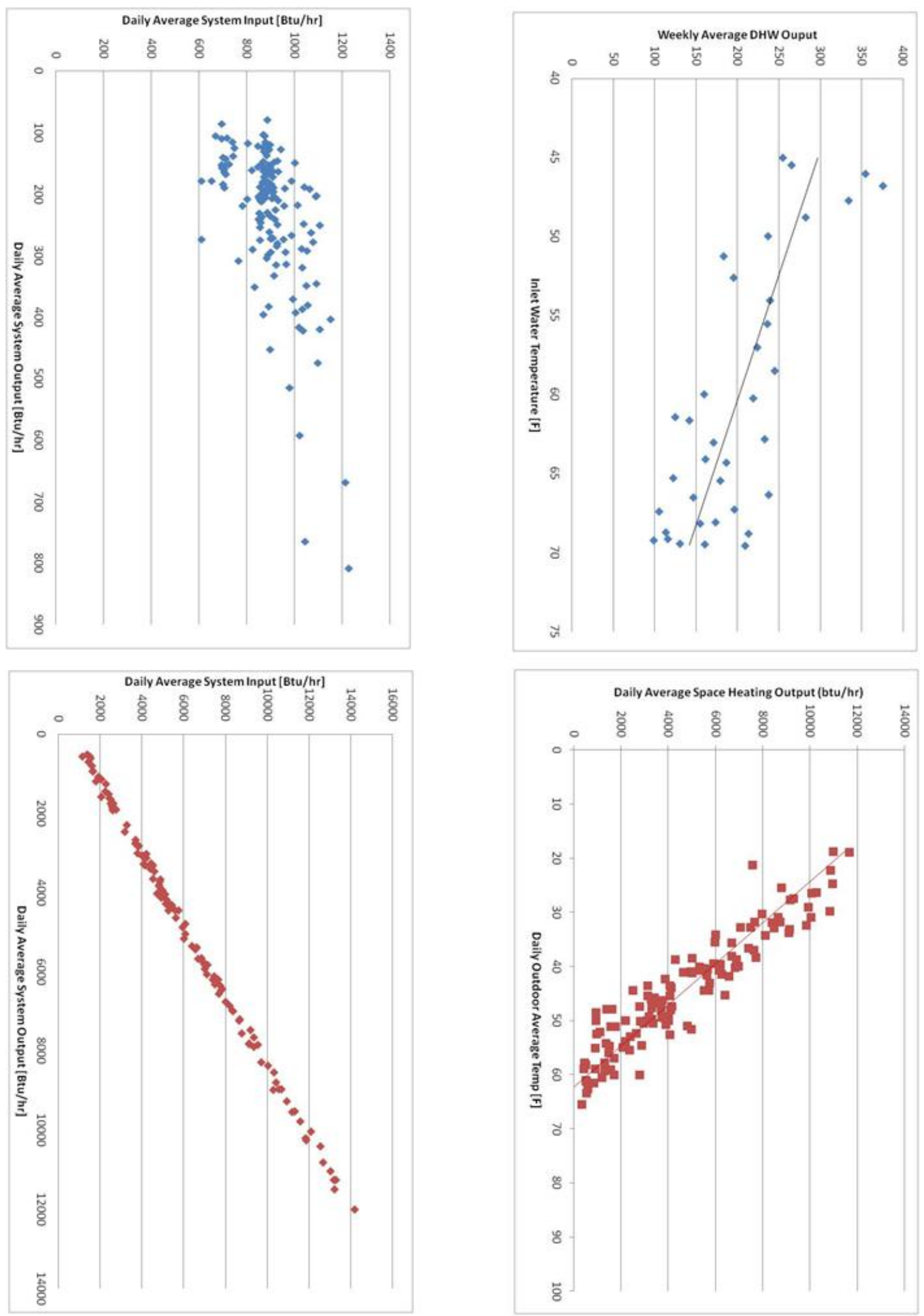

Site $\mathbf{1 0 5 6}$ 

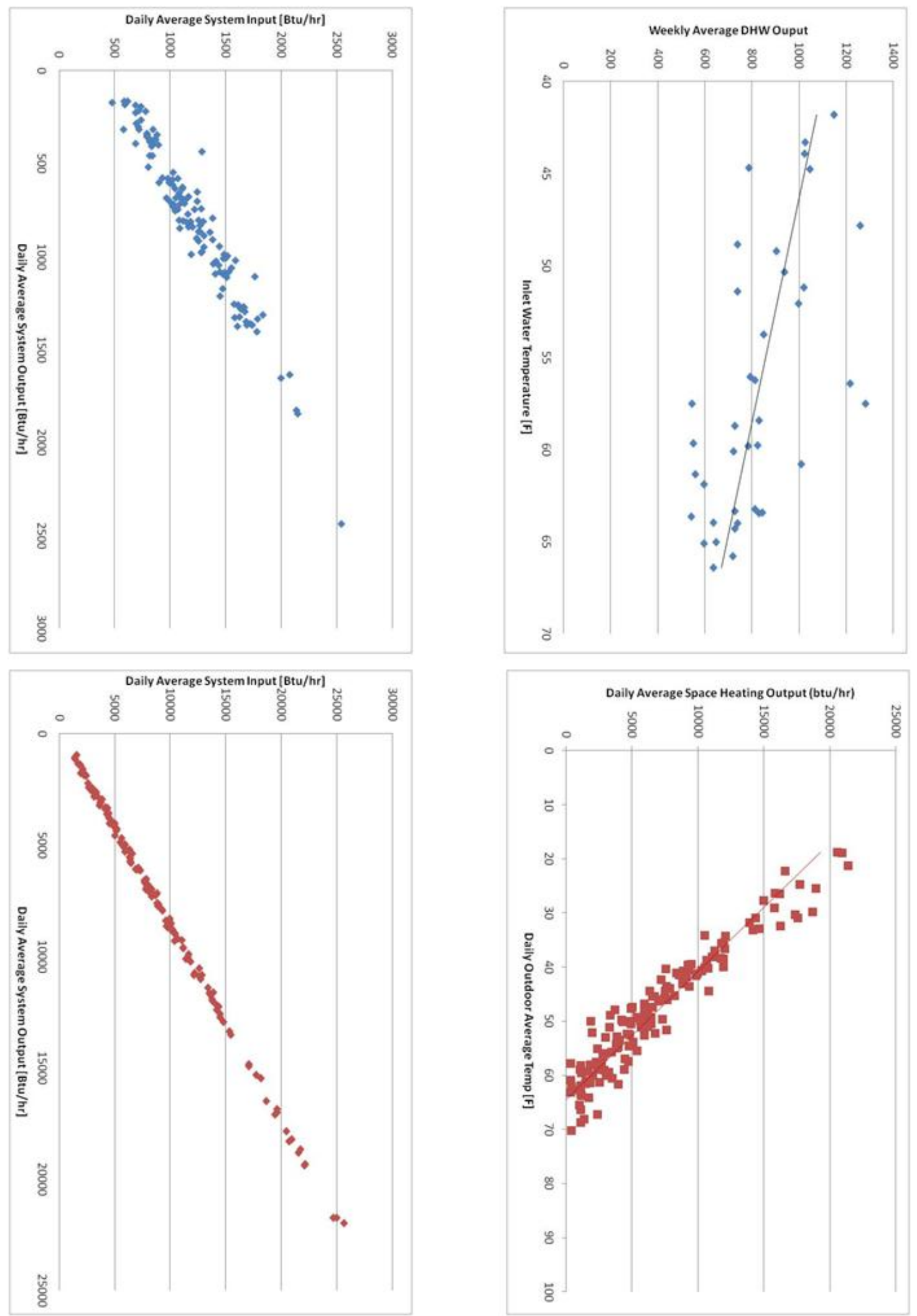

Site 1061 

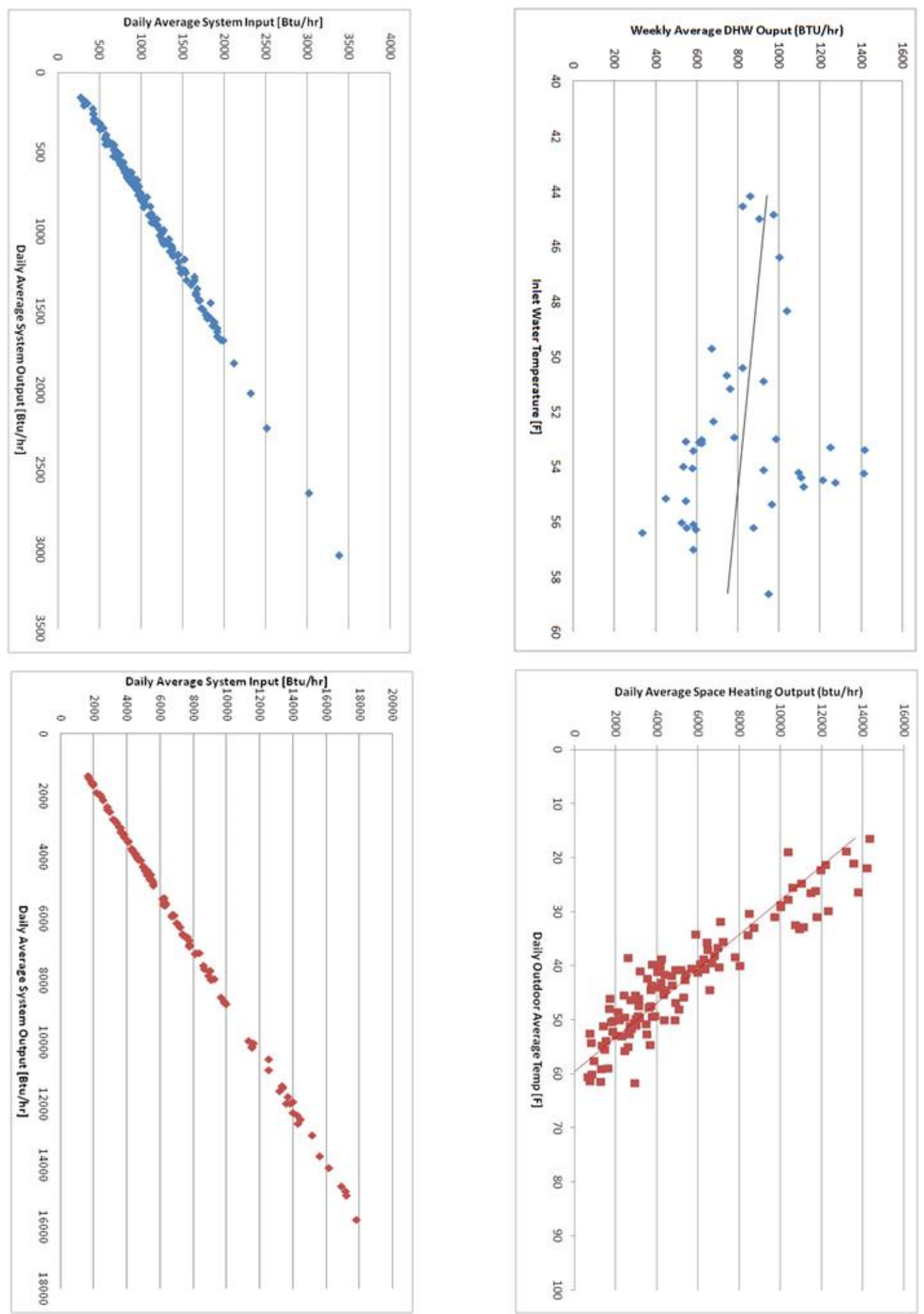

Site 1062 

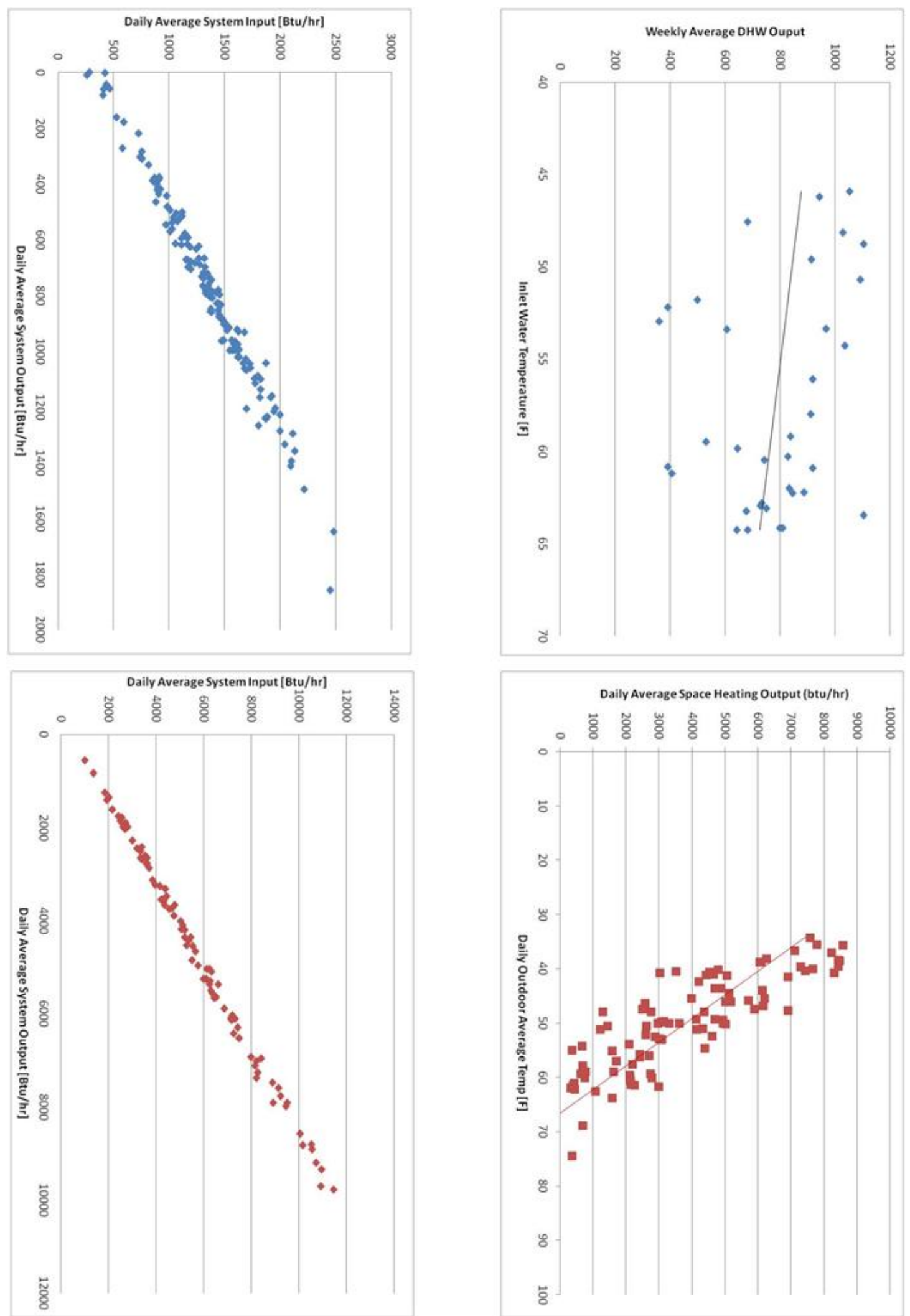

Site 1063 

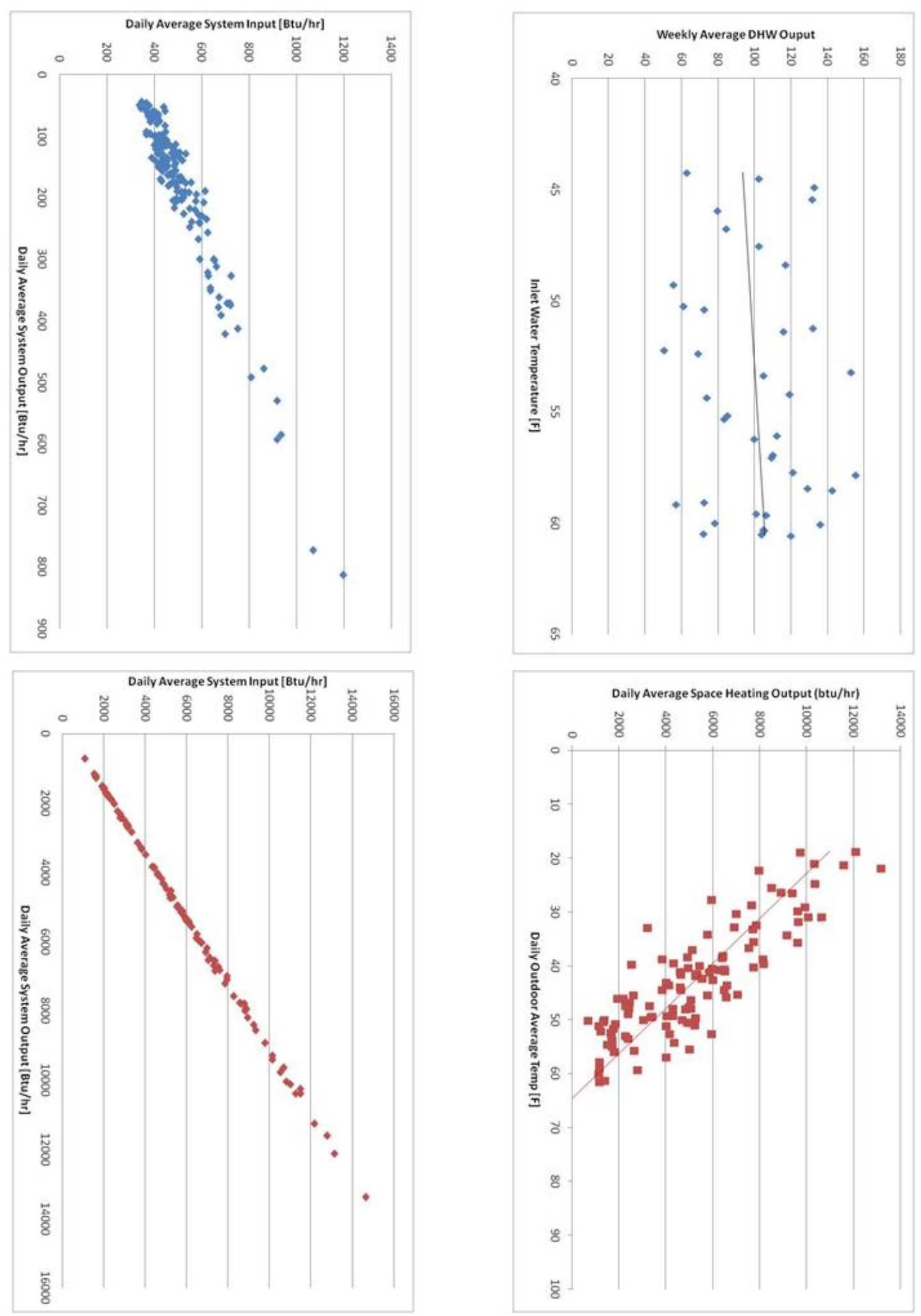

Site 1070 

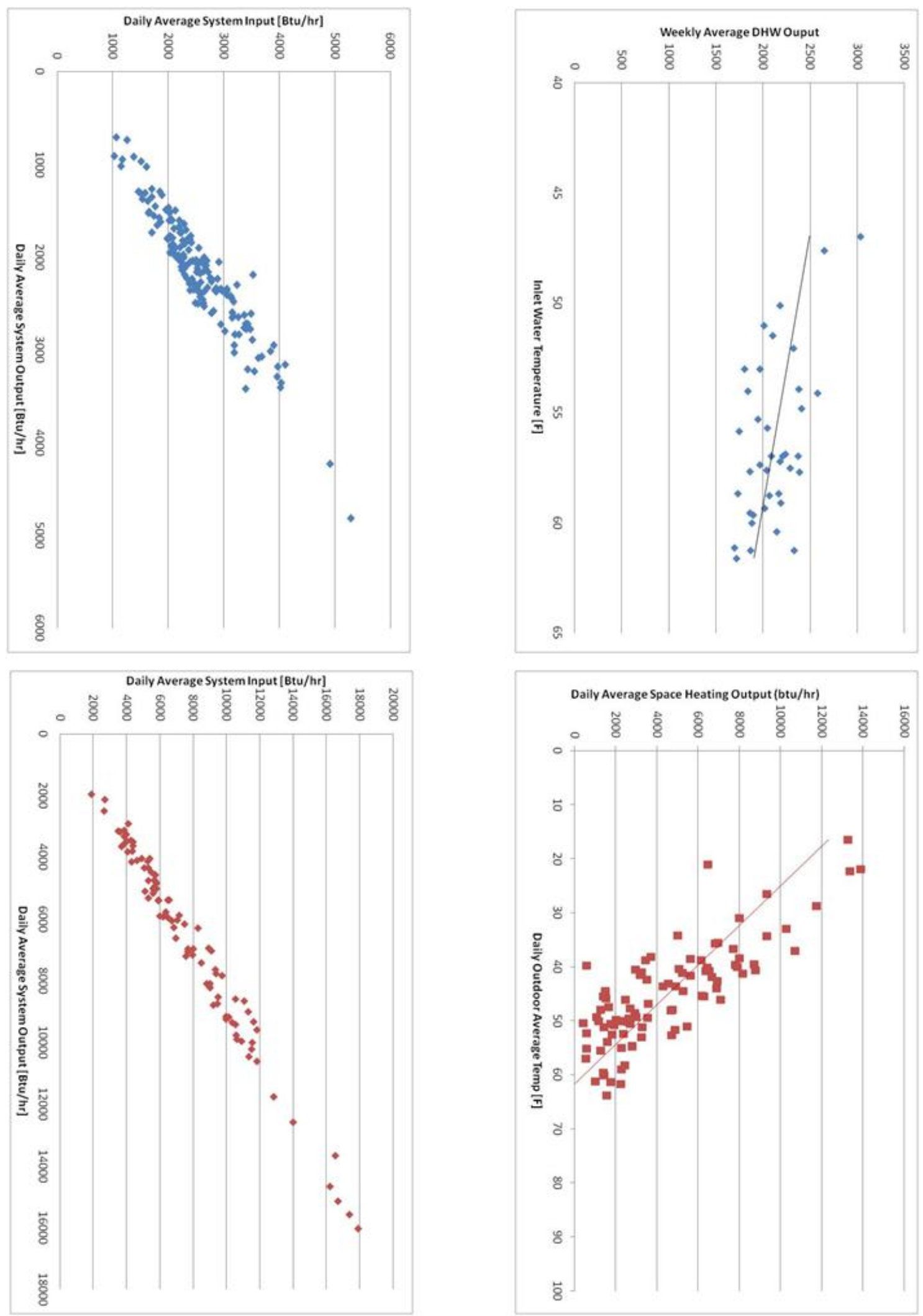

Site 1078 


\section{Appendix B}

Appendix B contains figures showing the relationships between daily natural gas usage for space heating and the average OAT.
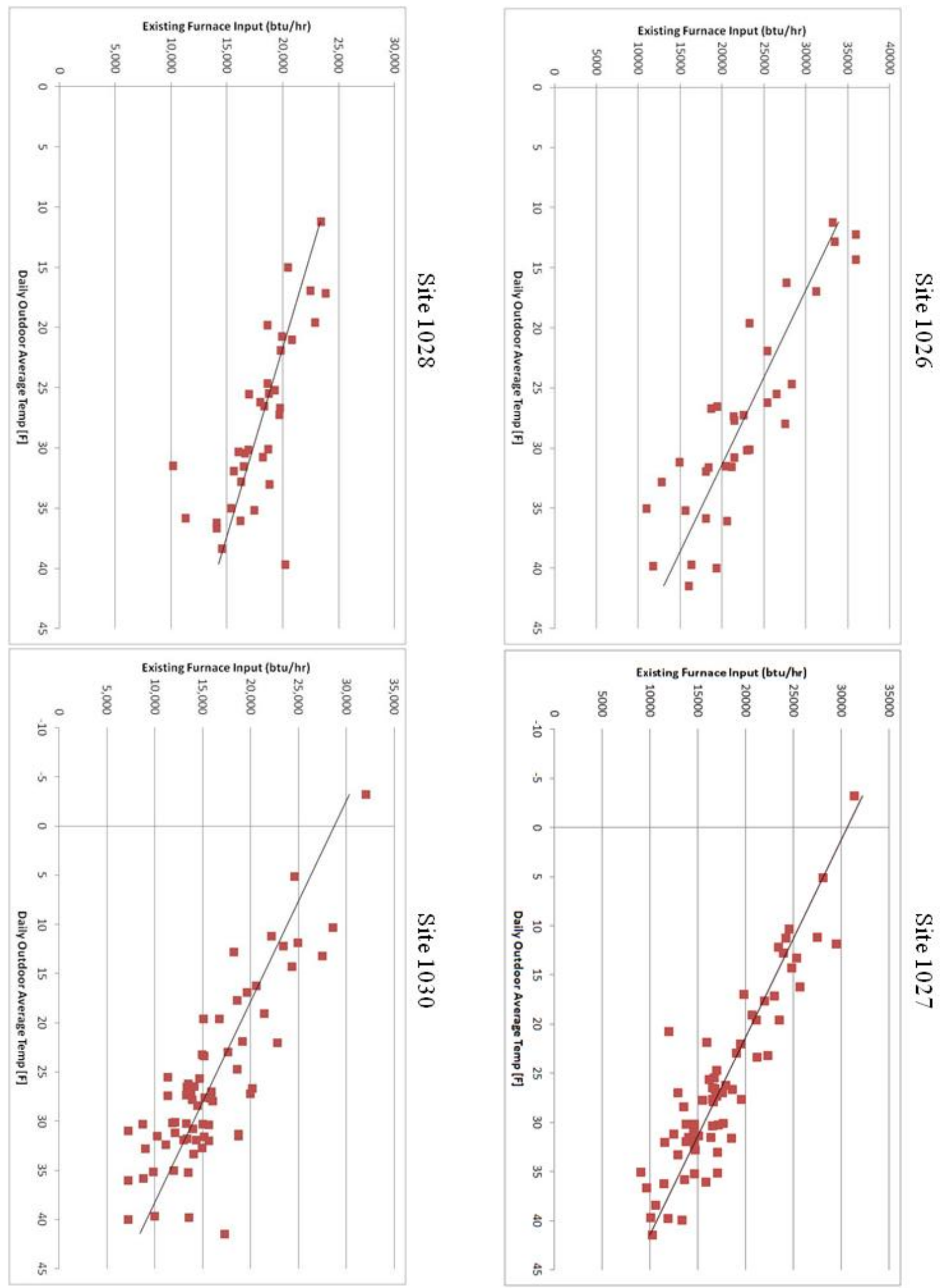

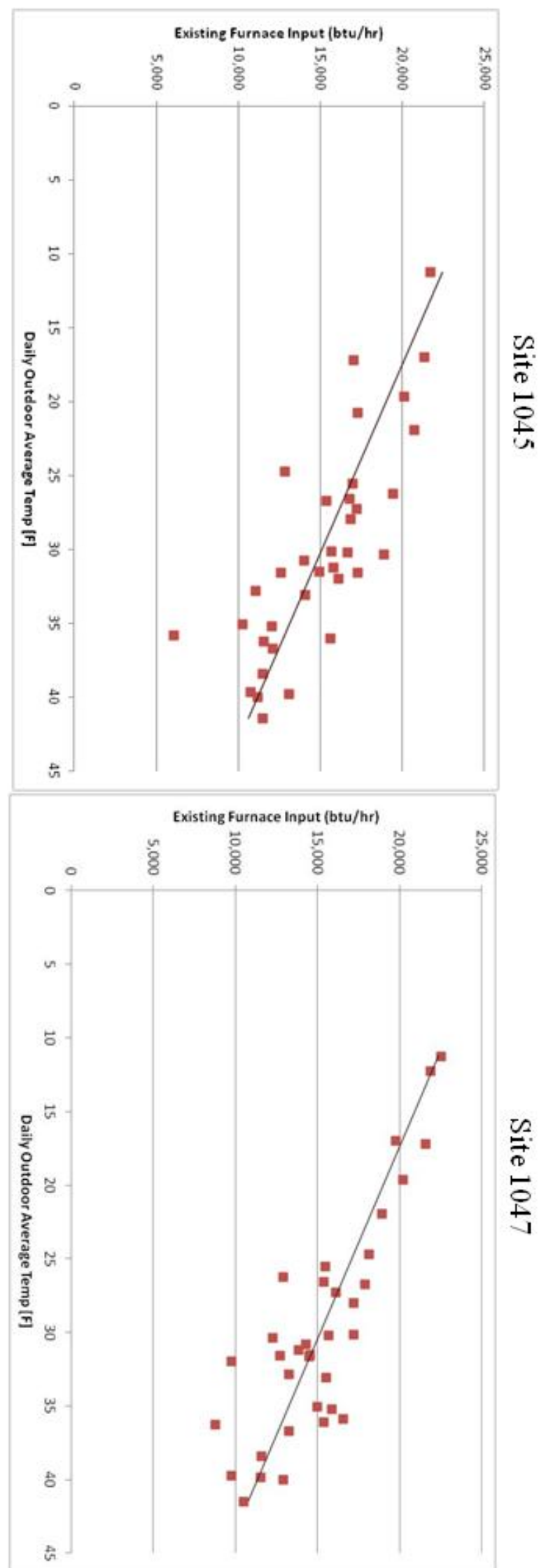
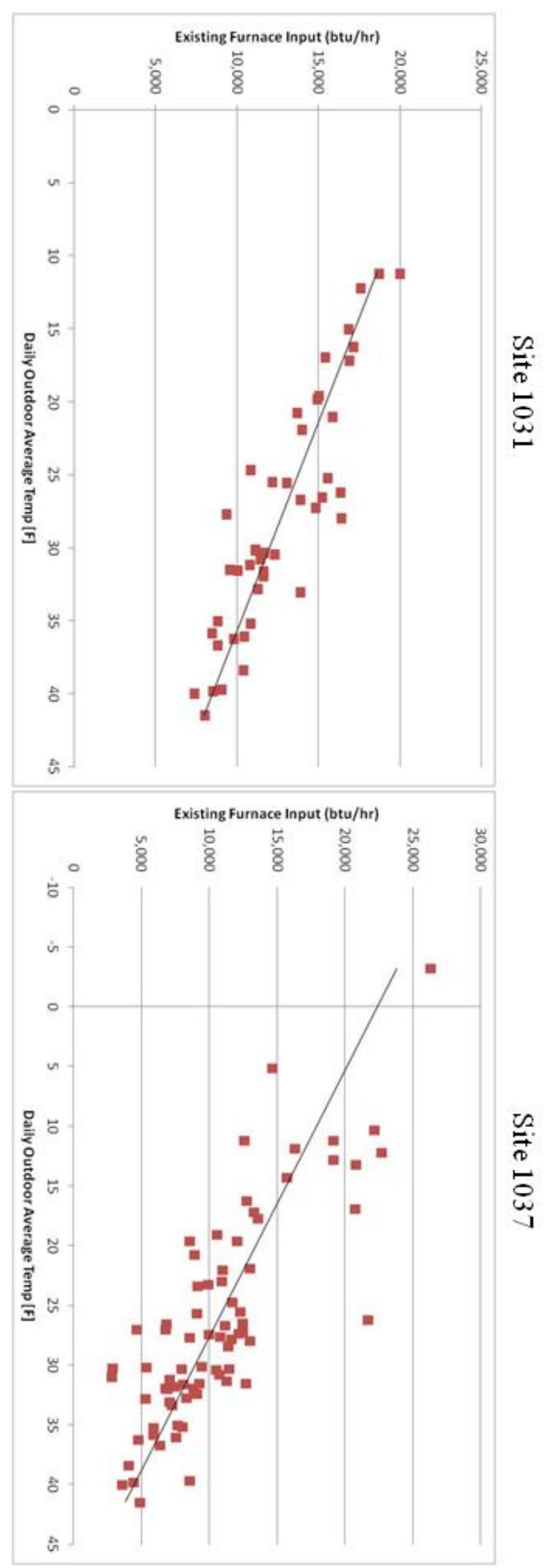

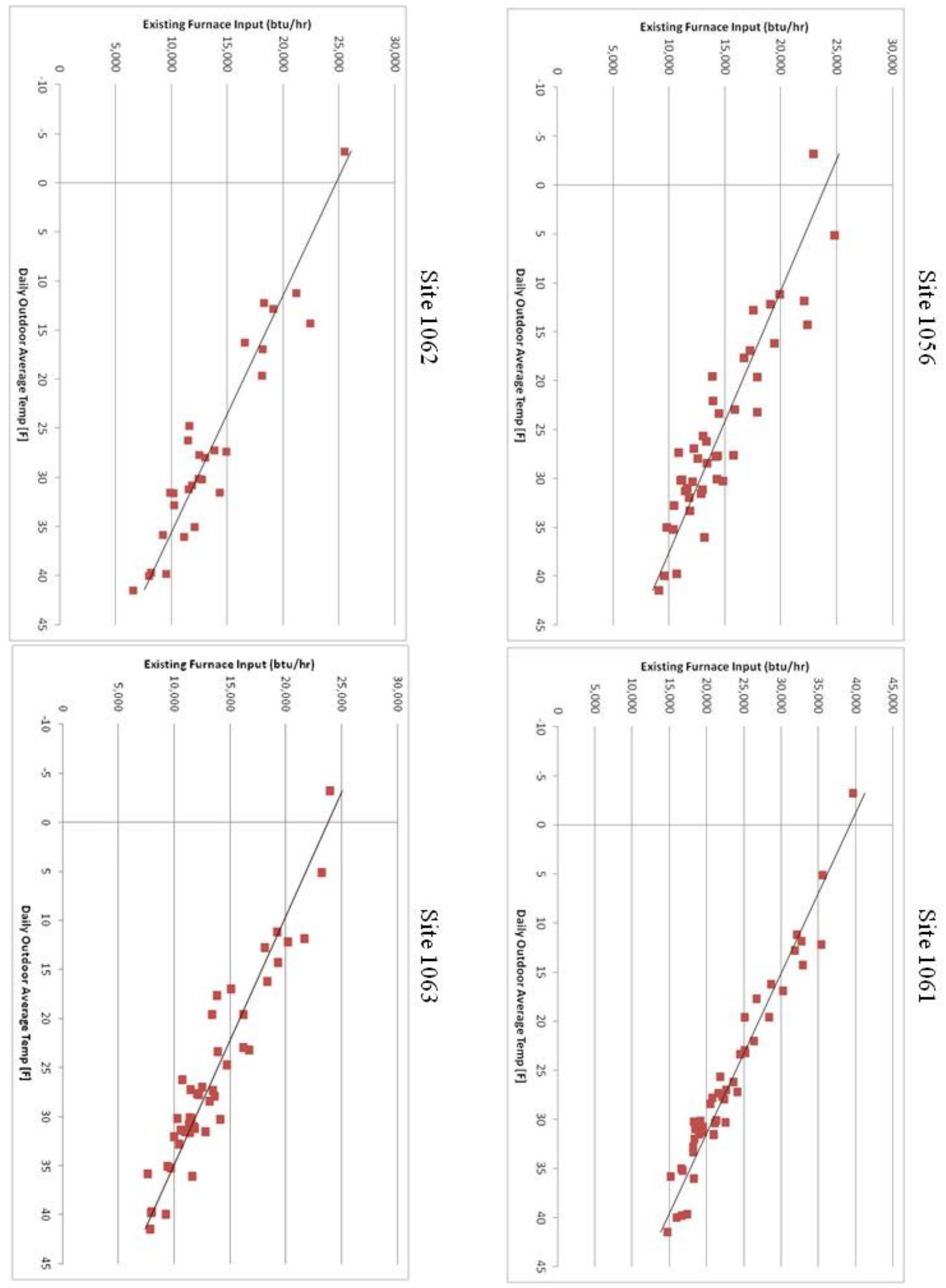

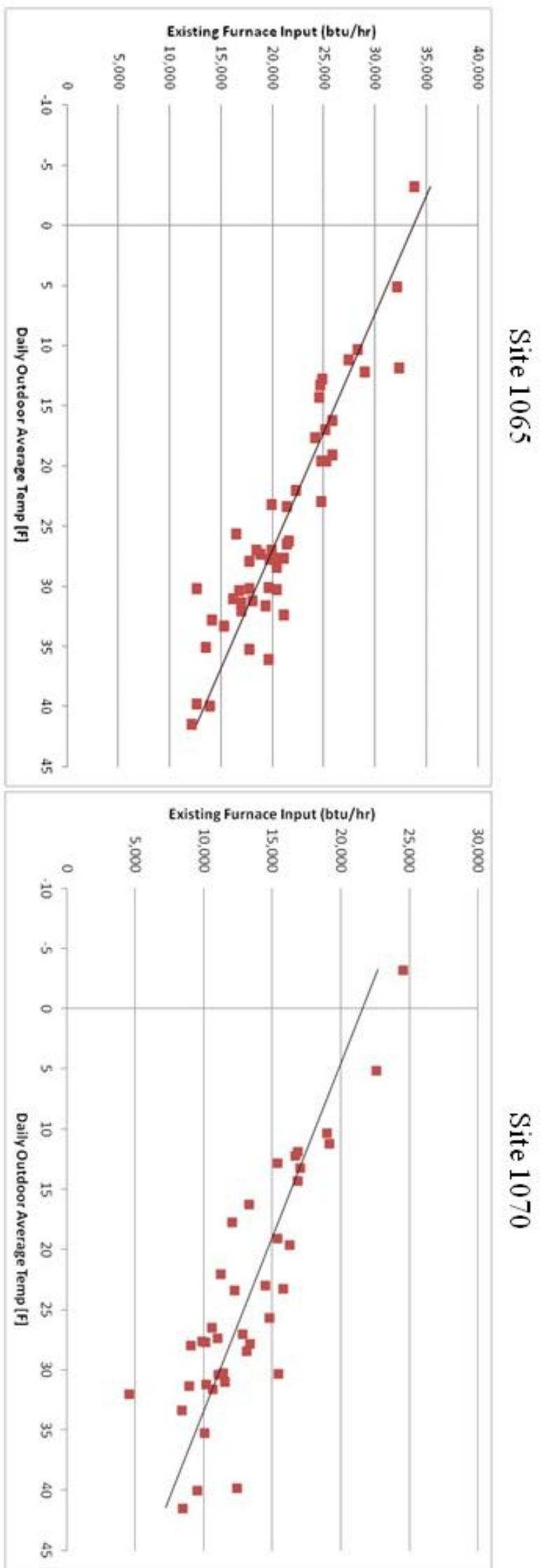
